LAWRENCE LIVERMORE N A T IO N A L LABORATORY
Simulation Analysis of Inspections of International Travelers at Los Angeles International Airport for US-VISIT

T. Edmunds, P. Sholl, Y. Yao, J. Gansemer, E.

Cantwell, D. Prosnitz, P. Rosenberg, G. Norton

March 5, 2004 
This document was prepared as an account of work sponsored by an agency of the United States Government. Neither the United States Government nor the University of California nor any of their employees, makes any warranty, express or implied, or assumes any legal liability or responsibility for the accuracy, completeness, or usefulness of any information, apparatus, product, or process disclosed, or represents that its use would not infringe privately owned rights. Reference herein to any specific commercial product, process, or service by trade name, trademark, manufacturer, or otherwise, does not necessarily constitute or imply its endorsement, recommendation, or favoring by the United States Government or the University of California. The views and opinions of authors expressed herein do not necessarily state or reflect those of the United States Government or the University of California, and shall not be used for advertising or product endorsement purposes.

This work was performed under the auspices of the U.S. Department of Energy by University of California, Lawrence Livermore National Laboratory under Contract W-7405-Eng-48. 


\title{
Simulation Analysis of Inspections of International Travelers at Los Angeles International Airport for US-VISIT*
}

\author{
Thomas Edmunds, Patricia Sholl, Yiming Yao, \\ James Gansemer, Elizabeth Cantwell, and Donald Prosnitz \\ Lawrence Livermore National Laboratory \\ Paul Rosenberg and Glenn Norton \\ Department of Homeland Security \\ Bureau of Immigration and Customs Enforcement
}

February 4, 2004 


\section{Executive Summary}

The United States Visitor and Immigrant Status Indicator Technology Program (US-VISIT) will deploy biometric and other systems to identify and track foreign nationals entering and exiting the U.S. Evaluation of the large number of possible policy options and technical configurations for implementation of US-VISIT requires validated system analyses with appropriate tools that can address the requirements of this new program and its processes. Early identification of performance issues and capability gaps will prove critical to the success of the program.

The objectives of the US-VISIT Project at Lawrence Livermore National Laboratory (LLNL)/Homeland Security Organization are to develop and/or utilize tools to acquire and manage the data needed to provide these analyses, to model experimental reengineered processes or technical designs, and to support data analysis, policy determinations, system architecture and/or planning ongoing elsewhere. This report describes our modeling efforts to estimate the impacts of US-VISIT in terms of traveler wait times and queue lengths. Our model uses data from the Los Angeles International Airport (LAX).

Currently, there is no available dataset that indicates how long a traveler waits in a queue to be inspected. However, the Interagency Border Inspection System (IBIS) and Port of Entry Office Management System (POMS) data together provide the basis for modeling the wait time. This study is unique in that it uses and analyzes data only recently available from IBIS to provide more accurate input for the simulation model and a better characterization of the current process than previously possible.

Class-of-admission and primary inspection confirmation time data from IBIS, in conjunction with flight arrival time and inspector availability data from POMS drive simulations customized for evaluation of alternative implementations of US-VISIT and Visa Waiver Program (VWP) biometrics-enabled passport. Average traveler wait time and queue lengths prior to US VISIT implementation that are predicted by the simulation model have been validated against LAX POMS and IBIS data from June 2003. These simulation analyses can assist decision makers in identifying system performance issues and capability gaps. For example, a scenario where all VWP passengers are inspected under the current US-VISIT process is analyzed in this report. 
A summary of results is given in the table below.

\begin{tabular}{|l|l|c|c|c|c|}
\hline & Scenario & $\begin{array}{c}\text { Primary queue } \\
\text { average wait } \\
\text { time (min.) }\end{array}$ & $\begin{array}{c}\text { Change in } \\
\text { average } \\
\text { wait time } \\
\text { (min.) }\end{array}$ & $\begin{array}{c}\text { Primary queue } \\
\text { maximum length } \\
\text { (\# people)78 }\end{array}$ & $\begin{array}{c}\text { Change in } \\
\text { queue } \\
\text { length }\end{array}$ \\
\hline 0 & Base Case (“as-is") & $30.3+/-4.6$ & - & $1190+/-94$ & - \\
\hline 1 & $\begin{array}{l}\text { US-VISIT (NIV } \\
\text { prints \& photo) }\end{array}$ & $43.2+/-5.4$ & +12.9 & $1374+/-108$ & +184 \\
\hline 2 & VWP Photo & $33.8+/-4.6$ & +3.5 & $1250+/-101$ & +60 \\
\hline 3 & $\begin{array}{l}\text { NIV prints, photo }+ \\
\text { VWP photo }\end{array}$ & $46.4+/-5.0$ & +16.1 & $1424+/-108$ & +234 \\
\hline 4 & $\begin{array}{l}\text { NIV holders and } \\
\text { VWP Travelers } \\
\text { (prints and photo) }\end{array}$ & $51.3+/-4.5$ & +21.0 & $1521+/-108$ & +334 \\
\hline
\end{tabular}

\begin{tabular}{|c|c|}
\hline 0 & No Biometric acquired \\
\hline 1 & $\begin{array}{l}10 \text { seconds required to acquire prints (increase in overall inspection time) } \\
5 \text { seconds required to acquire photo (increase in overall inspection time) } \\
100 \% \text { of NIVs are enrolled prior to arrival } \\
5 \text { seconds computer and communication time required to check prints (done in parallel } \\
\text { with interview) } \\
\text { No automated face recognition technology } \\
\text { Simulation time 00:00 hours (EST) June } 25 \text { through 03:00 (EST) hours June } 26\end{array}$ \\
\hline 2 & $\begin{array}{l}5 \text { seconds additional time required to take live photo at primary inspection } \\
10 \text { seconds required to verify photo (1-to- } 1) \text { and check against facial watchlist } \\
100 \% \text { of the VWP passengers are in possession of an accredited biometric encoded } \\
\text { passport }\end{array}$ \\
\hline 3 & $\begin{array}{l}\text { NIV's processed according to Scenario } 1 \\
\text { VWP's processes according to Scenario2 }\end{array}$ \\
\hline 4 & $\begin{array}{l}\text { NIV and VWP common assumptions } \\
\text { 1) } 15 \text { seconds required to acquire prints and capture photo } \\
\text { 2) Simulation time 00:00 hours (EST) June } 25 \text { through 03:00 (EST) hours June } 26 \\
\text { NIV assumptions } \\
\text { 1) } 100 \% \text { of NIVs are enrolled prior to arrival } \\
\text { 2) } 5 \text { seconds computer time required for } 1 \text {-to-1 check prints } \\
\text { VWP holder assumptions } \\
\text { 1) } 0 \% \text { of VWPs are enrolled prior to arrival } \\
\text { 2) } 8 \text { seconds computer time required for } 1 \text {-to-n check printsz }\end{array}$ \\
\hline
\end{tabular}




\section{Table of Contents}

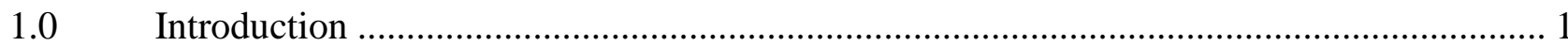

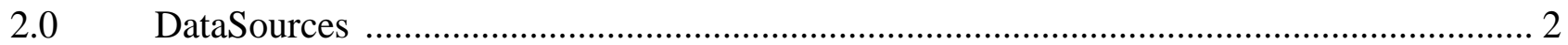

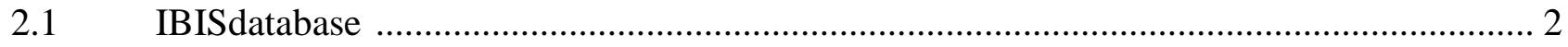

$2.2 \quad$ POMS database

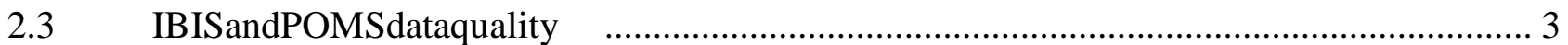

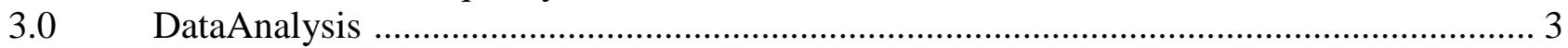

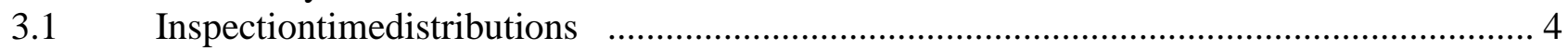

3.1.1 Determination of Primary Inspection Time Distributions .......................................... 5

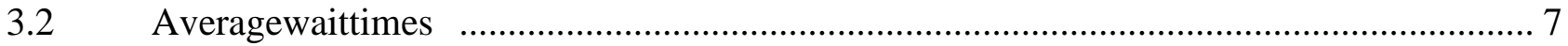

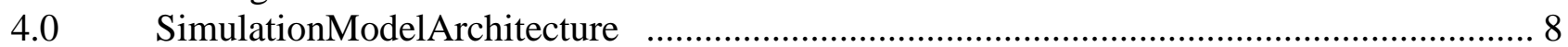

4.1 Traveler arrivals generation and characterization processes ..................................... 8

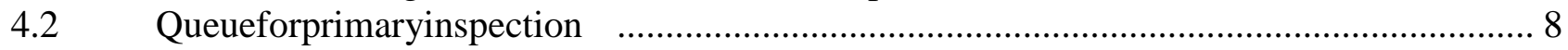

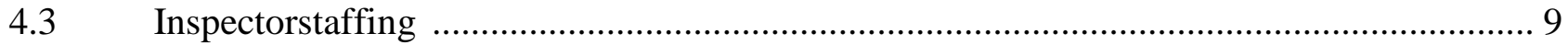

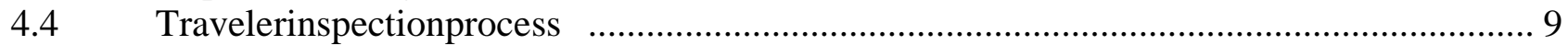

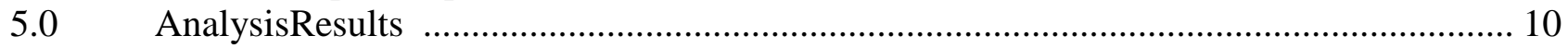

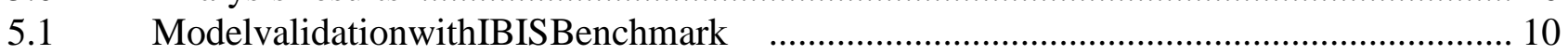

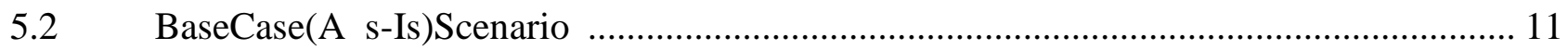

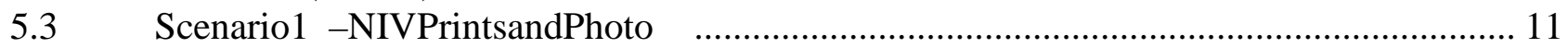

5.3.1 Sensitivity study of print and photo acquisition time ............................................. 13

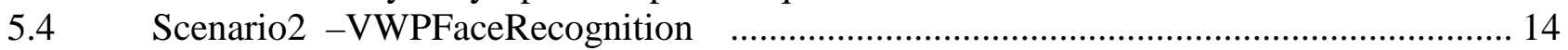

5.5 Scenario 3 - NIV Prints + VWP Face Recognition............................................................. 14

5.6 Scenario 4 - NIV holders and VWP travelers (prints and photo) ........................................ 14

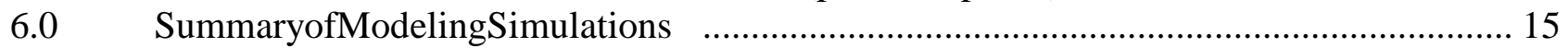

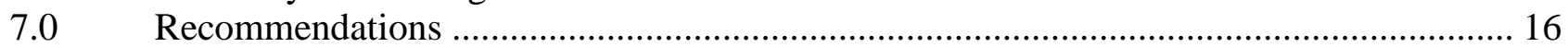

Appendix A Sample IBIS Records Used for Modeling …….................................................. 18

Appendix B Inspection Time Probability Distributions by Class-of-Admit................................ 19

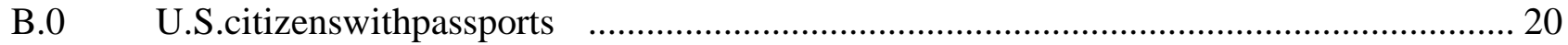

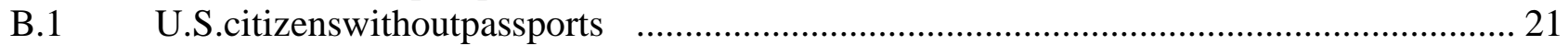

B.2 Canadian citizens with documents ........................................................................... 22

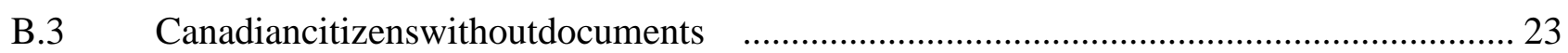

B.4 Legal Permanent Residents (LPR) …………….................................................... 24

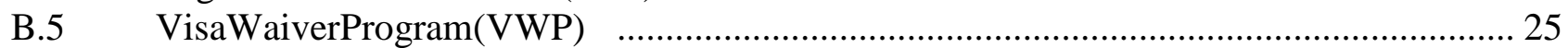

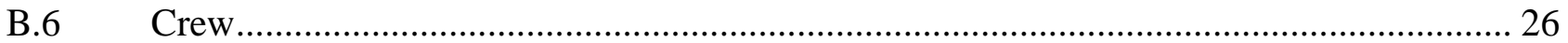

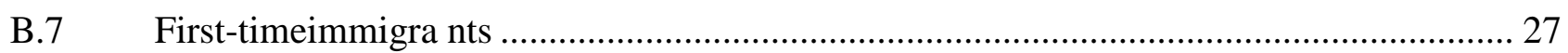

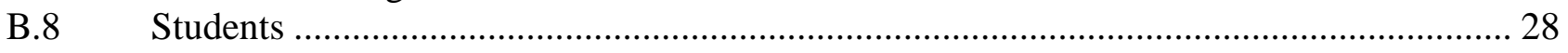

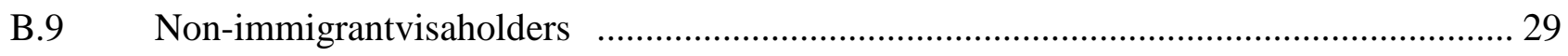

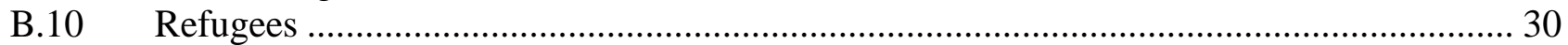

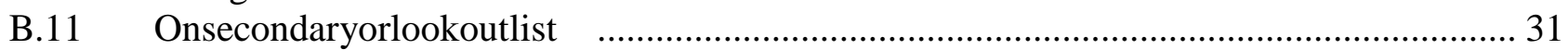

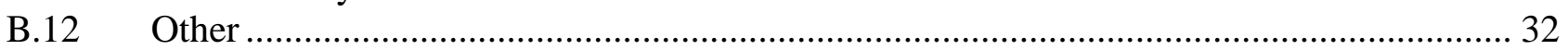

Appendix C Views of Simulation Model........................................................................... 34

Appendix D Traveler Arrival Data File ................................................................................... 41

Appendix E Cross Index Between Visa Codes in IBIS and Traveler Type............................... 54

Appendix F List of Acronyms and Terms ........................................................................... 55

Appendix G Business Rules to Populate Missing Class-of-Admission Fields ............................ 57 


\section{List of Figures}

Figure 3-1 - Data Preparation and Use for Simulation Modeling ……………................................... 4

Figure 3-2 - Primary Inspection Time Distribution for U.S. Citizens with Passports........................... 6

Figure 3-3 - Number of IBIS Travelers for June 25, 2003 ............................................................ 7

Figure 3-4 - Wait Times at LAX Airport TBIT........................................................................ 7

Figure 5-1 - Wait Time Cumulative Probability Distribution Function ............................................ 12

Figure 5-2 - Wait Time vs. Biometrics Acquisition Time............................................................ 13

Figure 5-3 - Maximum Queue Size vs. Biometrics Acquisition Time.............................................. 13

Figure C-1 - Traveler generation and characterization................................................................. 34

Figure C-2 - Details of traveler generation and inspection time sampling...................................... 35

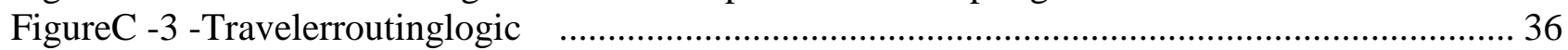

Figure C-4 - Process routing by traveler type............................................................................... 37

Figure C-5 - Details of prints and face processes - acquire biometrics in primary ........................... 38

Figure C-6 - Details of prints and face processes - interview and check biometrics in parallel....... 39

Figure C-7 - Output of Simulation Model ................................................................................. 40

\section{List of Tables}

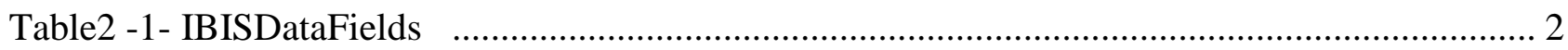

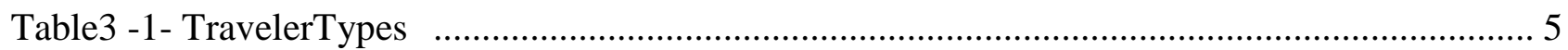

Table 5-1 - Lane Assignments for Primary Inspections at LAX-TBIT for June 25 ………………... 10

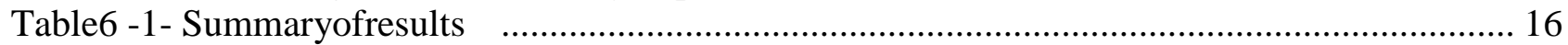

Table B-1 - Sample sizes for primary inspection time distributions by traveler type ....................... 19 


\subsection{Introduction}

The objectives of the United States Visitor and Immigrant Status Indicator Technology Program $\left(U S-V I S I T^{l}\right)$ are to facilitate travel, secure our nation, and combat terrorism by improving the processes, policies, and systems utilized to collect and report information on foreign nationals who apply for visas, attempt to enter the country at ports of entry $(P O E)$, request benefits such as change of status or adjustment of status, and/or depart the United States. In addition, the USVISIT Program must facilitate legitimate trade and respect personal privacy.

Early identification of performance issues and capability gaps will prove critical to the success of this program. Evaluation of the large number of possible policy options and technical configurations for implementation of US-VISIT requires validated system analyses with appropriate tools that can address the unique requirements of this new program and its processes. The goals of the US-VISIT Project at Lawrence Livermore National Laboratory (LLNL)/Homeland Security Organization are to develop and/or utilize tools to acquire and manage the data needed to provide these analyses, to model experimental reengineered processes or technical designs, and to support data analysis, policy determinations, system architecture and/or planning ongoing elsewhere.

This report describes our modeling efforts and a specific study of international arrivals at Los Angeles International Airport - Tom Bradley International Terminal (LAX-TBIT). Since LAX is a multiple inspectional facility, we limited our modeling and reporting only to the TBIT terminal. TBIT was selected as it the largest of the inspectional facilities and accounts for two thirds of the total LAX arrivals during the month. Class-of-admission (COßland primary inspection confirmation time data from the Interagency Border Inspection System (IBIS), in conjunction with flight arrival time and inspector availability data from the Port of Entry Office Management System (POMS), drive simulations customized for evaluation of alternative implementations in support of US-VISIT and Visa Waiver Program (VWP) biometrics-enabled passport programs.

This study is unique in that it uses and analyzes data only recently available from IBIS to provide more accurate input for the simulation model and a better characterization of the current process than previously possible. The report and model are designed to predict changes to primary queue lengthand wait time as a measure of system performance due to changes in inspection processes. Average traveler wait time and end-of-day primary queue size prior to US-VISIT implementation that are predicted by the simulation model have been validated against LAX POMS and IBIS data from June 2003. To estimate the impacts of the US-VISIT Program, we run a simulation model for a 24-hour period at TBIT, introduce additional requirements such as the collection of biometrics, and compute changes in performance metrics such as wait time and primary queue length for various implementation scenarios. Analysis of LAX-TBIT data was made more complex because the POE was in a transition period when legacy Customs inspectors were being trained on the job to work the primary line, an older version class-of-admission screen was utilized at the POE, and they had not yet installed the now upgraded communication infrastructure.

\footnotetext{
${ }^{1}$ All italicized terms are defined in Appendix F.
} 


\subsection{Data Sources}

\subsection{IBIS database}

The primary data source for the analysis is the IBIS database, which contains records of all name queries performed at the POEs. The US Customs and Border Protection Bureau (CBP), Office of Information Technology staff in Newington, VA, provided IBIS data for the month of June 2003.

The use of actual traveler records from IBIS is unique to this study as other current simulation models use estimates of traveler processing times (in addition to time and motion studies from subject matter experts at the POE for the Workforce Analysis Model (WAM) $)^{2}$. Sample data records extracted from the database that were used in this study are shown in Appendix A. The IBIS fields extracted from the traveler records for this study are shown in Table 2.1.

\section{Table 2-1 - IBIS Data Fields}

1. Confirmation date

2. Confirmation time

3. Confirmation terminal

4. Site ID

5. IATA Airport Code for Site ID

6. INS Port code for Site ID

7. Estimated arrival date

8. Secondary Referral Code

9. Lookout Type Code

10. Airline Carrier Code

11. Flight Number

12. Departure Airport Code

13. Gender Code

14. Date of birth

15. Document Type Code

16. Document Country Code

17. Visa Class of Entry Code

18. Admit Until Date

19. Length of Stay (days)

IBIS data fields one through four specify when and where the traveler is confirmed at primary inspection. Fields seven, ten and eleven uniquely identify the flight. Field seventeen contains the class of admission. The other fields, such as gender and date of birth, were extracted for use within the model to show how those factors may be used to influence policy decisions and/or process and wait times, however, these analyses were not included in our simulations. The IBIS data does not include the flight arrival (block) time or inspector availability, so that a traveler's history at the POE cannot be traced from the IBIS data alone.

\subsection{POMS database}

The POMS database provides the other data needed to trace the history of a given traveler at the POE. The POMS database contains the block time for the flight ${ }^{3}$ and also indicates how many

\footnotetext{
${ }^{2}$ Prior to this study, the integrity of the data in the two databases had not been evaluated nor compared to each other for consistency.

${ }^{3}$ Times in the two databases are expressed in two different time zones; IBIS times are EST and POMS times are recorded as local time (PST).
} 
primary and secondary inspectors were on duty at the time the flight arrived. The arrival date, airline carrier code and airline flight number from each database can be cross-indexed to establish the time a traveler arrives at the gate. The flight logs and schedules for LAX for the month of June 2003 were provided by the CBP inspection staff at LAX.

The POMS data also indicate how many primary and secondary inspectors were on duty at the time the flight arrived. Finally, the flight data in POMS show the total number of travelers and a count of the following classes: visa waiver program passengers (VWP), crew, first time immigrants, and non-immigrants with visas. Although the POMS database is structured to record the numbers of U.S. citizens and legal permanent residents (LPRs), the exact number of these cannot be operationally determined and therefore must be estimated. Therefore, in our simulations the counts of these categories as well as non-immigrants exempt I-94s (e.g., Canadians) are combined and reported as one class.

\subsection{IBIS and POMS data quality}

Some data anomalies were encountered while analyzing the IBIS and POMS databases. Typical anomalies include:

1. Invalid visa-class-of-entry code - Certain invalid characters can be entered into this field in the IBIS database. Many records contained the code "***" in the COA field.

2. Multiple formats for data field - For example, "E37" was recorded in some records as "E37," and as "E-37" in others.

3. Missing data - For some IBIS records the visa-class-of-entry, document country, and document type fields were blank. If all three of these fields are missing for a given record, it is nearly impossible to assign a code to that traveler. There are also several records with document type "V" (visa) that have no "admit until date" or "limit time of stay" information. Finally, some flight data was missing, erroneously entered, or incomplete in some IBIS and POMS records.

4. Crew designation - Sometimes crewmembers are not distinguished from passengers. There does not seem to be a consistent format for indicating a traveler as "crew" in IBIS. Sometimes the character " $C$ " is appended to the flight number, sometimes the visa-classof-entry is marked as "CREW," or D1.

The IBIS records that did not contain a class-of-admission code were particularly problematic because this data field is required for accurate analysis and evaluation of US-VISIT implementation impacts and architectures. Of the 554,167 LAX records obtained from IBIS, there were 353,125 records for TBIT during the month of June 2003. 47.5\% of these records pertained to U.S. citizens or LPRs who do not require a COA. Of the remaining records, 93\% included a visa-class-of-admission code. $51 \%$ of the remaining records without a COA were assigned a visa code using business rules that are based upon document country and document type. These business rules are included in Appendix G. The remaining records that could not be assigned with these business rules were assigned a code of "other" (2\% of the TBIT travelers during June 2003).

\subsection{Data Analysis}

As indicated in Fig. 3-1, the IBIS records are processed to generate inspection time distributions that are used by the simulation model. The class-of-admission fields and business rules discussed 
in the preceding section are used to identify a traveler type (see Sec. 3.1). These completed records are further analyzed to generate inspection time distributions by type of traveler.

POMS flight records provide traveler counts for several types of travelers including VWP travelers, immigrants, and non-immigrant aliens that are used directly in the simulation. However, as stated in Sec. 2.2 the remainder of the passengers are aggregated into a single class for modeling purposes. As shown in the figure, monthly IBIS records are used to compute the fraction of each traveler type, which are in turn used to split this grouped POMS number into its constituent traveler types for use in the simulation model. These POMS traveler records with augmented type assignments are used to drive the simulation model.

During the course of the simulation, the inspection time distributions derived from the IBIS data are sampled and applied to individual travelers generated from the augmented POMS data. Details of some of these procedures are described in the following sections.

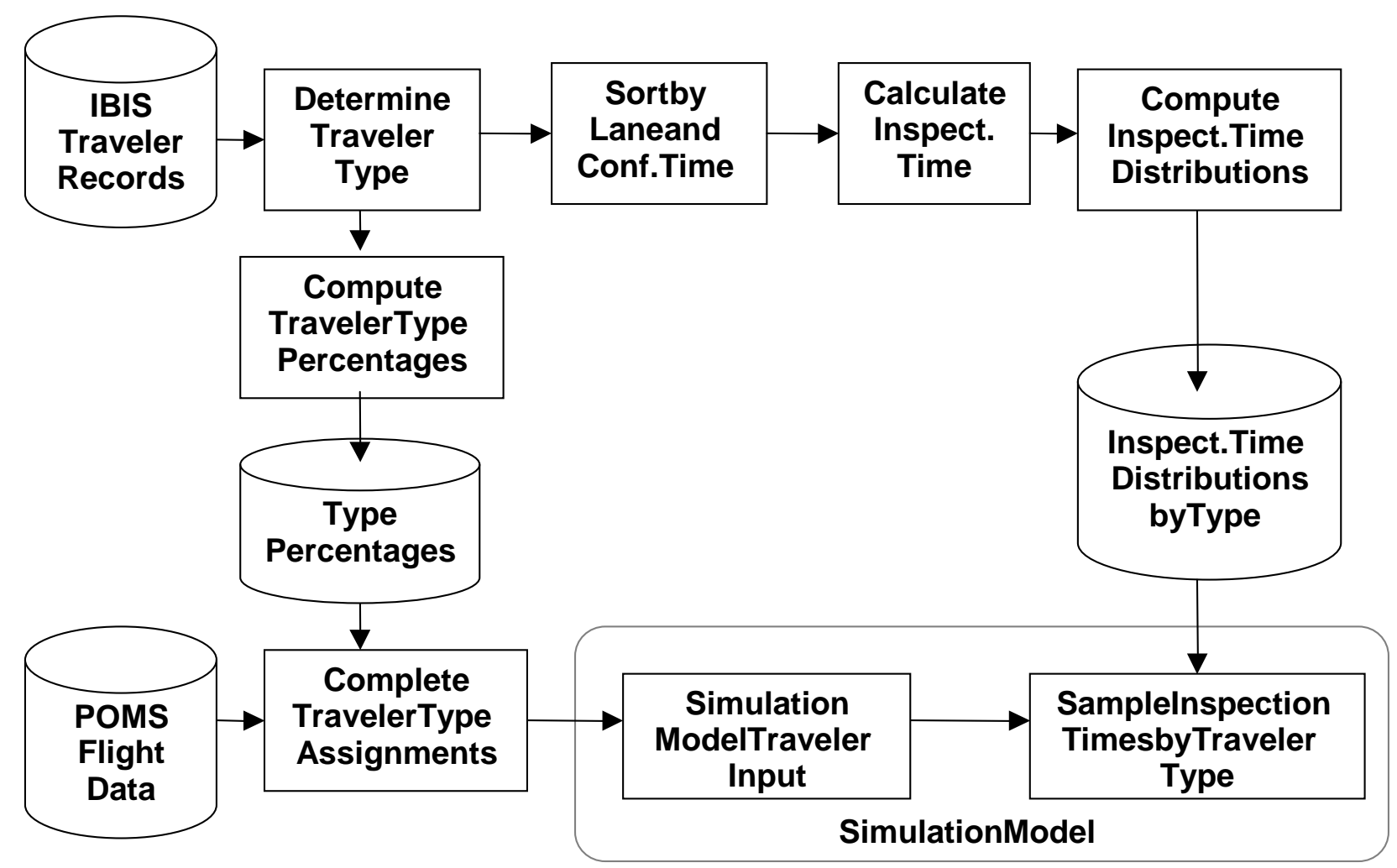

Figure 3-1 - Data Preparation and Use for Simulation Modeling

\subsection{Inspection time distributions}

The confirmation time stamps in the IBIS records provide a basis for calculating inspection times of the various types of travelers due to the implementation of the class of admission software. An underlying assumption of this analysis is that the second traveler was waiting for inspection in that lane at the time the first traveler was confirmed so that the entire time difference can be attributed to his inspection. If there is no one waiting in the queue for this lane at the time the first traveler is confirmed, the time difference between confirmation timestamps cannot be entirely attributed to inspection time of the second traveler and our methodology would overestimate the inspection time. 
To prevent biasing the results, thresholds were set on inspection times to eliminate these cases from the distributions. The thresholds were determined by evaluating all process times for a particular traveler type, eliminating times that did not appear to be part of the real distributions. See Appendix B for details of the distributions.

For a given lane number, the difference between successive confirmation times indicates how long the inspection process for the traveler took. For example, the first two records in Appendix A show successive confirmation times for lane CU03. The first passenger is a 70 year-old female holding a Japanese passport entering under visa code WT (temporary visitor for pleasure). This passenger is confirmed at time 17:00:53 (hh:mm:ss). The second passenger is a 67 year-old male holding a Japanese passport also entering under visa code WT. This second passenger is confirmed at time 17:01:31. The difference between these two confirmation times implies an inspection time of 38 seconds for the second passenger.

The many non-immigrant visa classes of admission along with those for returning U.S. citizens and legal permanent residents were consolidated into 13 traveler types ${ }^{4}$ for the purpose of best modeling inspection times or procedures. The types are shown in Table 3.1 and a cross-index between all visa classes and types are shown in Appendix E.

\section{Table 3-1 - Traveler Types}

0. U.S. citizen with passport

1. U.S. citizen without passport

2. Canadian with documentation

3. Canadian without documentation

4. Legal Permanent Residents (LPR)

5. Visa Waiver Program (VWP)

6. Crew

7. First time immigrant

8. Student, exchange visitor, and dependent visas (Student-NIV)

9. Other Non-immigrant with visa

10. Refugee

11. Not used

12. Other

\subsubsection{Determination of Primary Inspection Time Distributions}

The TBIT records were analyzed and process time distributions computed. Figure 3-2 shows an empirical distribution for all 102,127 type 0 TBIT travelers in June 2003 and a lognormal fit to the data. Note that the fitted lognormal distribution does not capture the double peaks in the distribution in the 10 to 40 second time range.

\footnotetext{
${ }^{4}$ Although 13 passenger types are listed, type 11 was reserved for future use so only 12 types of passenger types are used in our report.
} 


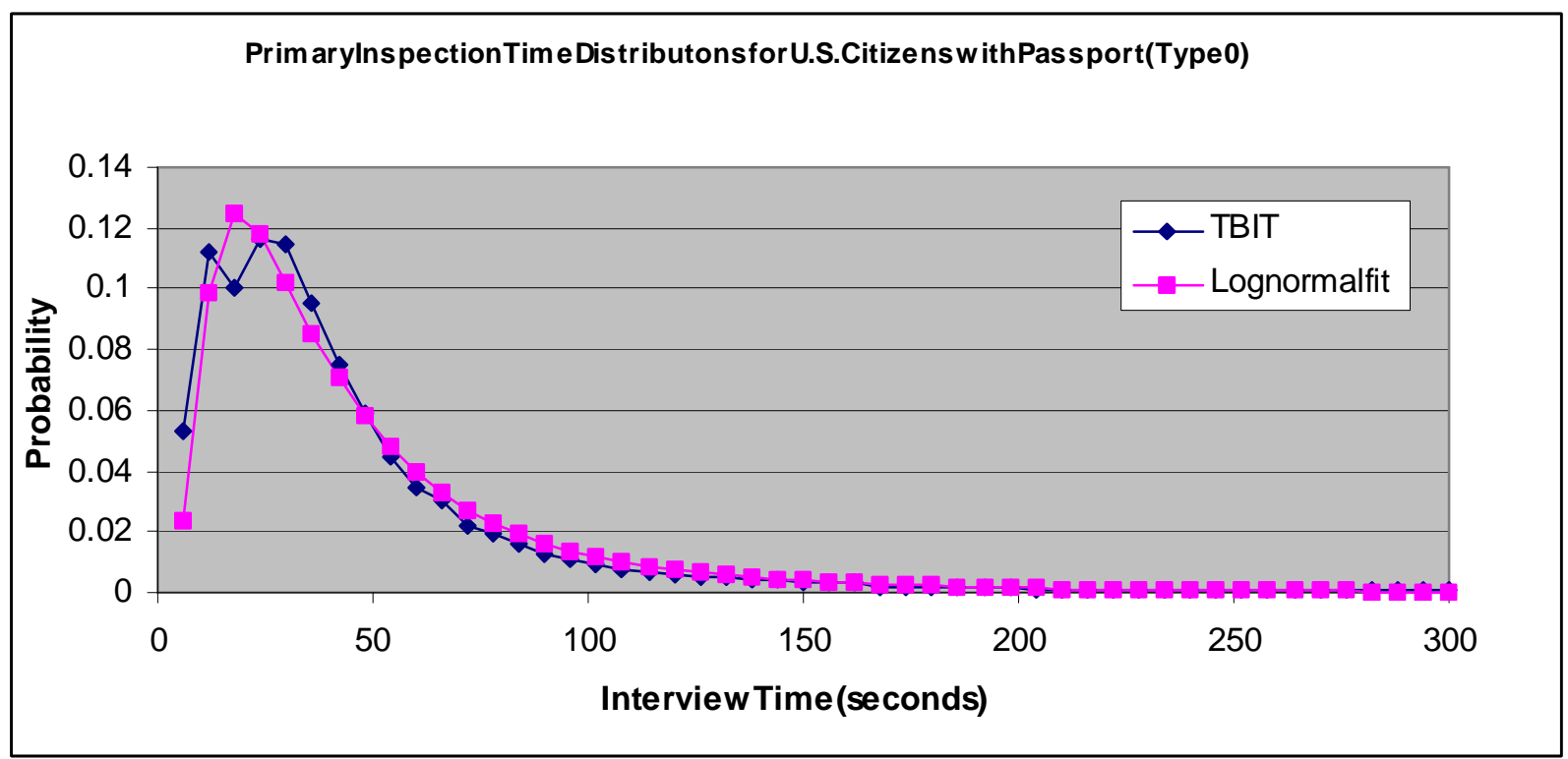

Figure 3-2 - Primary Inspection Time Distribution for U.S. Citizens with Passports

Data for traveler type 2 (U.S. Citizen without passport), type 5 (VWP), and 9 (NIV) also exhibited multiple peaks. Accordingly, we elected to sample directly from the TBIT empirical distributions to drive the simulation models rather than sample a fitted lognormal distribution. This sampling from empirical distributions generated from large datasets distinguishes this study from previous works.

Limited data were available for two of the traveler types - type 3 (Canadians without passports) and type 7 (first time immigrants) ${ }^{5}$ — so the empirical distributions are less reliable for these traveler types. However, given the infrequent observations of these types, errors in these distributions are unlikely to have significant impact on the results.

Figure 3-3 shows the number of travelers by type for June $25^{\text {th }}, 2003$. As indicated by the data in the figure, most of the travelers are U.S. citizens with passports, non-immigrant visa holders, and citizens of countries participating in the Visa Waiver Program.

\footnotetext{
${ }^{5}$ IBIS crossing records indicate that 104 first time immigrants were admitted at LAX for the month of June, however the Inspections field workload report (G22.1) for LAX indicates that a total of 3,966 were processed at the POE.
} 


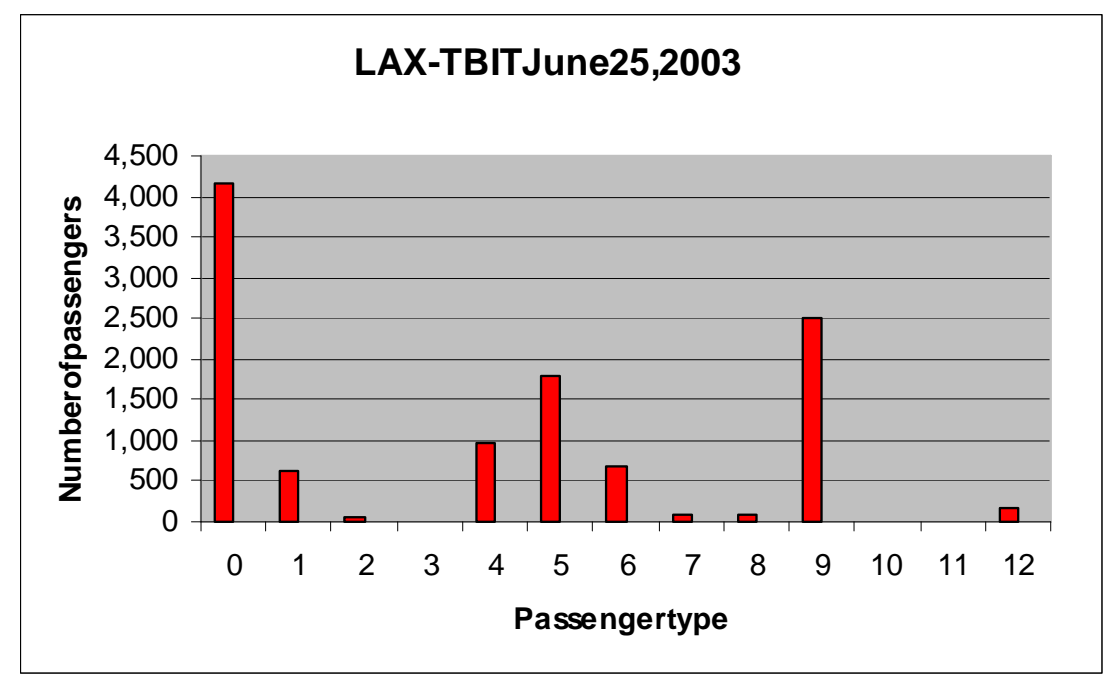

Figure 3-3 - Number of IBIS Travelers for June 25, 2003

\subsection{Average wait times}

Currently, there is no available dataset that indicates how long a traveler waits in a queue to be inspected; however IBIS and POMS data together provide the basis for modeling the wait time based upon the following: The primary inspection cycle time (time to deplane and walk to primary queue + queue time + inspection time) can be determined using the flight block times in POMS in combination with the primary confirmation time in IBIS. If deplane and walk time are subtracted from primary inspection cycle time, the remaining value is wait time (queue time + inspection time). Daily wait times of U.S. and non-U.S. citizens for all of LAX were calculated based on a sample size of 161,646 during the month of June, and are shown in Fig. 3.4.

As the figure indicates, there is significant day-to-day variation in wait times. Wait times are relatively low on Tuesdays, and significantly higher on Sundays. Wait times vary by more than a factor of two between low and high days. Wednesday, June $25^{\text {th }}$, a moderately high load day, was selected for the analysis.

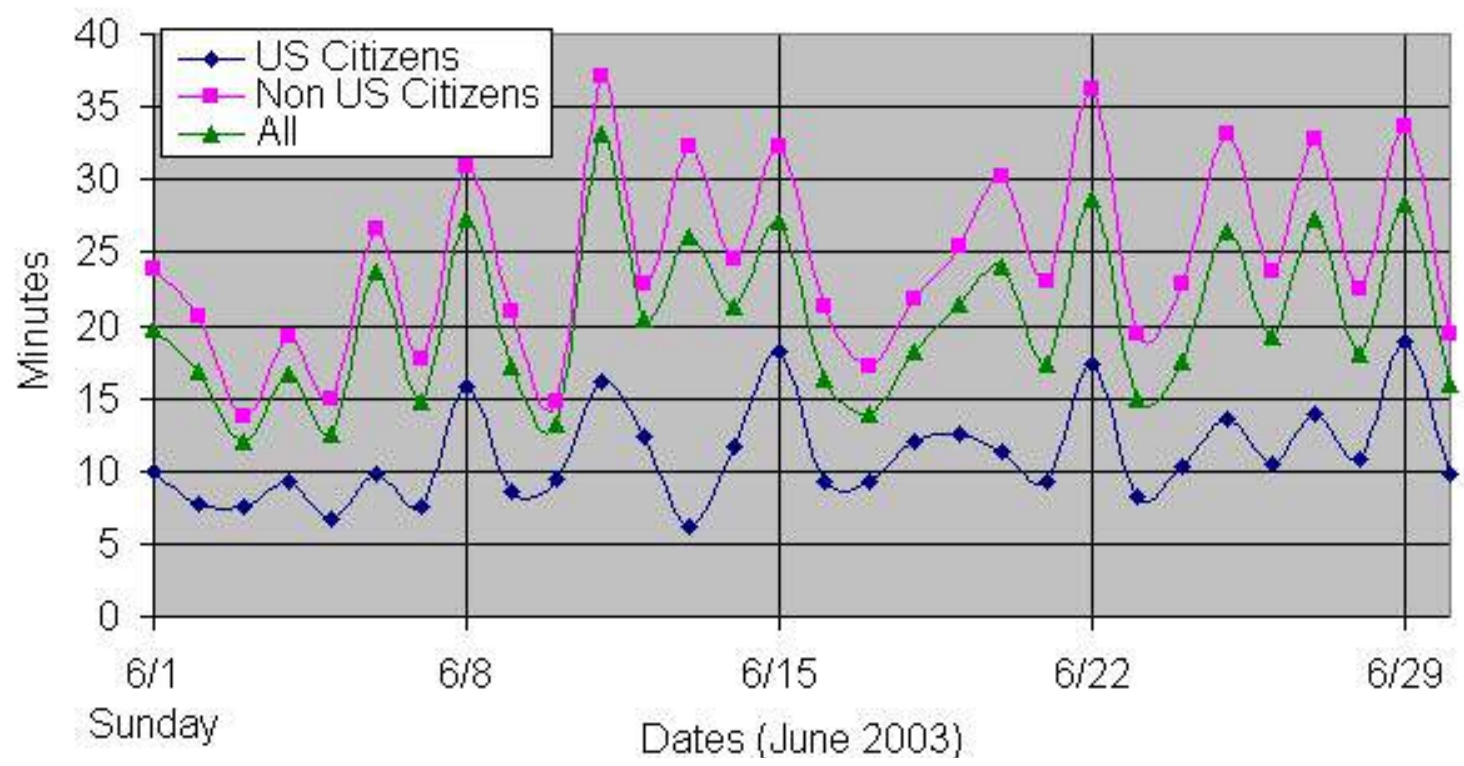

Figure 3-4 - Wait Times at LAX Airport TBIT 


\subsection{Simulation Model Architecture}

A discrete event simulation model was developed using the Extend ${ }^{\mathrm{TM}}$ 6.0.3 commercial software package. Views of the graphical interface of the model are shown in Appendix C. The model includes approximately 400 modules from the Extend libraries.

\subsection{Traveler arrivals generation and characterization processes}

The total number of arriving travelers and the flight arrival time were extracted from the flight logs to drive the simulation model (see Figs. C.1 and C.2). As discussed in Sec. 3.0, the IBIS data are used to further refine the number of each type of traveler for each flight (see Appendix D).

Traveler timing and sequencing at the primary inspection queue is influenced by deplaning activities and walking from the gate to the queue. By observing POMS data, an average deplane and walk time of 10 minutes was used for the analysis. Note that simply adding the walk time for a particular flight to the block time would place all travelers from a particular flight at the primary queue at the same instant. This large bulk arrival event would tend to overestimate wait time relative to a more realistic process in which travelers deplane at different times and walk to the primary queue at different speeds. Accordingly, each traveler is delayed by a random amount uniformly distributed between 5 and 15 minutes to reflect an average walk time of 10 minutes with a variation of $+/-5$ minutes about that mean. ${ }^{6}$

Each traveler is then assigned an inspection time based upon a sample from the appropriate distribution for that traveler type. The probability that the traveler will be referred to secondary inspection based upon interview responses can also be assigned to the traveler. Finally, a unique identification number is assigned to each traveler for use in the simulation model so that biometric information can be associated with the traveler throughout the simulation.

\subsection{Queue for primary inspection}

The authors went onsite to LAX to observe actual inspections and queuing. Three types of primary inspection queues were present at LAX's TBIT and are represented in the model: U.S. citizen lanes, alien lanes, and crew lanes (see Fig. C.3). We observed that as travelers arrive they are routed into their corresponding queue. At TBIT, if the line in one of the queue types becomes inordinately long, travelers may be rerouted to a queue type with lower current utilization. For example, if a floor supervisor observes that there are 500 aliens waiting for inspection in the alien queue, while there are only a few U.S. citizens in line, she may choose to reroute aliens into one of the U.S. citizen queues. To enable this behavior in the simulation model, U.S. citizen and alien queue lengths are monitored and non-U.S. citizens are allowed to move from their native queue to the U.S. citizen queue if their expected queue time is significantly higher than that in the other queues. In general, an attempt is made to expedite the inspection of U.S. citizens and LPR's over other passengers. To simulate this, an alien lane crossover rate parameter is included in the model architecture to allow control over the flow of aliens from the alien queue to the U.S. queue in order to preserve performance levels for U.S. citizens. For the Base Case Scenario, this alien crossover rate parameter was set to zero.

\footnotetext{
${ }^{6}$ Note that if a constant deplane or walk time is added to all passenger histories, the computed average wait time is not affected. The added constant simply delays both entry into the system and exit from the system by the same amount. The numerical difference between entry and exit time is not affected by adding a constant to both factors.
} 
The simulation model was also designed to permit automated inspections at kiosks ${ }^{7}$ (see Fig. C.1) that could be used to process travelers as determined by statute or policy. These kiosks are not currently used by the model but could be to demonstrate their usage rates and effects on other resource needs and overall wait and inspection times. As indicated in the figure, each traveler could be checked to see if the traveler type is amenable for use of the kiosks. If the traveler is not approved for use of the kiosk, the traveler is routed to the current primary inspection queues. If the traveler attempts to use the kiosk and is denied, the model is designed to route that traveler to a primary inspector.

\subsection{Inspector staffing}

As indicated previously, number of inspectors on primary for each flight is recorded in the flight logs. However, the flight logs do not indicate how many lanes were dedicated to inspecting U.S. citizens vs. aliens. The traveler types derived from IBIS records for the month of June were used to infer the number of U.S. citizen, crew and other lanes in use throughout the modeled 24-hour period.

\subsection{Traveler inspection process}

As shown in Fig. C.4, the model accommodates three biometrics-based traveler inspection processes in addition to the current process. They are:

1. No biometrics (the current process)

2. Fingerprints only

3. Face recognition only

4. Fingerprints and face (no face recognition)

Each traveler can be routed through one of these four processes. Processes 2-4 presume that certain biometrics are checked during primary inspection. Non-immigrant visa holders (NIVs) that are "pre-enrolled" ${ }^{8}$ in the system are modeled as requiring only a 1-to- 1 verification check against existing visa records in the US-VISIT database and that a 1-to-n check against the watchlist has been conducted prior to arrival of the traveler at the POE. This scenario also assumes that all travelers are preenrolled and that the pre-enrolled alien's biometric file can be determined accurately in advance of the alien's arrival. This is due to the fact that currently (USVISIT Increment 1) the unique biometric data record is retrieved from the database using a textstring search of biographic and document data. If the NIV bearer is not enrolled or his record cannot be found, a 1-to-n check against a watchlist and enrolled database must be executed. The I-to-n watchlist check is performed during the primary inspection. However the 1-to-n check against the US-VISIT enrollment database, while initiated during the primary inspection, may not be completed until after the primary inspection ${ }^{9}$. Percent enrolled, time for 1-to-1 queries, and 1-to-n search times are also parameters in the simulation model. A process model has also

\footnotetext{
${ }^{7}$ The INS Passenger Accelerated Service System (INSPASS) was operational at TBIT during the time of our study. Due to its relatively low usage; it was not included in the simulation.

${ }^{8}$ Pre-enrolled in this paper and in the US visit context refers to only to the prior acquisition of biometric data and is not the same as the term pre-enrolled for current automated inspection processes such as SENTRI.

${ }^{9}$ The current number of enrollment records the system is capable of returning match results or creating a unique fingerprint identification number during the inspection. However, when it does, that information is not made available to the inspector. As the size of the enrollment database increases it is anticipated that the full query and response may, with current resources, take up to 24 hours.
} 
been developed in the model for visa waiver passengers from countries that have passports with a machine-readable and verifiable digital photo stored in the passport. In this process, the captured photo is compared against the digitally encoded photo and compared against a watchlist.

Figures C.5 and C.6 show details of the biometrics modeling. Although each simulation run will generate different results, typical output is shown in Fig. C.7.

\subsection{Analysis Results}

\subsection{Model validation with IBIS Benchmark}

The IBIS Benchmark Scenario simulation model was used to simulate the IBIS data for a single 24-hour period (June 25). Analysis of the June 25 IBIS records indicate that the mean wait time (primary queue time + inspection time) for all travelers at the LAX Tom Bradley International Terminal (TBIT) was 26.5 minutes. The model was configured to simulate the process. The simulation results using the POMS flight data are shown in Appendix D and estimated primary inspection time distributions are shown in Appendix B.

As discussed in Sec. 4.3, the lane assignments for June 25 TBIT, which was inferred from analysis of the IBIS records, is shown in Table 5.1 for the three types of queues.

Table 5-1 - Lane Assignments for Primary Inspections at LAX-TBIT for June 25

\begin{tabular}{|r|r|r|c|c|c|}
\hline $\begin{array}{r}\text { Time (sec) } \\
\text { Start }\end{array}$ & $\begin{array}{c}\text { Time } \\
\text { (sec) End }\end{array}$ & $\begin{array}{c}\text { Time } \\
\text { (hr) End }\end{array}$ & $\begin{array}{c}\text { Number of } \\
\text { Inspectors } \\
\text { Inspecting U.S. } \\
\text { Citizens }\end{array}$ & $\begin{array}{c}\text { Number of } \\
\text { Inspectors } \\
\text { Inspecting Other } \\
\text { Passengers }\end{array}$ & $\begin{array}{c}\text { Number of } \\
\text { Inspectors } \\
\text { Inspecting Crew }\end{array}$ \\
\hline 0 & 3600 & $1: 00$ & 5 & 9 & 1 \\
\hline 3600 & 7200 & $2: 00$ & 5 & 12 & 1 \\
\hline 7200 & 14400 & $4: 00$ & 2 & 2 & 1 \\
\hline 14400 & 43200 & $12: 00$ & 2 & 4 & 1 \\
\hline 43200 & 46800 & $13: 00$ & 4 & 8 & 1 \\
\hline 46800 & 50400 & $14: 00$ & 9 & 9 & 1 \\
\hline 50400 & 54000 & $15: 00$ & 10 & 12 & 1 \\
\hline 54000 & 57600 & $16: 00$ & 10 & 13 & 1 \\
\hline 57600 & 61200 & $17: 00$ & 10 & 10 & 1 \\
\hline 61200 & 64800 & $18: 00$ & 10 & 12 & 1 \\
\hline 64800 & 72000 & $20: 00$ & 10 & 16 & 1 \\
\hline 72000 & 75600 & $21: 00$ & 5 & 9 & 1 \\
\hline 75600 & 86400 & $24: 00$ & 5 & & \\
\hline
\end{tabular}

The simulation model was executed with the POMS staffing schedule, flight arrival time and traveler manifest data. As a result, for the 24-hour period at TBIT, the model simulated the inspections of 11,102 travelers arriving on 55 flights at TBIT on June 25.

To estimate the mean and variance of the wait time, 10 simulation runs were made. The simulation model output is shown in Fig. C.7. As shown in the left hand side of the figure, the 
simulation model predicts a wait time of 27.9+/-3.9 minutes. The 26.5 minute mean computed with the sampled IBIS records is within the $95 \%$ confidence interval determined by the model ${ }^{10}$. The maximum queue length for each of the 10 simulation runs was also recorded. As indicated in the lower left corner of the figure, the mean of this maximum queue length for these runs was $1190+/-93.0$ passengers.

Typical queue times for U.S. citizens and non-citizens are shown in the upper and lower graphs in the figure, respectively ${ }^{11}$. The blue line with the higher peaks corresponds to the number of passengers waiting in the queue as measured against the left hand scale. As shown on the top graph, the number of passengers in the U.S. queue peaks at approximately 300 at 7:12 p.m. $(69,120$ seconds). The queue time of the last person to leave the queue is denoted by the red line, which is measured against the right hand scale. The peak queue time of 28 minutes occurs just after the peak queue length. As shown in the bottom graph, the peak queue length and wait times for non-U.S. citizens are 800 persons and 135 minutes, respectively. Note that the peak wait time for non-U.S. citizens occurs approximately 2.5 hours after the peak queue length. At the end of the simulation run, midnight EST on June 25, there are 561+/-115 passengers in the U.S. citizen and other queues. ADIS and IBIS data suggest that there were 450 travelers waiting in the primary queue at the end of the 24-hour period.

\subsection{Base Case (As-Is) Scenario}

As indicated in Sec. 5.1, the benchmark model shows 561 passengers in the primary inspection queue at the end of the day. The IBIS records show that these passengers are inspected the next day, so their confirmation time stamps and wait time statistics would be included in the IBIS dataset for June 26. To provide a more accurate representation of inspections for June 25 , the average wait time for the Base Case Scenario includes the wait times of those passengers in the queue at the end of June 25. Accordingly, the simulation time is extended to include 00:00-03:00 hours on June 26 , however flights only arrive in the initial 24 hour period. The average wait time for all travelers processed during this 27 -hour period for the ten runs is $30.3+/-4.6$ minutes, the maximum queue length is $1190+/-94$ passengers, and the ending queue is 0 . Note that more effective lane management can reduce the average wait time. For example, if the alien crossover rate is set to $20 \%$ so that U.S. Citizen inspectors are more effectively utilized, the average wait time for the base case is reduced to $21.1+/ 12.4$ minutes.

\subsection{Scenario $1-$ NIV Prints and Photo}

In this scenario, all of the 2,578 non-immigrant visa holders (types 8 and 9 ) ${ }^{12}$ were required to enroll their fingerprints and photo in a database prior to entry into the U.S. ${ }^{13}$. At primary

\footnotetext{
${ }^{10}$ Simulation results are reported as a mean and a $95 \%$ confidence interval for the mean. The $95 \%$ confidence interval is approximately equal to the mean plus or minus two standard deviations.

${ }^{11}$ Because random sampling drives the simulation model, each simulation run will generate somewhat different outcomes.

12 The simulations in this study did not exclude certain non-immigrant visa holders specifically exempted from US-VISIT Increment 1 processing by policy. Additionally, alien crew in possession of D-1 visas (Traveler type 6) were not included in the simulations.

13 Although it is recognized that initially NIV holders will not be pre-enrolled, our analysis indicates that as long as the biometric query and response times remain less than the time it takes to inspect an NIV holder and that the biometric query and inspection occur concurrently there is no need to model for less than $100 \%$ enrollment.
} 
inspection, fingerprints are reacquired and electronically compared to the person's prints on file by IDENT. A live photo is also acquired, visually compared by the inspector to the photograph on file, and archived.

Assumptions regarding this scenario are as follows:

1. 10 seconds ${ }^{14}$ required to acquire prints (increase in overall inspection time)

2. 5 seconds required to acquire photo (increase in overall inspection time)

3. $100 \%$ of NIVs are enrolled prior to arrival

4. 5 seconds computer and communication time required to check prints (done in parallel with interview)

5. No automated face recognition technology

6. Simulation time 00:00 hours (EST) June 25 through 03:00 (EST) hours June 26

The wait time for this scenario is 43.2+/-5.4 minutes, an increase of 12.9 minutes over the Base Case. Relative to the Base Case, the maximum primary queue length increases by 184 passengers to $1374++108$. A typical ending primary inspection queue at the end of the simulation run is 0 .

The cumulative distributions of traveler wait times for the Base Case and Scenario 1 are shown in Fig. 5.1. The upper curve in the figure indicates that, in the Base Case with no biometrics, $50 \%$ of the travelers wait less than 20 minutes and $95 \%$ of the travelers wait less than 90 minutes. For Scenario 1 , the $50^{\text {th }}$ and $95^{\text {th }}$ percentiles are 22 minutes and 145 minutes, respectively.

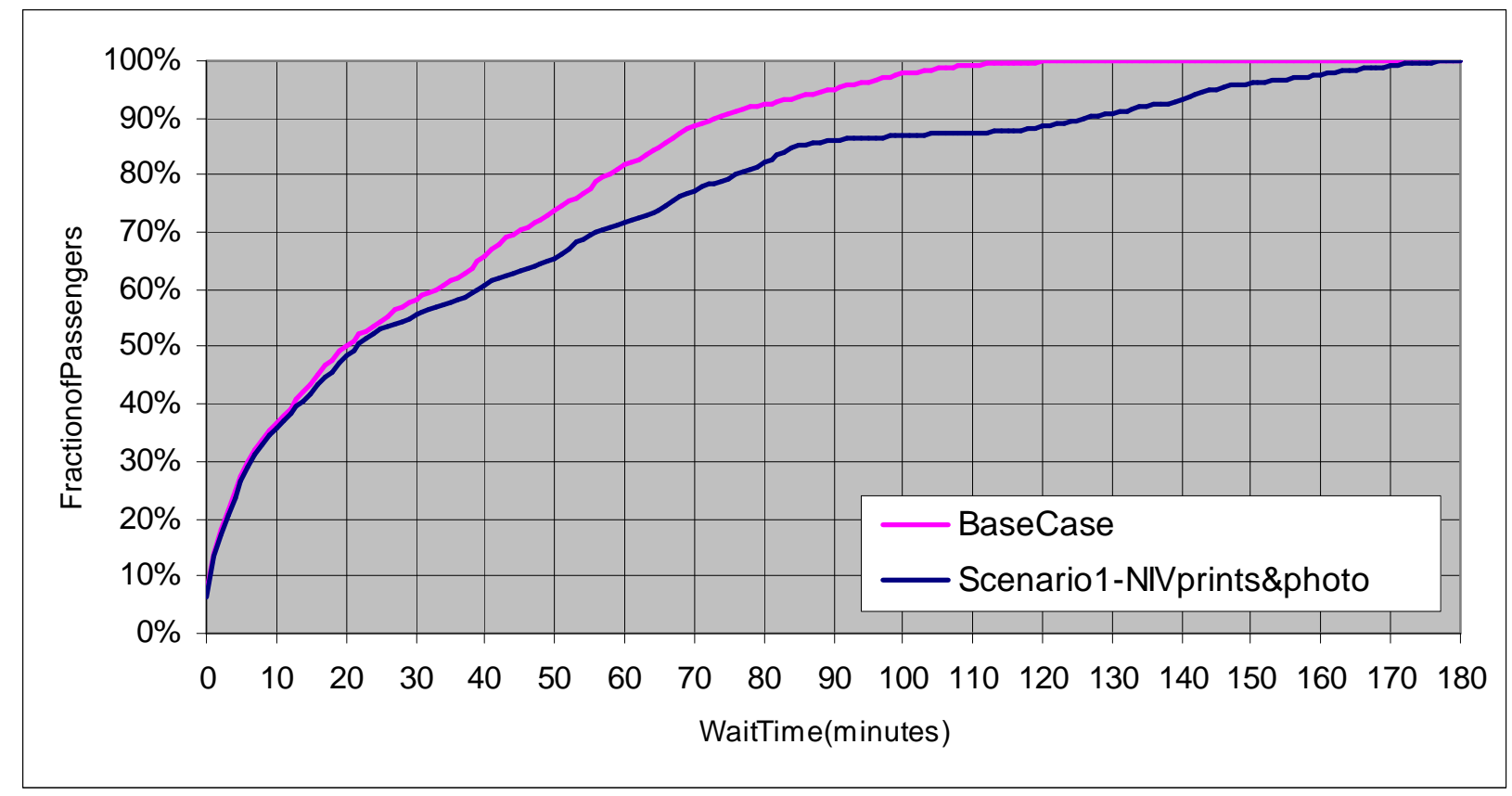

Figure 5-1 - Wait Time Cumulative Probability Distribution Function

\footnotetext{
${ }^{14}$ When and where possible, these model parameters are based on input from IDENT Program managers.
} 


\subsubsection{Sensitivity study of print and photo acquisition time}

A sensitivity study was conducted to explore the impact of increased print and photo acquisition times over the baseline assumption of 15 seconds ( 10 seconds for prints and 5 seconds for photo). Results are show in Figs. 5.2 and 5.3. Print and photo acquisition times of 0 seconds in Figs. 5.2 and 5.3 would correspond to the Base Case scenario with no prints or photo.

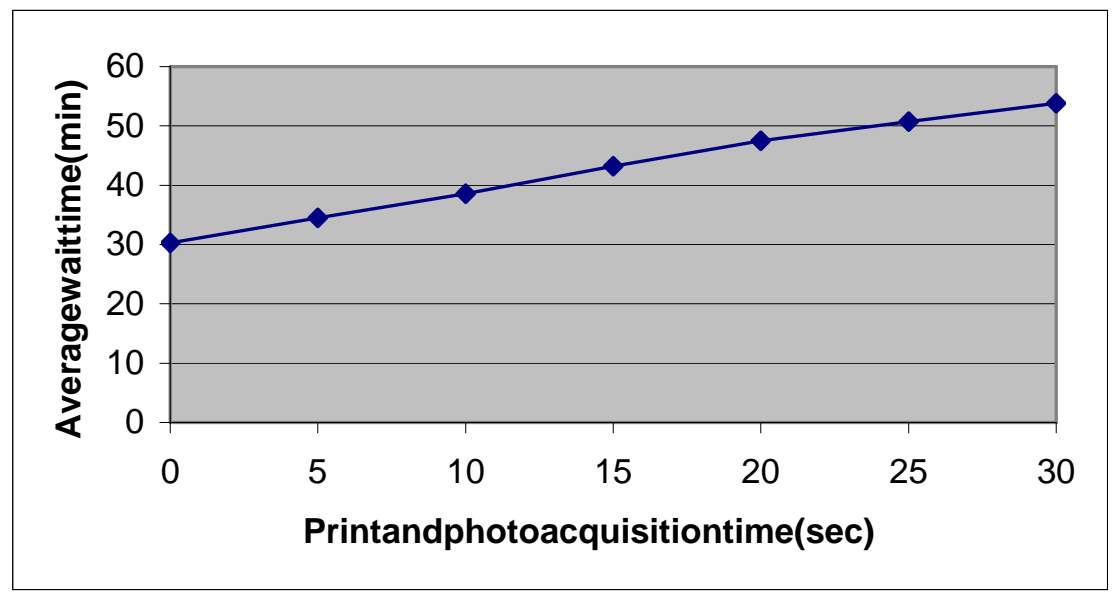

Figure 5-2 - Wait Time vs. Biometrics Acquisition Time

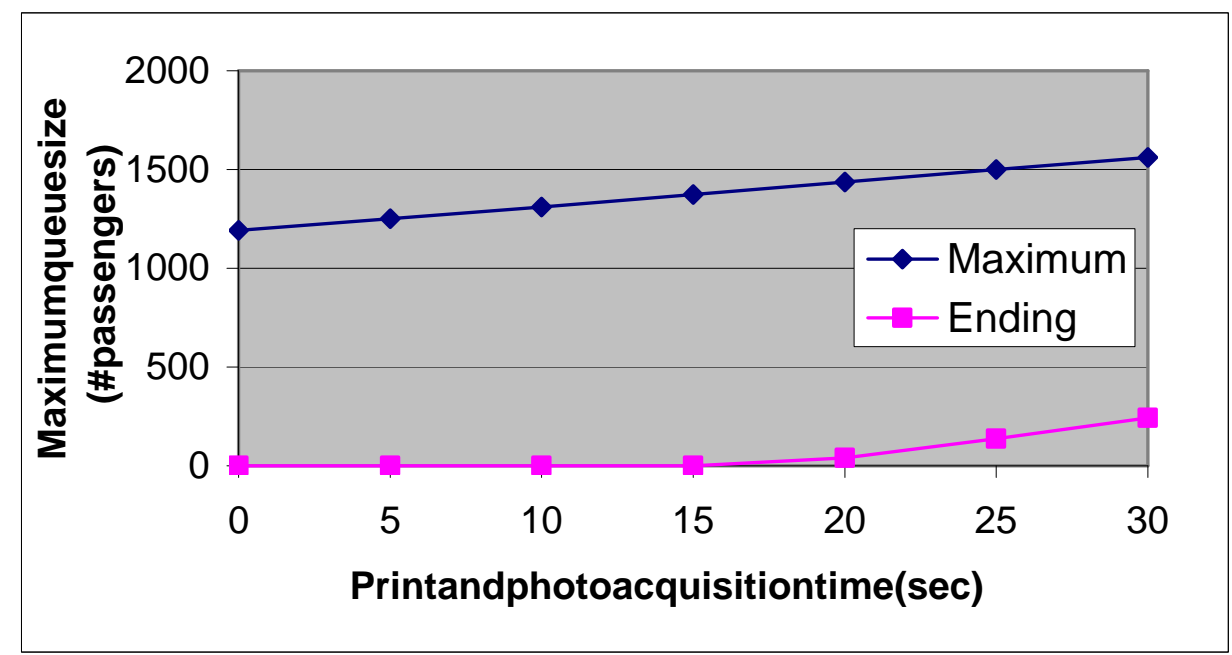

Figure 5-3 - Maximum Queue Size vs. Biometrics Acquisition Time

As indicated by the data in the figures, the average wait time increases by 4 minutes and the maximum queue length increases by about 60 travelers for every 5 second increase in print and photo acquisition time. These numbers can be used as a "rule-of-thumb" for trade-offs in systems design parameters vs. impact on travelers for similar type and sized operations. Another key performance measure is the ending queue length, as travelers in the queue at the end of the 27hour simulation period have been waiting at least three hours. This ending queue becomes greater than zero for print and photo acquisition times greater than 15 seconds. The travelers in this ending queue have been waiting over three hours. This suggests 15 seconds for print and photo acquisition as a design goal for US-VISIT (assuming current staffing at TBIT and strict segregation of US Citizens and alien travelers at the primary inspection lanes).

As discussed in Sec. 5.3, implementation of US-VISIT could significantly affect traveler wait time. These calculations are based upon our Base Case Scenario, which segregates U.S. citizens 
from all alien passengers. Two independent modifications of the Base Case Scenario were made. In the first modification, LPRs are allowed to wait in the same queue as U.S. citizens (as is current practice). This measure would result in a average wait time of $26.2+/-3.2$ minutes, a maximum queue length of $1119+/-82$ travelers, and an ending queue length of 0 travelers. Relative to the Base Case Scenario, the average wait time decreases 4.1 minutes, maximum queue length decreases 71 travelers, and ending queue length is zero.

The second modification explored involved rerouting some percentage of all alien passengers to the U.S. citizen inspection lanes when the expected queue time in those lanes is lower. To this end, the alien crossover parameter was set to $20 \%$. Introduction of this crossover behavior would result in an average wait time of 27.4+/-3.4 minutes, a maximum queue length of 1194+ 68 travelers, and an ending queue length of zero travelers. Relative to the Base Case Scenario, the average wait time decreases 2.9 minutes, maximum queue length increases by 4 travelers, and ending queue length is zero.

\subsection{Scenario 2 - VWP Face Recognition}

In this scenario, it is assumed that all VWP passengers will be in possession of advanced travel documents. This scenario assumes that processes for NIVs in Scenario 1 are not being implemented simultaneously. The following assumptions apply for this scenario:

1. 5 seconds additional time required to take live photo at primary inspection

2. 10 seconds required to verify photo (1-to-1) and check against facial watchlist

3. $100 \%$ of the VWP passengers are in possession of an accredited biometric encoded passport

The average wait time for this scenario increases by 3.5 minutes to $33.8+/-4.6$, relative to the Base Case ("as-is") scenario. The maximum queue length is $1250+/-101$, an increase of 60 passengers.

\subsection{Scenario $3-$ NIV Prints + VWP Face Recognition}

In this scenario, NIV passengers are fingerprinted and live photos are visually compared to photos on file. For VWP passengers, face recognition software is used, but no fingerprints are taken. The assumptions for this case are the same as those in Scenario 1 for NIVs and Scenario 2 for VWPs.

The average wait time for this scenario increases by 16.1 minutes to $46.4+/-5.0$, relative to the Base Case Scenario. The maximum queue length is $1424+/-108$, an increase of 234 passengers relative to the Base Case.

\subsection{Scenario 4 - NIV holders and VWP travelers (prints and photo)}

One possible inspection alternative would be to process all Visa Waiver passengers under

Scenario 1 conditions, with the alternative assumptions that none would be 'pre-enrolled' and, that over time, many travelers will be reencountered and inspected as pre-enrolled NIV holders, e.g. 1-to-1 checks only.

NIV and VWP common assumptions 
1. 15 seconds ${ }^{15}$ required to acquire prints and capture photo

2. Simulation time 00:00 hours (EST) June 25 through 03:00 (EST) hours June 26

NIV assumptions

1. $100 \%$ of NIVs are enrolled prior to arrival

2. 5 seconds computer time required for 1-to-1 check prints

VWP holder assumptions

1. $0 \%$ of VWPs are enrolled prior to arrival

2. 8 seconds computer time required for 1-to-n check prints

The average wait time for this scenario increases by 21.0 minutes to $51.3+/-4.5$, relative to the Base Case Scenario. The maximum queue length is $1521+/-108$, an increase of 334 passengers relative to the Base Case.

The queue length at the end of the 27-hour simulation period is approximately 150 travelers. These travelers have been waiting in excess of three hours. The two mitigation measures described in Sec. 5.3.1, sending LPRs to the U.S. citizen primary inspection queue and setting the alien crossover rate to $20 \%$, can be used to eliminate these ending queues. Sending LPRs to U.S. citizen inspection queues reduces the average wait time to $34+/-3.0$ minutes while setting the alien crossover rate to $20 \%$ reduces the wait time to $35.7+/-2.9$ minutes.

\subsection{Summary of Modeling Simulations}

Simulation results are summarized in Table 6.1. Average wait times for all travelers and maximum queue lengths for primary inspection are reported, as well as changes in these performance measures relative to the Base Case Scenario ("as-is system"). As indicated by the data in the table, introduction of $100 \%$ pre-enrolled biometrics into US-VISIT (Scenario 1) would increase the average wait time for travelers by 12.9 minutes to 43.2 minutes. The maximum queue length increases by 184 travelers to 1374 .

Analysis of the VWP Face recognition Scenario 2 indicates that the addition of advanced travel documents and face recognition software at primary would increase the overall wait time by 3.5 minutes and maximum queue length by 60 travelers.

Implementation of the system represented in Scenario 3, which includes acquisition of prints and photos for NIV passengers and photos for VWP passengers, would increase the mean wait time by 16.1 minutes and maximum queue length by 234 travelers.

Recognizing that participatig countries in the Visa Waiver Program may not be able to meet the legislative date to produce biometric enabled passports and/or facial recognition software may not be mature enough to support the legislative mandate, policy decisions may need to be made as to how to inspect these passengers to support border and homeland security needs afforded us

\footnotetext{
${ }^{15}$ When and where possible, these model parameters are based on input from IDENT Program managers.
} 
the possibility to model a Scenario whereby all non-exempt NIV holders AND VWP passengers were all processed under Scenario 1. The single difference is that for VWP passengers that there would be no corresponding visa file on record against which to compare their photos. Implementation of Scenario 4, which directs VWP and NIV holders through Scenario 1 processes - fingerprint verification - would increase the mean wait time by 21.0 minutes and maximum queue length by 334 travelers.

Table 6-1 - Summary of results

\begin{tabular}{|l|l|c|c|c|c|}
\hline & \multicolumn{1}{|c|}{ Scenario } & $\begin{array}{c}\text { Primary queue } \\
\text { average wait } \\
\text { time (min.) }\end{array}$ & $\begin{array}{c}\text { Change in } \\
\text { average } \\
\text { wait time } \\
\text { (min.) }\end{array}$ & $\begin{array}{c}\text { Primary queue } \\
\text { maximum length } \\
\text { (\# people) }\end{array}$ & $\begin{array}{c}\text { Change in } \\
\text { queue } \\
\text { length }\end{array}$ \\
\hline 0 & Base Case ("as-is") & $30.3+/-4.6$ & - & $1190+/-94$ & - \\
\hline 1 & $\begin{array}{l}\text { US-VISIT (NIV } \\
\text { prints \& photo) }\end{array}$ & $43.2+/-5.4$ & +12.9 & $1374+/-108$ & +184 \\
\hline 2 & VWP Photo & $33.8+/-4.6$ & +3.5 & $1250+/-101$ & +60 \\
\hline 3 & $\begin{array}{l}\text { NIV prints, photo + } \\
\text { VWP photo }\end{array}$ & $46.4+/-5.0$ & +16.1 & $1424+/-108$ & +234 \\
\hline 4 & $\begin{array}{l}\text { NIV holders and } \\
\text { VWP Travelers } \\
\text { (prints and photo) }\end{array}$ & $51.3+/-4.5$ & +21.0 & $1521+/-108$ & +334 \\
\hline
\end{tabular}

\subsection{Recommendations}

As noted in the text of this report there were several instances where data needed to make the simulations more accurate was not available when it should have been and lacked edits and consistency. Of major concern is that this data set is the one upon which all the Increment 1 processing is being performed. One of the goals or objectives of any new or improved electronic arrival and departure system is to have data that is as accurate as possible. It is highly recommended that as the project moves forward that data being collected, the manner in which it is collected, and the edits (if any) that are applied be reviewed on a continual basis for quality assurance.

Based on our site visit in August 2003 and other anecdotal reports, system availability and slow response times are a concern to end-users. It is strongly recommended that a backup or local system be developed to address periods when centralized system performance is slow or unavailable. Since the site visit, it has been reported that the mainframe capacity has been doubled and telecommunications have been upgraded at LAX as well as at all major air POEs which should serve to alleviate some of these problems.

Print and photo acquisition times in excess of 15 seconds result in end of day queues that are non-zero. Since travelers waiting in the queue at the end of the 27-hour simulation period will have been waiting in excess of 3 hours, a maximum of 15 seconds is suggested as a design goal for biometric acquisition systems.

Future versions of the model will have more robust inspector allocation logic and can be driven by IBIS records rather than POMS flight schedules. It is strongly recommended that IBIS be modified to include flight block time. 
Simulation Analysis of Inspections of International Travelers at Los Angeles Int'l Airport for US-VISIT 


\section{Appendix A Sample IBIS Records Used for Modeling}

IATA INS

Conf. time Lane Site airport Port Flight ETA Sec. L.O. carrier Flt. Depart. Conf. date hhmmss no. ID code code date Code Code code Num. airport 20030625 20030625

20030625 20030625

20030625

20030625

20030625

20030625

20030625

20030625

20030625

20030625

20030625

20030625

20030625

20030625

20030625

20030625

20030625

20030625

20030625

20030625

20030625

20030625

20030625

20030625

20030625

20030625

20030625

20030625

20030625

20030625

20030625
170053 CU03 A273 LAX LOS 170131 CU03 A273 LAX LOS

170336 CU03 A273 LAX LOS 171003 CU03 A273 LAX LOS 171202 CU03 A273 LAX LOS 171342 CU03 A273 LAX LOS 171415 CU03 A273 LAX LOS 171755 CU03 A273 LAX LOS 171822 CU03 A273 LAX LOS 171906 CU03 A273 LAX LOS 172246 CU03 A273 LAX LOS 172308 CU03 A273 LAX LOS 172611 CU03 A273 LAX LOS 172847 CU03 A273 LAX LOS 173227 CU03 A273 LAX LOS 174504 CU03 A273 LAX LOS 174550 CU03 A273 LAX LOS 175936 CU03 A273 LAX LOS 180344 CU03 A273 LAX LOS 181053 CU03 A273 LAX LOS 181244 CU03 A273 LAX LOS 181630 CU03 A273 LAX LOS 182141 CU03 A273 LAX LOS 182221 CU03 A273 LAX LOS 182402 CU03 A273 LAX LOS 182513 CU03 A273 LAX LOS 182721 CU03 A273 LAX LOS 182737 CU03 A273 LAX LOS 183114 CU03 A273 LAX LOS 183253 CU03 A273 LAX LOS 183313 CU03 A273 LAX LOS 183841 CU03 A273 LAX LOS 184145 CU03 A273 LAX LOS 184248 CU03 A273 LAX LOS $20030625 \mathrm{~N}$ $20030625 \mathrm{~N}$ $20030625 \mathrm{~N}$ $20030625 \mathrm{~N}$ $20030625 \mathrm{~N}$ $20030625 \mathrm{~N}$ $20030625 \mathrm{~N}$ $20030625 \mathrm{~N}$ $20030625 \mathrm{~N}$ $20030625 \mathrm{~N}$ $20030625 \mathrm{~N}$ $20030625 \mathrm{~N}$ $20030625 \mathrm{~N}$ $20030625 \mathrm{~N}$ $20030625 \mathrm{~N}$ $20030625 \mathrm{~N}$ $20030625 \mathrm{~N}$ $20030625 \mathrm{~N}$ $20030625 \mathrm{~N}$ $20030625 \mathrm{~N}$ $20030625 \mathrm{~N}$ $20030625 \mathrm{~N}$ $20030625 \mathrm{~N}$ $20030625 \mathrm{~N}$ $20030625 \mathrm{~N}$ $20030625 \mathrm{~N}$ $20030625 \mathrm{~N}$ $20030625 \mathrm{~N}$ $20030625 \mathrm{~N}$ $20030625 \mathrm{~N}$ $20030625 \mathrm{~N}$ $20030625 \mathrm{~N}$ $20030625 \mathrm{~N}$

$\begin{array}{llrl}\text { N } & \text { JL } & 60 \mathrm{KIX} & \mathrm{F} \\ \mathrm{N} & \mathrm{JL} & 60 \mathrm{KIX} & \mathrm{M} \\ \mathrm{N} & \mathrm{OZ} & 202 \mathrm{ICN} & \mathrm{M} \\ \mathrm{N} & \mathrm{LH} & 456 \mathrm{FRA} & \mathrm{M} \\ \mathrm{N} & \mathrm{SQ} & 12 \mathrm{SIN} & \mathrm{F} \\ \mathrm{N} & \mathrm{SQ} & 12 \mathrm{SIN} & \mathrm{F} \\ \mathrm{N} & \mathrm{SQ} & 12 \mathrm{SIN} & \mathrm{M} \\ \mathrm{N} & \mathrm{SQ} & 12 \mathrm{SIN} & \mathrm{F} \\ \mathrm{N} & \mathrm{SQ} & 12 \mathrm{SIN} & \mathrm{M} \\ \mathrm{N} & \mathrm{MH} & 94 \mathrm{KUL} & \mathrm{M} \\ \mathrm{N} & \mathrm{LX} & 40 \mathrm{ZRH} & \mathrm{F} \\ \mathrm{N} & \mathrm{LX} & 40 \mathrm{ZRH} & \mathrm{M} \\ \mathrm{N} & \mathrm{SQ} & 12 \mathrm{SIN} & \mathrm{F} \\ \mathrm{N} & \mathrm{Cl} & 6 \mathrm{TPE} & \mathrm{M} \\ \mathrm{N} & \mathrm{LH} & 456 \mathrm{FRA} & \mathrm{F} \\ \mathrm{N} & \mathrm{OZ} & 202 \mathrm{ICN} & \mathrm{F} \\ \mathrm{Y} & \mathrm{OZ} & 202 \mathrm{ICN} & \mathrm{F} \\ \mathrm{N} & \mathrm{RG} & 8837 \mathrm{NRT} & \mathrm{F} \\ \mathrm{N} & \mathrm{LX} & 40 \mathrm{ZRH} & \mathrm{F} \\ \mathrm{N} & \mathrm{MX} & 920 \mathrm{MEX} & \mathrm{F} \\ \mathrm{N} & \mathrm{MX} & 920 \mathrm{MEX} & \mathrm{F} \\ \mathrm{N} & \mathrm{MH} & 94 \mathrm{KUL} & \mathrm{F} \\ \mathrm{N} & \mathrm{SQ} & 12 \mathrm{SIN} & \mathrm{M} \\ \mathrm{N} & \mathrm{SQ} & 12 \mathrm{SIN} & \mathrm{F} \\ \mathrm{N} & \mathrm{AF} & 62 \mathrm{G} & \mathrm{M} \\ \mathrm{Y} & \mathrm{BA} & 283 \mathrm{LHR} & \mathrm{M} \\ \mathrm{N} & \mathrm{BA} & 283 \mathrm{LHR} & \mathrm{M} \\ \mathrm{N} & \mathrm{BA} & 283 \mathrm{LHR} & \mathrm{F} \\ \mathrm{N} & \mathrm{BA} & 283 \mathrm{LHR} & \mathrm{M} \\ \mathrm{N} & \mathrm{SQ} & 12 \mathrm{SIN} & \mathrm{M} \\ \mathrm{N} & \mathrm{SQ} & 12 \mathrm{SIN} & \mathrm{F} \\ \mathrm{N} & \mathrm{MX} & 920 \mathrm{MEX} & \mathrm{M} \\ \mathrm{Y} & \mathrm{MX} & 920 \mathrm{MEX} & \mathrm{M} \\ \mathrm{N} & \mathrm{Cl} & 6 \mathrm{TPE} & \mathrm{M} \\ & & & \end{array}$

Passenger Doc. Visa Limit of

DOB Doc. country class of Admittance stay Gender ccyymmdd type code entry until date time $\begin{array}{lllll} & 19330110 \mathrm{P} & \text { JP } & \text { WT } & 20030923 \\ \text { M } & 19361216 \mathrm{P} & \text { JP } & \text { WT } & 20030923\end{array}$

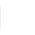
$19450630 \mathrm{P} \quad \mathrm{KR}$ $19441012 \mathrm{P} \quad$ IT $19180315 P$ US $19310119 \mathrm{~V} \quad$ IN $19290918 \mathrm{~V}$ US $19270906 \mathrm{P} \quad J P$ $19300528 P$ US $19720626 \mathrm{~V}$ TW $19440228 \mathrm{P} \quad \mathrm{SE}$ $19450628 \mathrm{P} \quad \mathrm{CH}$ $19640516 \mathrm{~V} \quad \mathrm{SG}$ $19630308 \mathrm{P}$ US $19301007 \mathrm{P} \quad \mathrm{DK}$ $19301011 \mathrm{~V} \quad \mathrm{KR}$ $19590710 \mathrm{P} \quad \mathrm{KR}$ $19811009 P \quad J P$ 19830417 P GB $19481113 \mathrm{C}$ US $19880307 \mathrm{~F}$ US $19651105 \mathrm{~V}$ TW $19360124 \mathrm{~V}$ IN $19401101 \mathrm{~V} \quad \mathrm{IN}$ $19590929 \mathrm{P} \quad \mathrm{IT}$ $19631024 \mathrm{P}$ US $19310914 \mathrm{P} \quad \mathrm{GB}$ $19290712 P \quad G B$ $19800917 \mathrm{P}$ US 19331118 P SG $19391025 P \quad S G$ $19261021 \mathrm{P}$ US $19290319 \mathrm{~V}$ US $19581102 \mathrm{~V}$ US 


\section{Appendix B Inspection Time Probability Distributions by Class-of-Admit}

Table B-1 - Sample sizes for primary inspection time distributions by traveler type

\begin{tabular}{|r|r|}
\hline \multicolumn{1}{|c|}{$\begin{array}{c}\text { Traveler } \\
\text { type }\end{array}$} & $\begin{array}{l}\text { Sample size for } \\
\text { TBIT } \\
\text { distributions }\end{array}$ \\
\hline 0 & 102,127 \\
\hline 1 & 15,431 \\
\hline 2 & 1,408 \\
\hline 3 & 2 \\
\hline 4 & 23,018 \\
\hline 5 & 52,199 \\
\hline 6 & 17,374 \\
\hline 7 & 63 \\
\hline 8 & 2,414 \\
\hline 9 & 77,219 \\
\hline 10 & 23 \\
\hline 11 & - \\
\hline 12 & 5,188 \\
\hline total & $\mathbf{2 9 6 , 4 6 6}$ \\
\hline
\end{tabular}


B.0 U.S. citizens with passports

$\begin{array}{rrrrrr}\text { Time (sec) } & \begin{array}{c}\text { TBIT } \\ \text { Probability }\end{array} & \begin{array}{c}\text { Lognormal } \\ \text { Probability }\end{array} & \begin{array}{c}\text { Time } \\ \text { (sec) }\end{array} & \begin{array}{c}\text { TBIT } \\ \text { Probability }\end{array} & \begin{array}{l}\text { Lognormal } \\ \text { Probability }\end{array} \\ 6 & 0.053000 & 0.024026 & 162 & 0.003000 & 0.003005 \\ 12 & 0.112000 & 0.098972 & 168 & 0.002000 & 0.002665 \\ 18 & 0.100000 & 0.124512 & 174 & 0.002000 & 0.002369 \\ 24 & 0.116000 & 0.118157 & 180 & 0.002000 & 0.002110 \\ 30 & 0.115000 & 0.102290 & 186 & 0.002000 & 0.001885 \\ 36 & 0.095000 & 0.085514 & 192 & 0.002000 & 0.001687 \\ 42 & 0.075000 & 0.070559 & 198 & 0.002000 & 0.001513 \\ 48 & 0.059000 & 0.058017 & 204 & 0.001000 & 0.001359 \\ 54 & 0.045000 & 0.047758 & 210 & 0.001000 & 0.001224 \\ 60 & 0.035000 & 0.039444 & 216 & 0.001000 & 0.001104 \\ 66 & 0.030000 & 0.032723 & 222 & 0.001000 & 0.000998 \\ 72 & 0.022000 & 0.027281 & 228 & 0.001000 & 0.000903 \\ 78 & 0.019000 & 0.022860 & 234 & 0.001000 & 0.000819 \\ 84 & 0.016000 & 0.019252 & 240 & 0.001000 & 0.000744 \\ 90 & 0.013000 & 0.016293 & 246 & 0.001000 & 0.000676 \\ 96 & 0.011000 & 0.013854 & 252 & 0.001000 & 0.000616 \\ 102 & 0.009000 & 0.011834 & 258 & 0.001000 & 0.000562 \\ 108 & 0.008000 & 0.010153 & 264 & 0.001000 & 0.000513 \\ 114 & 0.007000 & 0.008746 & 270 & 0.001000 & 0.000470 \\ 120 & 0.006000 & 0.007563 & 276 & 0.001000 & 0.000430 \\ 126 & 0.005000 & 0.006565 & 282 & 0.001000 & 0.000394 \\ 132 & 0.005000 & 0.005718 & 288 & 0.001000 & 0.000362 \\ 138 & 0.004000 & 0.004998 & 294 & 0.001000 & 0.000333 \\ 144 & 0.004000 & 0.004382 & 300 & 0.001000 & 0.000306 \\ 150 & 0.003000 & 0.003853 & & & \\ 156 & 0.003000 & 0.003398 & & & \end{array}$

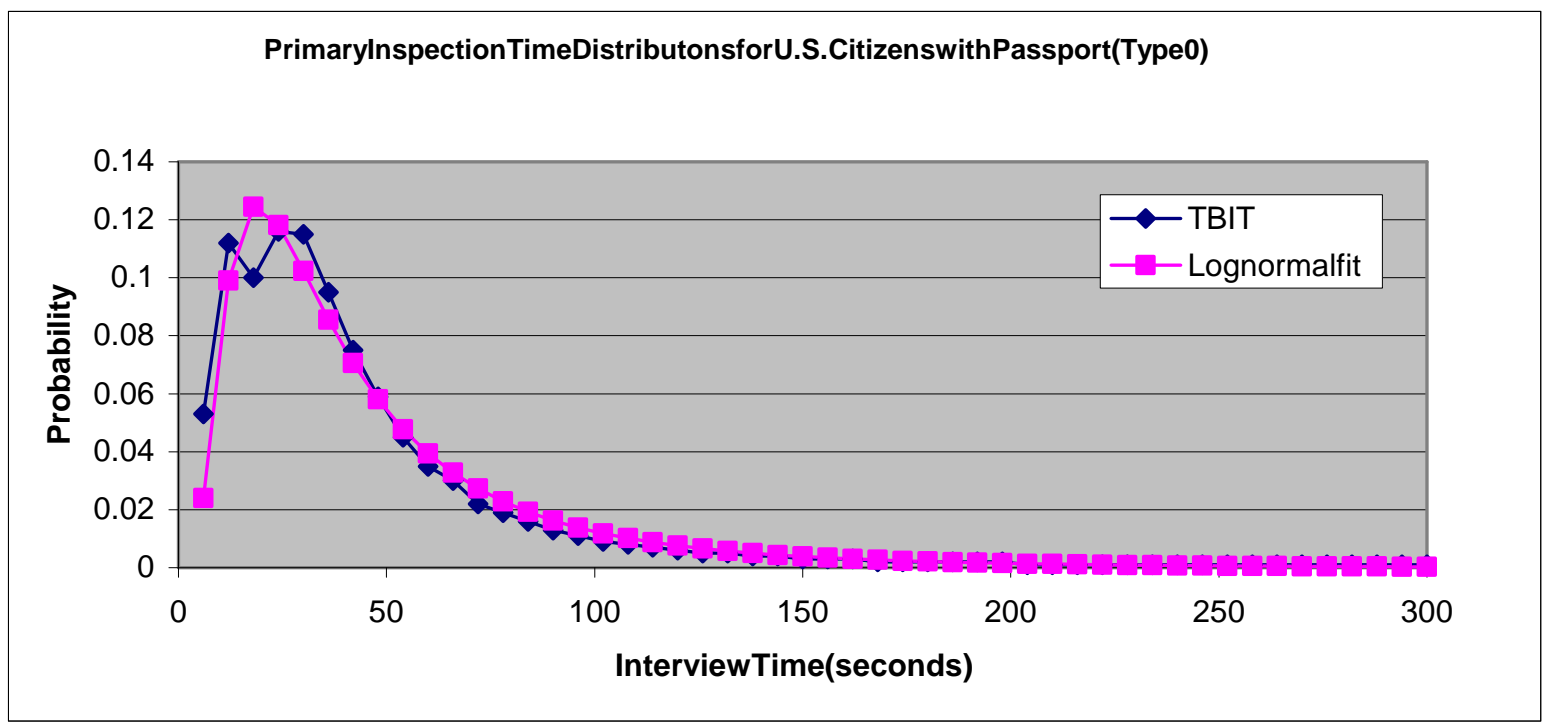


B.1 U.S. citizens without passports

$\begin{array}{rrrrrr}\text { Time (sec) } & \begin{array}{c}\text { TBIT } \\ \text { Probability }\end{array} & \begin{array}{l}\text { Lognormal } \\ \text { Probability }\end{array} & \begin{array}{c}\text { Time } \\ \text { (sec) }\end{array} & \begin{array}{c}\text { TBIT } \\ \text { Probability }\end{array} & \begin{array}{l}\text { Lognormal } \\ \text { Probability }\end{array} \\ 6 & 0.016979 & 0.014060 & 162 & 0.004731 & 0.005478 \\ 12 & 0.067008 & 0.064795 & 168 & 0.003823 & 0.004952 \\ 18 & 0.096235 & 0.090957 & 174 & 0.003240 & 0.004486 \\ 24 & 0.090273 & 0.094529 & 180 & 0.002527 & 0.004070 \\ 30 & 0.080682 & 0.088369 & 186 & 0.003240 & 0.003701 \\ 36 & 0.081524 & 0.078965 & 192 & 0.002527 & 0.003370 \\ 42 & 0.070831 & 0.069114 & 198 & 0.002203 & 0.003074 \\ 48 & 0.064027 & 0.059925 & 204 & 0.002527 & 0.002809 \\ 54 & 0.052881 & 0.051769 & 210 & 0.001879 & 0.002570 \\ 60 & 0.051325 & 0.044699 & 216 & 0.002463 & 0.002355 \\ 66 & 0.041281 & 0.038640 & 222 & 0.001685 & 0.002161 \\ 72 & 0.035902 & 0.033475 & 228 & 0.001231 & 0.001986 \\ 78 & 0.032921 & 0.029078 & 234 & 0.001944 & 0.001828 \\ 84 & 0.025857 & 0.025333 & 240 & 0.001620 & 0.001684 \\ 90 & 0.022034 & 0.022139 & 246 & 0.001037 & 0.001554 \\ 96 & 0.018988 & 0.019408 & 252 & 0.001491 & 0.001435 \\ 102 & 0.016136 & 0.017067 & 258 & 0.001231 & 0.001327 \\ 108 & 0.013868 & 0.015053 & 264 & 0.001102 & 0.001228 \\ 114 & 0.013868 & 0.013315 & 270 & 0.001102 & 0.001138 \\ 120 & 0.010693 & 0.011812 & 276 & 0.001426 & 0.001056 \\ 126 & 0.010239 & 0.010507 & 282 & 0.001231 & 0.000981 \\ 132 & 0.009850 & 0.009370 & 288 & 0.000713 & 0.000912 \\ 138 & 0.007971 & 0.008378 & 294 & 0.000842 & 0.000848 \\ 144 & 0.007841 & 0.007508 & 300 & 0.001166 & 0.000790 \\ 150 & 0.006999 & 0.006744 & & & \\ 156 & 0.006804 & 0.006072 & & & \\ & & & & & \end{array}$

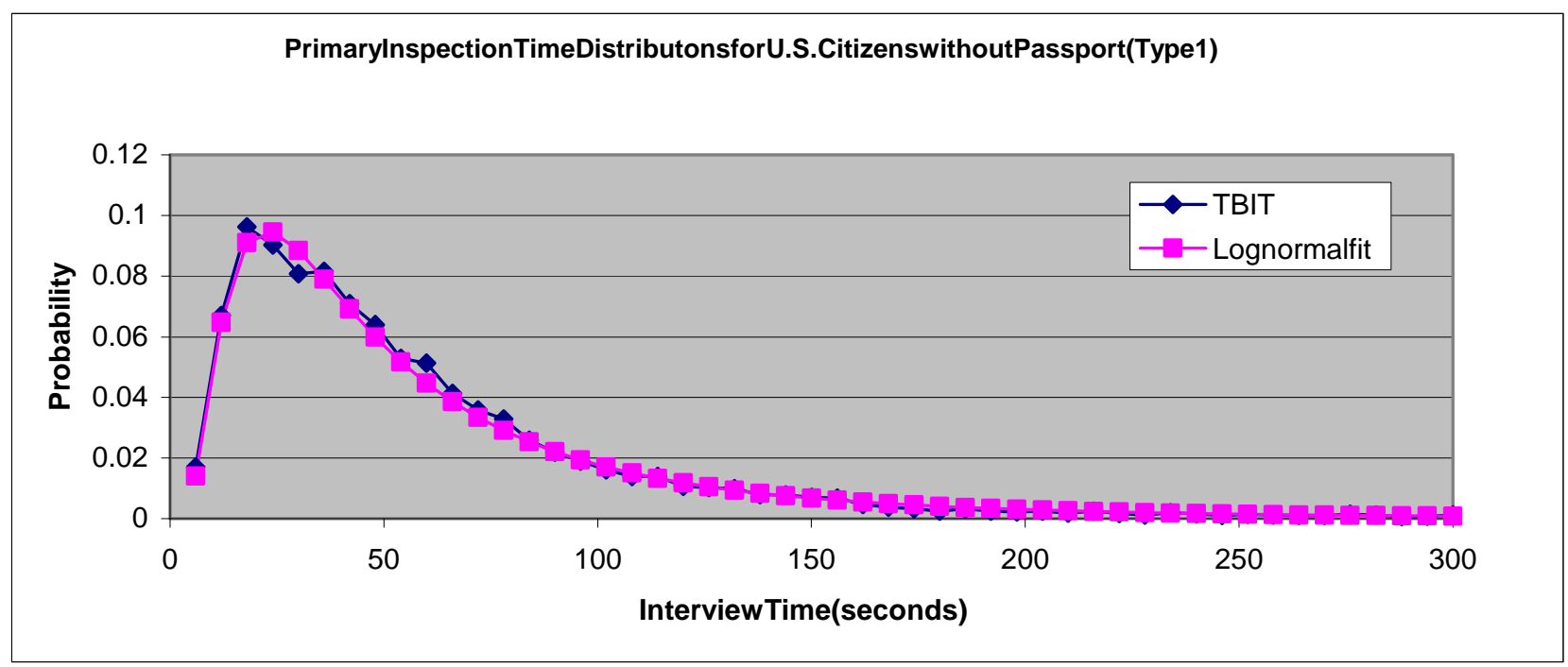




\section{B.2 Canadian citizens with documents}

\begin{tabular}{|c|c|c|c|c|c|}
\hline Time (sec) & $\begin{array}{c}\text { TBIT } \\
\text { Probability }\end{array}$ & $\begin{array}{l}\text { Lognormal } \\
\text { Probability }\end{array}$ & $\begin{array}{l}\text { Time } \\
\text { (sec) }\end{array}$ & $\begin{array}{c}\text { TBIT } \\
\text { Probability }\end{array}$ & $\begin{array}{l}\text { Lognormal } \\
\text { Probability }\end{array}$ \\
\hline 6 & 0.004972 & 0.000143 & 162 & 0.010653 & 0.003449 \\
\hline 12 & 0.004261 & 0.007279 & 168 & 0.004261 & 0.002918 \\
\hline 18 & 0.023438 & 0.033619 & 174 & 0.007813 & 0.002474 \\
\hline 24 & 0.052557 & 0.065732 & 180 & 0.007813 & 0.002102 \\
\hline 30 & 0.098722 & 0.088112 & 186 & 0.002841 & 0.001790 \\
\hline 36 & 0.093750 & 0.097506 & 192 & 0.004261 & 0.001527 \\
\hline 42 & 0.098722 & 0.096869 & 198 & 0.002841 & 0.001306 \\
\hline 48 & 0.099432 & 0.090182 & 204 & 0.002841 & 0.001119 \\
\hline 54 & 0.068182 & 0.080591 & 210 & 0.002131 & 0.000960 \\
\hline 60 & 0.067472 & 0.070132 & 216 & 0.002131 & 0.000826 \\
\hline 66 & 0.044034 & 0.059972 & 222 & 0.002131 & 0.000711 \\
\hline 72 & 0.044744 & 0.050695 & 228 & 0.006392 & 0.000614 \\
\hline 78 & 0.032670 & 0.042530 & 234 & 0.002841 & 0.000531 \\
\hline 84 & 0.028409 & 0.035510 & 240 & 0.002841 & 0.000460 \\
\hline 90 & 0.024148 & 0.029565 & 246 & 0.000000 & 0.000399 \\
\hline 96 & 0.023438 & 0.024580 & 252 & 0.000000 & 0.000347 \\
\hline 102 & 0.021307 & 0.020427 & 258 & 0.002841 & 0.000302 \\
\hline 108 & 0.013494 & 0.016981 & 264 & 0.005682 & 0.000263 \\
\hline 114 & 0.013494 & 0.014128 & 270 & 0.002841 & 0.000230 \\
\hline 120 & 0.017756 & 0.011769 & 276 & 0.000710 & 0.000201 \\
\hline 126 & 0.009233 & 0.009819 & 282 & 0.001420 & 0.000176 \\
\hline 132 & 0.007102 & 0.008207 & 288 & 0.002841 & 0.000155 \\
\hline 138 & 0.011364 & 0.006872 & 294 & 0.000000 & 0.000136 \\
\hline 144 & 0.007813 & 0.005766 & 300 & 0.000000 & 0.000120 \\
\hline 150 & 0.004972 & 0.004848 & & & \\
\hline 156 & 0.006392 & 0.004084 & & & \\
\hline
\end{tabular}

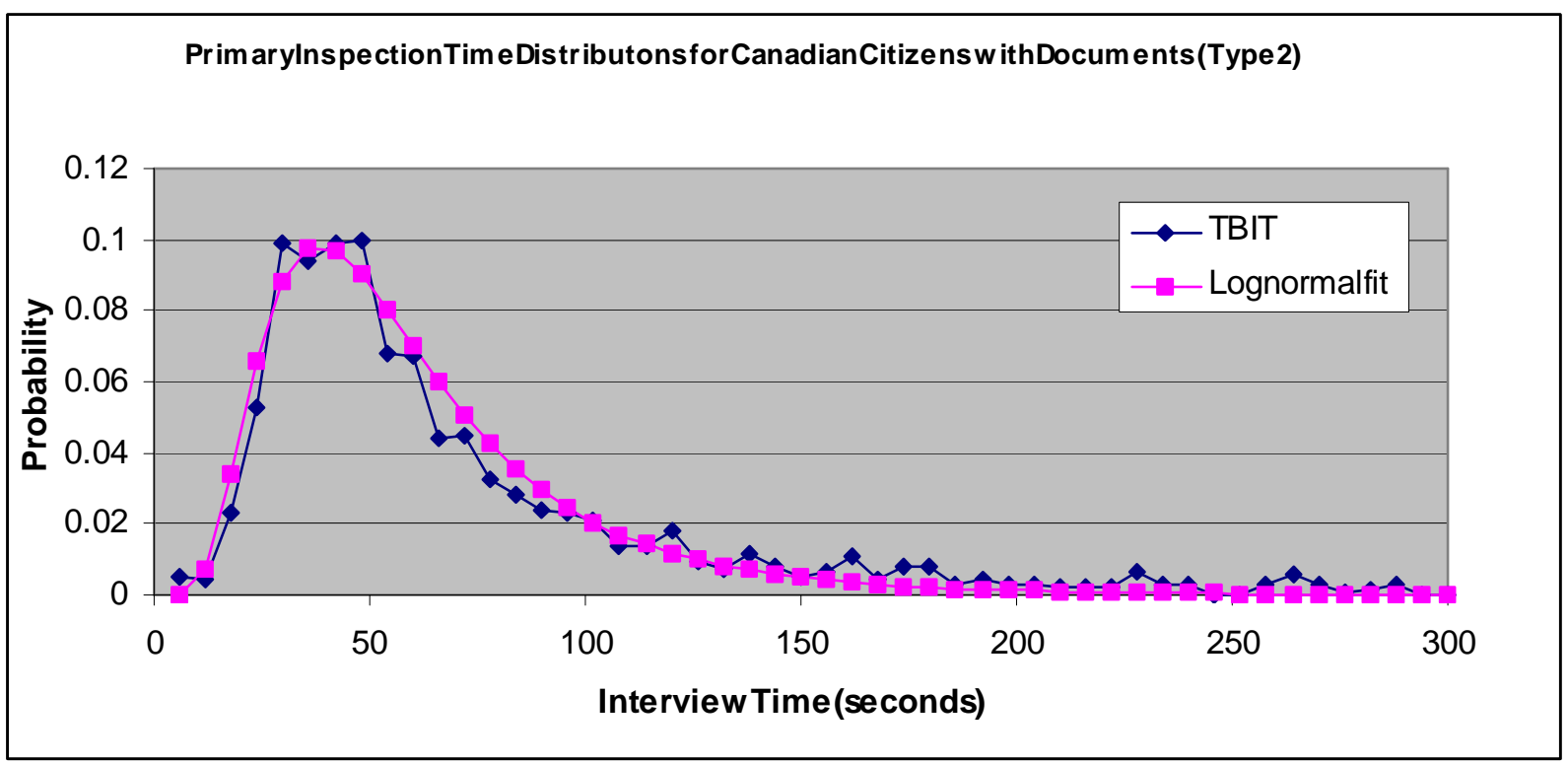




\section{B.3 Canadian citizens without documents}

\section{TBIT}

Time (sec) Probability

$6 \quad 0.500000$

$12 \quad 0.000000$

$18 \quad 0.000000$

$24 \quad 0.000000$

$30 \quad 0.000000$

$36 \quad 0.000000$

$42 \quad 0.000000$

$48 \quad 0.000000$

$54 \quad 0.000000$

$\begin{array}{ll}60 & 0.000000\end{array}$

$66 \quad 0.500000$

$72 \quad 0.000000$

$\begin{array}{ll}78 & 0.000000\end{array}$

$84 \quad 0.000000$

$90 \quad 0.000000$

$96 \quad 0.000000$

$102 \quad 0.000000$

$108 \quad 0.000000$

$114 \quad 0.000000$

$120 \quad 0.000000$

$126 \quad 0.000000$

$132 \quad 0.000000$

$138 \quad 0.000000$

$144 \quad 0.000000$

$\begin{array}{ll}150 & 0.000000\end{array}$

$\begin{array}{ll}156 & 0.000000\end{array}$
Time TBIT

(sec) Probability

$\begin{array}{ll}162 & 0.000000\end{array}$

$168 \quad 0.000000$

$174 \quad 0.000000$

$\begin{array}{ll}180 & 0.000000\end{array}$

$186 \quad 0.000000$

$192 \quad 0.000000$

$198 \quad 0.000000$

$204 \quad 0.000000$

$210 \quad 0.000000$

$216 \quad 0.000000$

$222 \quad 0.000000$

$228 \quad 0.000000$

$234 \quad 0.000000$

$240 \quad 0.000000$

$246 \quad 0.000000$

$252 \quad 0.000000$

$258 \quad 0.000000$

$264 \quad 0.000000$

$270 \quad 0.000000$

$276 \quad 0.000000$

$282 \quad 0.000000$

$288 \quad 0.000000$

$294 \quad 0.000000$

$300 \quad 0.000000$

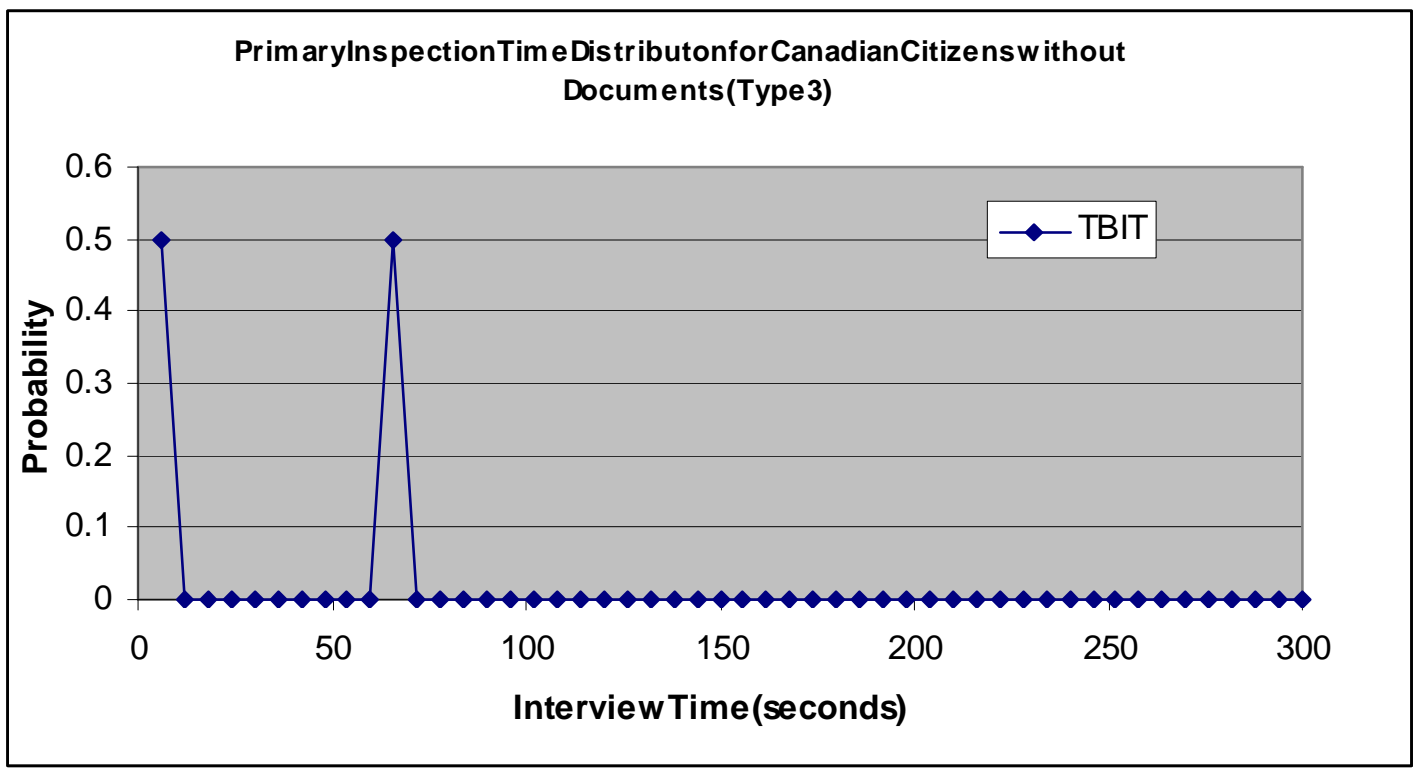




\section{B.4 Legal Permanent Residents (LPR)}

$\begin{array}{rrrrrr}\text { Time (sec) } & \text { Probability } & \begin{array}{c}\text { Lognormal } \\ \text { Probability }\end{array} & \begin{array}{c}\text { Time } \\ \text { (sec) }\end{array} & \begin{array}{c}\text { TBIT } \\ \text { Probability }\end{array} & \begin{array}{l}\text { Lognormal } \\ \text { Probability }\end{array} \\ 6 & 0.015119 & 0.002665 & 162 & 0.007690 & 0.008715 \\ 12 & 0.038709 & 0.023637 & 168 & 0.006951 & 0.007936 \\ 18 & 0.047441 & 0.048352 & 174 & 0.005604 & 0.007238 \\ 24 & 0.055869 & 0.063216 & 180 & 0.005691 & 0.006609 \\ 30 & 0.061778 & 0.069130 & 186 & 0.005908 & 0.006044 \\ 36 & 0.065948 & 0.069335 & 192 & 0.005995 & 0.005534 \\ 42 & 0.069511 & 0.066357 & 198 & 0.004822 & 0.005073 \\ 48 & 0.067295 & 0.061805 & 204 & 0.004301 & 0.004657 \\ 54 & 0.063168 & 0.056631 & 210 & 0.003519 & 0.004280 \\ 60 & 0.058997 & 0.051373 & 216 & 0.004518 & 0.003938 \\ 66 & 0.049179 & 0.046317 & 222 & 0.003345 & 0.003627 \\ 72 & 0.044009 & 0.041608 & 228 & 0.003389 & 0.003345 \\ 78 & 0.034191 & 0.037305 & 234 & 0.003345 & 0.003088 \\ 84 & 0.032540 & 0.033418 & 240 & 0.003041 & 0.002854 \\ 90 & 0.030411 & 0.029933 & 246 & 0.003519 & 0.002640 \\ 96 & 0.027283 & 0.026824 & 252 & 0.003215 & 0.002445 \\ 102 & 0.022287 & 0.024057 & 258 & 0.003389 & 0.002266 \\ 108 & 0.019941 & 0.021598 & 264 & 0.002737 & 0.002102 \\ 114 & 0.017334 & 0.019414 & 270 & 0.003389 & 0.001952 \\ 120 & 0.016378 & 0.017475 & 276 & 0.002607 & 0.001815 \\ 126 & 0.013555 & 0.015752 & 282 & 0.002042 & 0.001688 \\ 132 & 0.014119 & 0.014219 & 288 & 0.002259 & 0.001572 \\ 138 & 0.011817 & 0.012855 & 294 & 0.002303 & 0.001465 \\ 144 & 0.011382 & 0.011638 & 300 & 0.002172 & 0.001366 \\ 150 & 0.008124 & 0.010553 & & & \\ 156 & 0.007863 & 0.009583 & & & \\ & & & & & \end{array}$

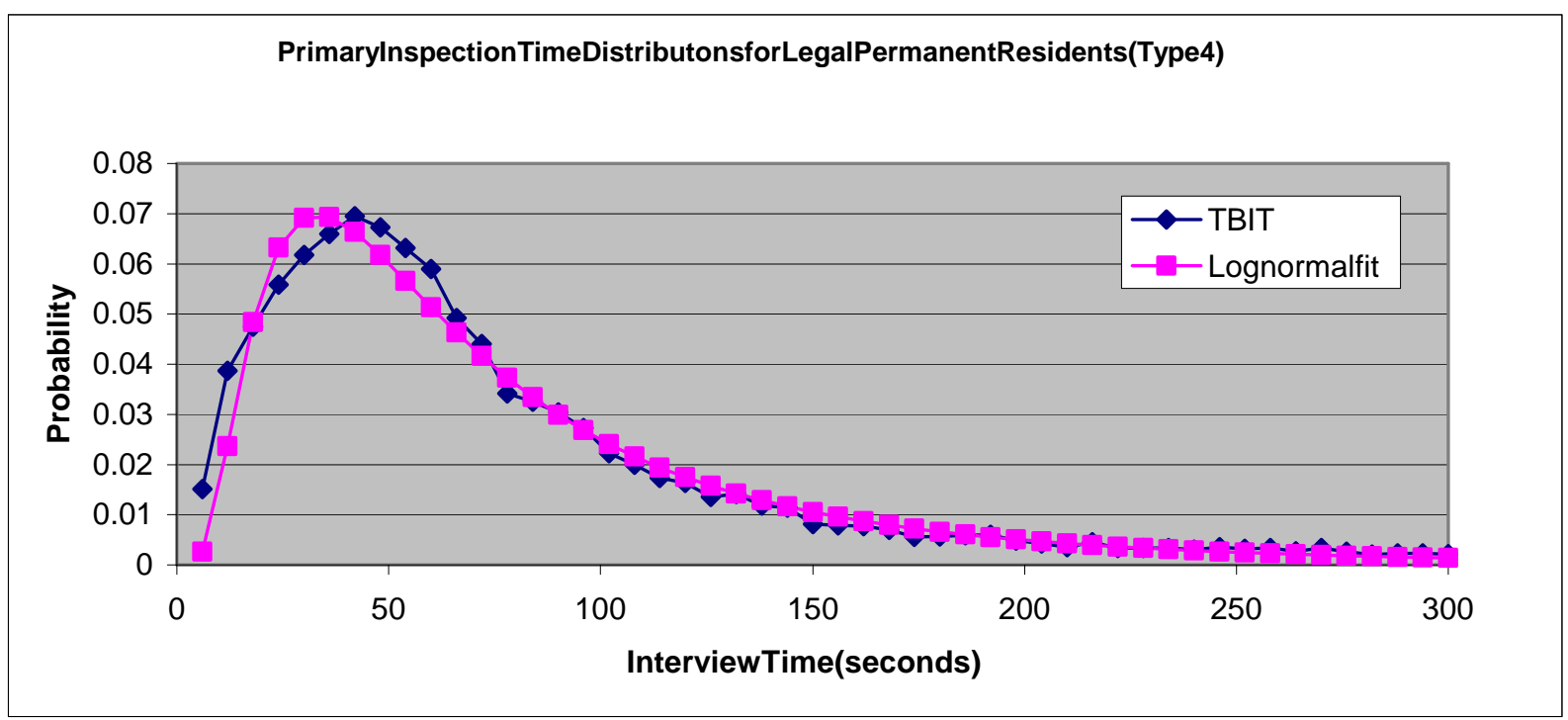




\section{B.5 Visa Waiver Program (VWP)}

$\begin{array}{rrrrrr}\text { Time (sec) } & \begin{array}{c}\text { TBIT } \\ \text { Probability }\end{array} & \begin{array}{c}\text { Lognormal } \\ \text { Probability }\end{array} & \begin{array}{c}\text { Time } \\ \text { (sec) }\end{array} & \begin{array}{c}\text { TBIT } \\ \text { Probability }\end{array} & \begin{array}{c}\text { Lognormal } \\ \text { Probability }\end{array} \\ 6 & 0.007127 & 0.000155 & 162 & 0.011954 & 0.013807 \\ 12 & 0.021648 & 0.003829 & 168 & 0.011341 & 0.012692 \\ 18 & 0.033851 & 0.014069 & 174 & 0.009464 & 0.011673 \\ 24 & 0.033200 & 0.026507 & 180 & 0.009789 & 0.010743 \\ 30 & 0.032989 & 0.037227 & 186 & 0.008736 & 0.009892 \\ 36 & 0.033717 & 0.044859 & 192 & 0.007510 & 0.009116 \\ 42 & 0.040116 & 0.049443 & 198 & 0.007069 & 0.008405 \\ 48 & 0.045441 & 0.051529 & 204 & 0.006897 & 0.007756 \\ 54 & 0.049484 & 0.051751 & 210 & 0.005920 & 0.007162 \\ 60 & 0.053449 & 0.050670 & 216 & 0.005747 & 0.006618 \\ 66 & 0.055652 & 0.048730 & 222 & 0.005192 & 0.006119 \\ 72 & 0.052951 & 0.046261 & 228 & 0.005422 & 0.005663 \\ 78 & 0.050959 & 0.043505 & 234 & 0.004100 & 0.005244 \\ 84 & 0.047702 & 0.040630 & 240 & 0.004234 & 0.004859 \\ 90 & 0.043123 & 0.037749 & 246 & 0.004291 & 0.004506 \\ 96 & 0.038813 & 0.034938 & 252 & 0.003946 & 0.004182 \\ 102 & 0.036955 & 0.032246 & 258 & 0.003142 & 0.003883 \\ 108 & 0.030882 & 0.029701 & 264 & 0.002893 & 0.003608 \\ 114 & 0.028296 & 0.027317 & 270 & 0.003295 & 0.003355 \\ 120 & 0.023985 & 0.025099 & 276 & 0.002778 & 0.003122 \\ 126 & 0.023372 & 0.023047 & 282 & 0.002337 & 0.002907 \\ 132 & 0.020824 & 0.021156 & 288 & 0.002701 & 0.002709 \\ 138 & 0.017587 & 0.019417 & 294 & 0.002433 & 0.002526 \\ 144 & 0.016552 & 0.017823 & 300 & 0.002050 & 0.002356 \\ 150 & 0.014847 & 0.016363 & & & \\ 156 & 0.013238 & 0.015028 & & & \end{array}$

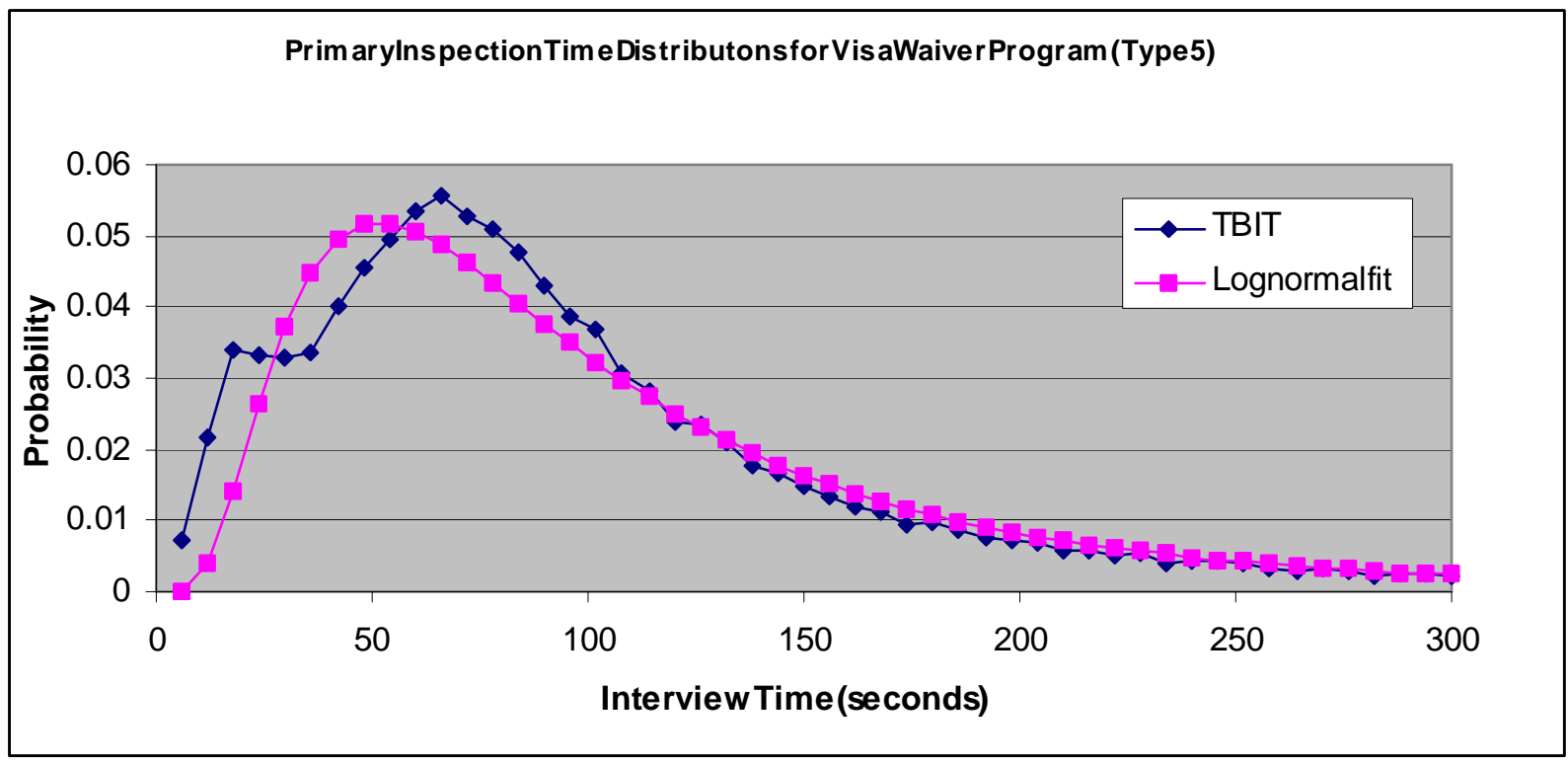




\section{B.6 Crew}

$\begin{array}{rrrrrr}\text { Time (sec) } & \begin{array}{c}\text { TBIT } \\ \text { Probability }\end{array} & \begin{array}{c}\text { Lognormal } \\ \text { Probability }\end{array} & \begin{array}{c}\text { Time } \\ \text { (sec) }\end{array} & \begin{array}{c}\text { TBIT } \\ \text { Probability }\end{array} & \begin{array}{c}\text { Lognormal } \\ \text { Probability }\end{array} \\ 6 & 0.007828 & 0.000053 & 162 & 0.003914 & 0.000555 \\ 12 & 0.010130 & 0.006926 & 168 & 0.002935 & 0.000430 \\ 18 & 0.026591 & 0.044818 & 174 & 0.002648 & 0.000334 \\ 24 & 0.090077 & 0.097771 & 180 & 0.001727 & 0.000261 \\ 30 & 0.135087 & 0.131011 & 186 & 0.002302 & 0.000204 \\ 36 & 0.142742 & 0.137195 & 192 & 0.001381 & 0.000161 \\ 42 & 0.118568 & 0.125317 & 198 & 0.002130 & 0.000127 \\ 48 & 0.093243 & 0.105603 & 204 & 0.001784 & 0.000100 \\ 54 & 0.074019 & 0.084698 & 210 & 0.001612 & 0.000080 \\ 60 & 0.053931 & 0.065863 & 216 & 0.001554 & 0.000063 \\ 66 & 0.042132 & 0.050231 & 222 & 0.001094 & 0.000051 \\ 72 & 0.032175 & 0.037853 & 228 & 0.001496 & 0.000041 \\ 78 & 0.025728 & 0.028325 & 234 & 0.001266 & 0.000033 \\ 84 & 0.020318 & 0.021119 & 240 & 0.000921 & 0.000026 \\ 90 & 0.014965 & 0.015724 & 246 & 0.001209 & 0.000021 \\ 96 & 0.014217 & 0.011712 & 252 & 0.001266 & 0.000017 \\ 102 & 0.012720 & 0.008735 & 258 & 0.000633 & 0.000014 \\ 108 & 0.008806 & 0.006530 & 264 & 0.000921 & 0.000011 \\ 114 & 0.007482 & 0.004895 & 270 & 0.000806 & 0.000009 \\ 120 & 0.007540 & 0.003681 & 276 & 0.000748 & 0.000008 \\ 126 & 0.006677 & 0.002778 & 282 & 0.000633 & 0.000006 \\ 132 & 0.005410 & 0.002104 & 288 & 0.000863 & 0.000005 \\ 138 & 0.004144 & 0.001600 & 294 & 0.001094 & 0.000004 \\ 144 & 0.003338 & 0.001221 & 300 & 0.000576 & 0.000003 \\ 150 & 0.003511 & 0.000935 & & & \\ 156 & 0.003108 & 0.000719 & & & \end{array}$

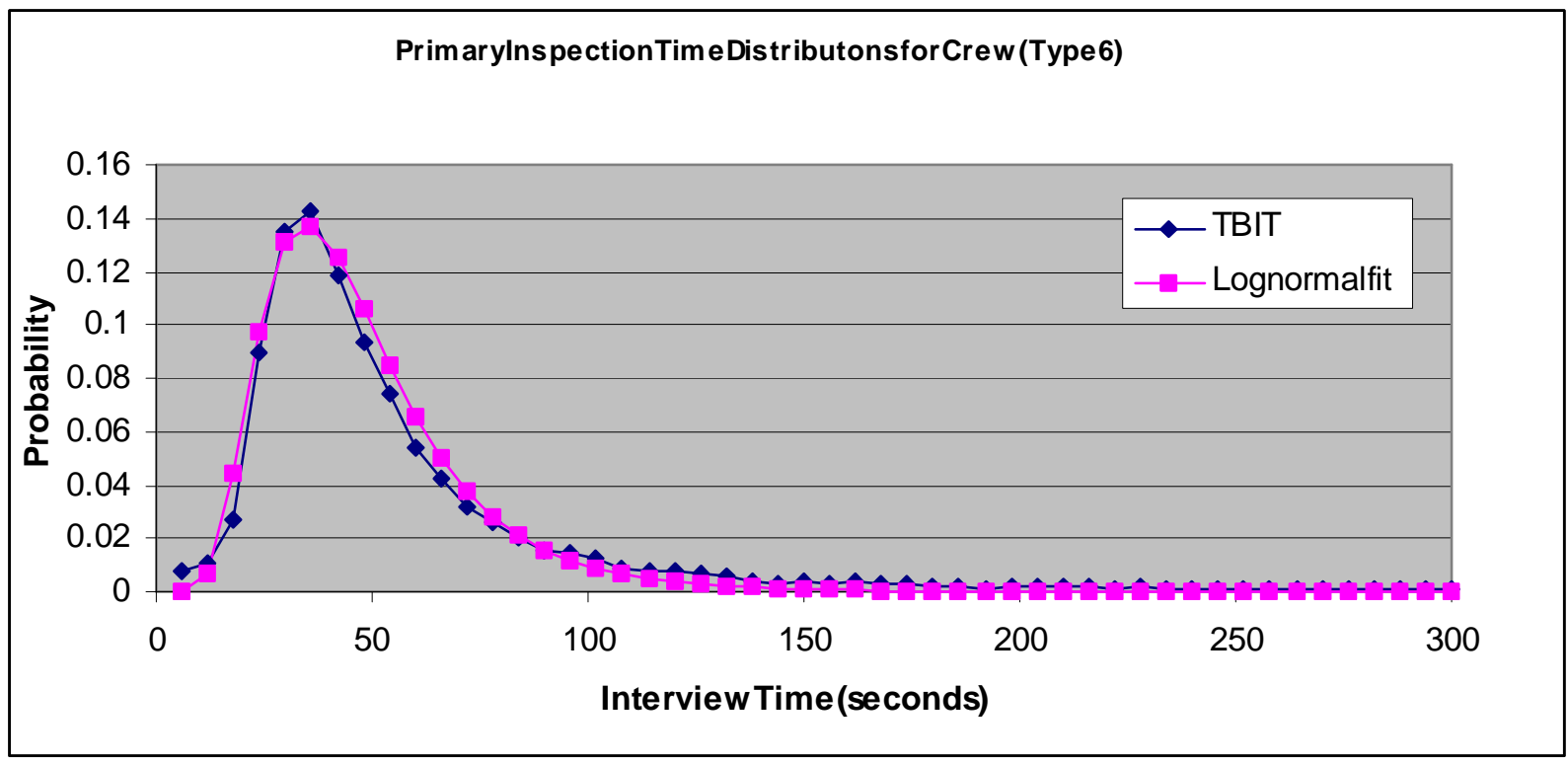




\section{B.7 First-time immigrants}

TBIT

Time (sec) Probability

$6 \quad 0.027778$

$12 \quad 0.027778$

$18 \quad 0.000000$

$24 \quad 0.000000$

$30 \quad 0.027778$

$36 \quad 0.055556$

$42 \quad 0.027778$

$48 \quad 0.027778$

$54 \quad 0.000000$

$\begin{array}{ll}60 & 0.027778\end{array}$

$\begin{array}{ll}66 & 0.027778\end{array}$

$\begin{array}{ll}72 & 0.027778\end{array}$

$\begin{array}{ll}78 & 0.000000\end{array}$

$84 \quad 0.000000$

$90 \quad 0.000000$

$\begin{array}{ll}96 & 0.027778\end{array}$

$102 \quad 0.000000$

$108 \quad 0.083333$

$114 \quad 0.000000$

$120 \quad 0.055556$

$126 \quad 0.000000$

$132 \quad 0.055556$

$138 \quad 0.000000$

$144 \quad 0.027778$

$150 \quad 0.000000$

$156 \quad 0.027778$
Time TBIT

(sec) Probability

$162 \quad 0.000000$

$168 \quad 0.055556$

$174 \quad 0.000000$

$180 \quad 0.027778$

$186 \quad 0.027778$

$192 \quad 0.055556$

$198 \quad 0.055556$

$204 \quad 0.027778$

$210 \quad 0.000000$

$216 \quad 0.027778$

$222 \quad 0.055556$

$228 \quad 0.027778$

$234 \quad 0.000000$

$240 \quad 0.027778$

$246 \quad 0.000000$

$252 \quad 0.000000$

$258 \quad 0.000000$

$264 \quad 0.027778$

$270 \quad 0.027778$

$276 \quad 0.000000$

$282 \quad 0.000000$

$288 \quad 0.000000$

$294 \quad 0.000000$

$300 \quad 0.000000$

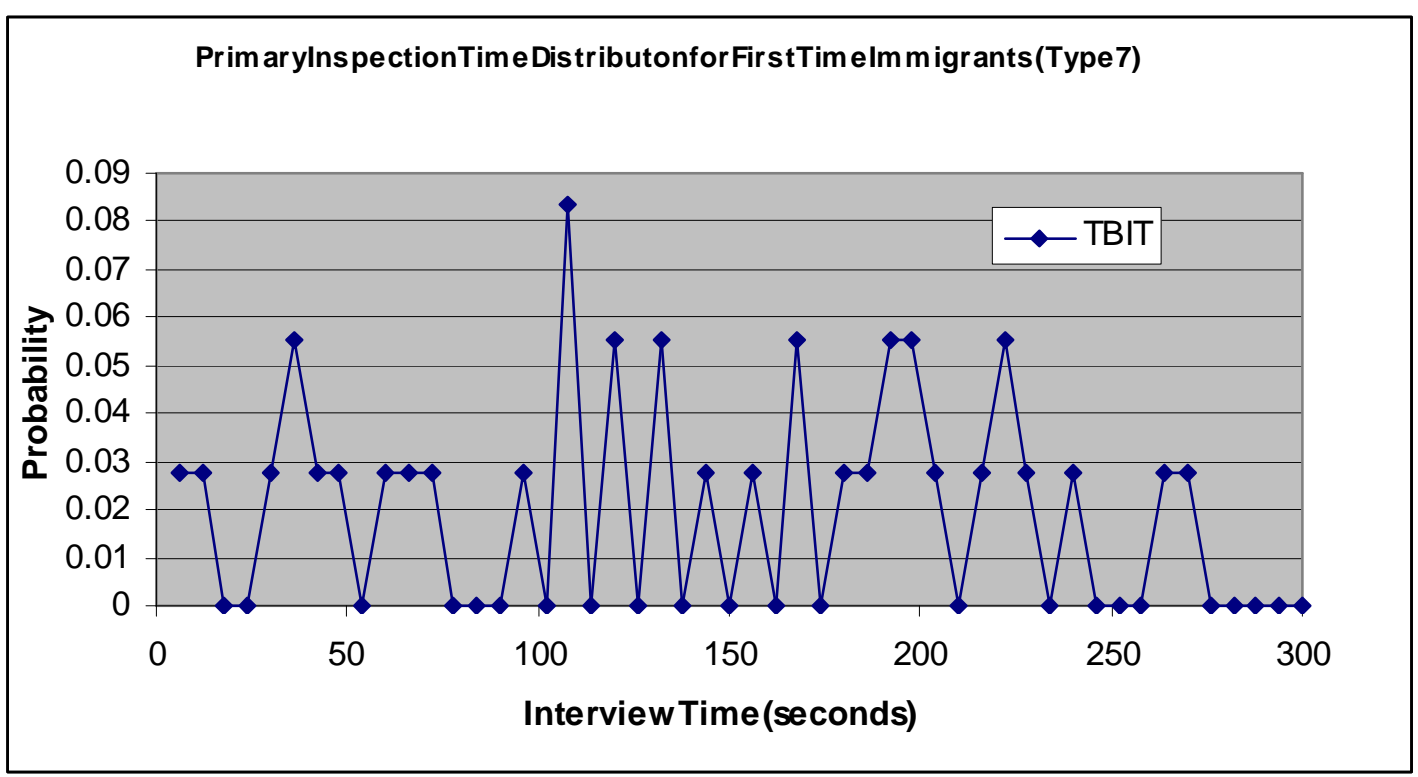




\section{B.8 Students}

$\begin{array}{rrrrrr}\text { Time (sec) } & \begin{array}{c}\text { TBIT } \\ \text { Probability }\end{array} & \begin{array}{c}\text { Lognormal } \\ \text { Probability }\end{array} & \begin{array}{c}\text { Time } \\ \text { (sec) }\end{array} & \begin{array}{c}\text { TBIT } \\ \text { Probability }\end{array} & \begin{array}{l}\text { Lognormal } \\ \text { Probability }\end{array} \\ 12 & 0.009942 & 0.000614 & 324 & 0.014085 & 0.014244 \\ 24 & 0.024855 & 0.007493 & 336 & 0.015327 & 0.013304 \\ 36 & 0.032726 & 0.019349 & 348 & 0.017399 & 0.012433 \\ 48 & 0.028998 & 0.030077 & 360 & 0.009528 & 0.011627 \\ 60 & 0.029826 & 0.037701 & 372 & 0.009528 & 0.010879 \\ 72 & 0.034797 & 0.042327 & 384 & 0.008699 & 0.010186 \\ 84 & 0.045153 & 0.044602 & 396 & 0.012842 & 0.009543 \\ 96 & 0.034797 & 0.045188 & 408 & 0.010356 & 0.008947 \\ 108 & 0.045153 & 0.044620 & 420 & 0.008285 & 0.008393 \\ 120 & 0.048467 & 0.043298 & 432 & 0.008285 & 0.007878 \\ 132 & 0.048882 & 0.041508 & 444 & 0.008699 & 0.007400 \\ 144 & 0.048882 & 0.039452 & 456 & 0.007457 & 0.006955 \\ 156 & 0.043082 & 0.037267 & 468 & 0.009528 & 0.006541 \\ 168 & 0.040597 & 0.035048 & 480 & 0.007042 & 0.006156 \\ 180 & 0.036040 & 0.032855 & 492 & 0.007457 & 0.005797 \\ 192 & 0.036454 & 0.030730 & 504 & 0.006214 & 0.005462 \\ 204 & 0.031897 & 0.028696 & 516 & 0.005800 & 0.005149 \\ 216 & 0.023198 & 0.026768 & 528 & 0.004143 & 0.004858 \\ 228 & 0.023612 & 0.024953 & 540 & 0.004557 & 0.004585 \\ 240 & 0.022784 & 0.023252 & 552 & 0.005800 & 0.004330 \\ 252 & 0.020298 & 0.021664 & 564 & 0.005385 & 0.004092 \\ 264 & 0.022370 & 0.020186 & 576 & 0.004971 & 0.003869 \\ 276 & 0.014499 & 0.018812 & 588 & 0.007457 & 0.003660 \\ 288 & 0.022784 & 0.017537 & 600 & 0.003728 & 0.003464 \\ 300 & 0.013256 & 0.016355 & & & \\ 312 & 0.014085 & 0.015259 & & & \end{array}$

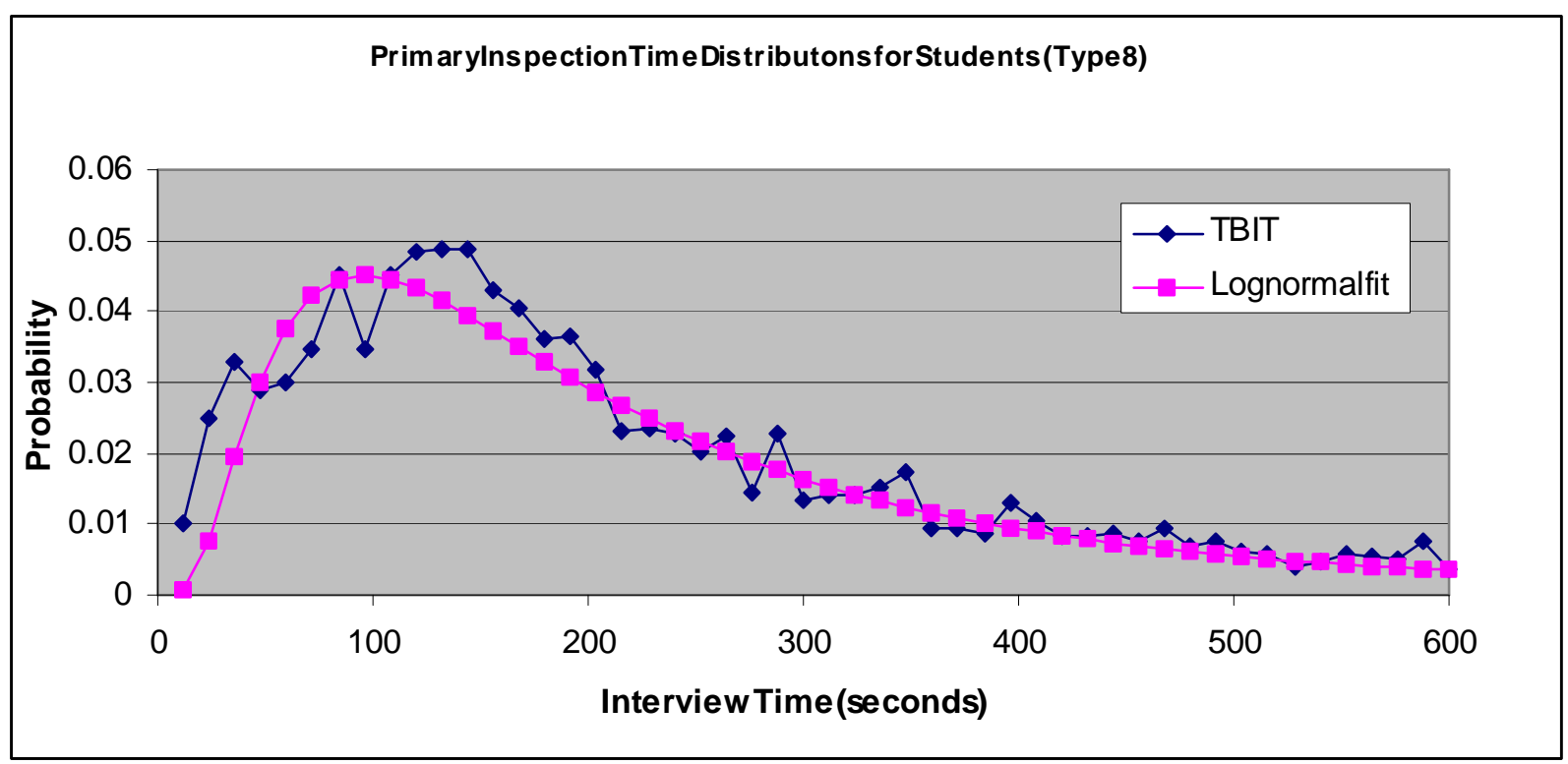


B.9 Non-immigrant visa holders

$\begin{array}{rrrrrr}\text { Time (sec) } & \begin{array}{c}\text { TBIT } \\ \text { Probability }\end{array} & \begin{array}{c}\text { Lognormal } \\ \text { Probability }\end{array} & \begin{array}{c}\text { Time } \\ \text { (sec) }\end{array} & \begin{array}{c}\text { TBIT } \\ \text { Probability }\end{array} & \begin{array}{l}\text { Lognormal } \\ \text { Probability }\end{array} \\ 6 & 0.004740 & 0.006620 & 162 & 0.013896 & 0.010889 \\ 12 & 0.022300 & 0.030730 & 168 & 0.013611 & 0.010175 \\ 18 & 0.052383 & 0.047096 & 174 & 0.011901 & 0.009519 \\ 24 & 0.067445 & 0.053998 & 180 & 0.010088 & 0.008915 \\ 30 & 0.065748 & 0.055458 & 186 & 0.009959 & 0.008358 \\ 36 & 0.055181 & 0.054095 & 192 & 0.008923 & 0.007844 \\ 42 & 0.045041 & 0.051360 & 198 & 0.008573 & 0.007368 \\ 48 & 0.038967 & 0.048036 & 204 & 0.008249 & 0.006929 \\ 54 & 0.035160 & 0.044543 & 210 & 0.006980 & 0.006521 \\ 60 & 0.033114 & 0.041104 & 216 & 0.006747 & 0.006143 \\ 66 & 0.034797 & 0.037831 & 222 & 0.006371 & 0.005792 \\ 72 & 0.034020 & 0.034778 & 228 & 0.005996 & 0.005465 \\ 78 & 0.034033 & 0.031961 & 234 & 0.005284 & 0.005162 \\ 84 & 0.033165 & 0.029380 & 240 & 0.004740 & 0.004879 \\ 90 & 0.032919 & 0.027027 & 246 & 0.005038 & 0.004615 \\ 96 & 0.031339 & 0.024885 & 252 & 0.004364 & 0.004368 \\ 102 & 0.030290 & 0.022938 & 258 & 0.004183 & 0.004138 \\ 108 & 0.028167 & 0.021169 & 264 & 0.003833 & 0.003923 \\ 114 & 0.026159 & 0.019561 & 270 & 0.003613 & 0.003721 \\ 120 & 0.024566 & 0.018099 & 276 & 0.003471 & 0.003532 \\ 126 & 0.022546 & 0.016768 & 282 & 0.003250 & 0.003355 \\ 132 & 0.021186 & 0.015555 & 288 & 0.003004 & 0.003189 \\ 138 & 0.019529 & 0.014448 & 294 & 0.003367 & 0.003033 \\ 144 & 0.017547 & 0.013437 & 300 & 0.002486 & 0.002887 \\ 150 & 0.016304 & 0.012512 & & & \\ 156 & 0.015424 & 0.011665 & & & \end{array}$

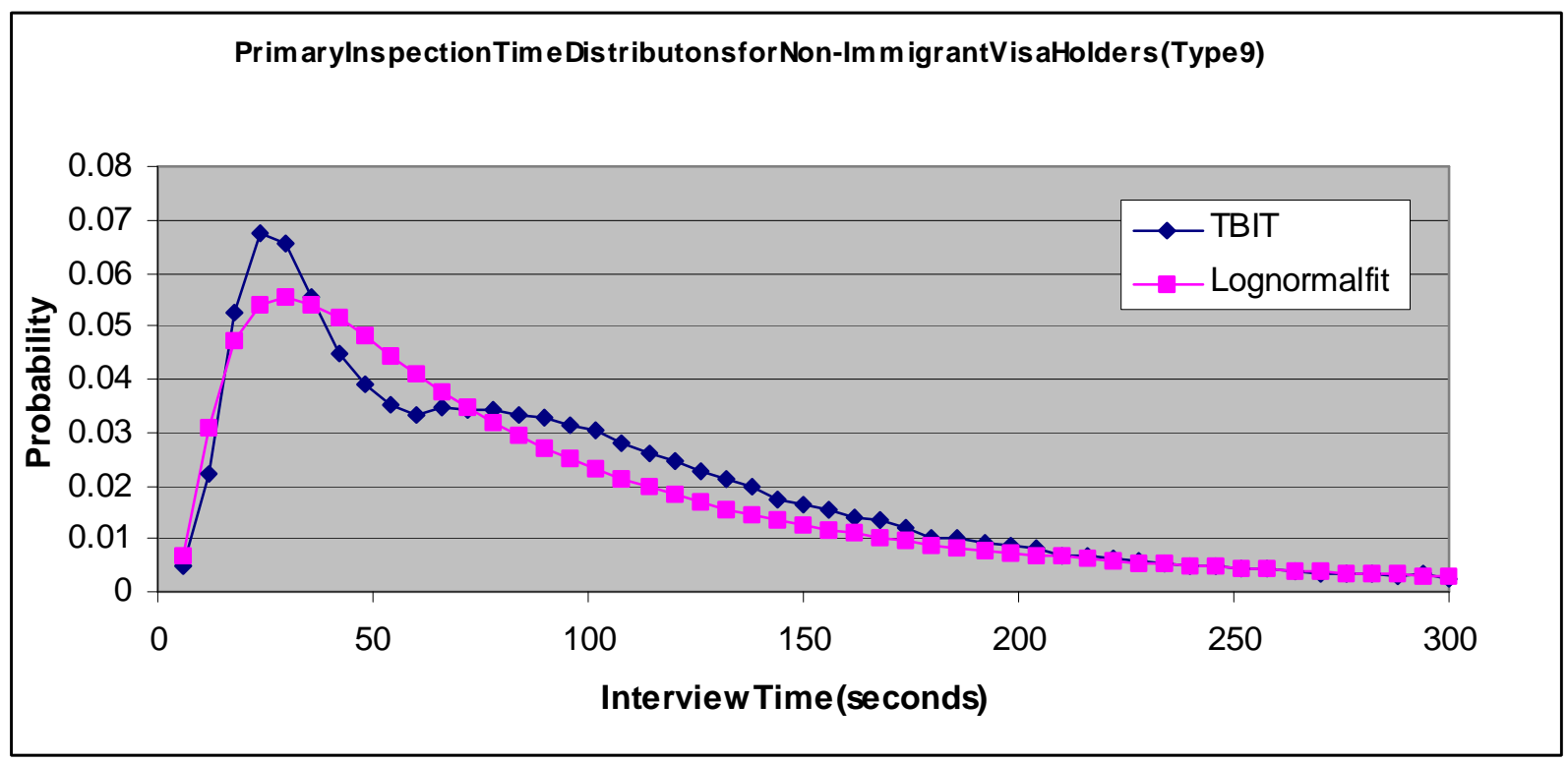


TBIT

Time (sec) Probability

$6 \quad 0.173913$

$12 \quad 0.173913$

$18 \quad 0.086957$

$24 \quad 0.086957$

$30 \quad 0.086957$

$36 \quad 0.043478$

$42 \quad 0.000000$

$48 \quad 0.043478$

$54 \quad 0.043478$

$\begin{array}{ll}60 & 0.086957\end{array}$

$66 \quad 0.000000$

$72 \quad 0.000000$

$\begin{array}{ll}78 & 0.000000\end{array}$

$84 \quad 0.000000$

$90 \quad 0.000000$

$96 \quad 0.000000$

$102 \quad 0.000000$

$108 \quad 0.000000$

$114 \quad 0.000000$

$120 \quad 0.000000$

$126 \quad 0.000000$

$132 \quad 0.043478$

$138 \quad 0.043478$

$144 \quad 0.000000$

$150 \quad 0.000000$

$\begin{array}{ll}156 & 0.043478\end{array}$
Time TBIT

(sec) Probability

$\begin{array}{ll}162 & 0.000000\end{array}$

$168 \quad 0.000000$

$174 \quad 0.000000$

$\begin{array}{ll}180 & 0.043478\end{array}$

$186 \quad 0.000000$

$192 \quad 0.000000$

$198 \quad 0.000000$

$204 \quad 0.000000$

$210 \quad 0.000000$

$216 \quad 0.000000$

$222 \quad 0.000000$

$228 \quad 0.000000$

$234 \quad 0.000000$

$240 \quad 0.000000$

$246 \quad 0.000000$

$252 \quad 0.000000$

$258 \quad 0.000000$

$264 \quad 0.000000$

$\begin{array}{ll}270 & 0.000000\end{array}$

$276 \quad 0.000000$

$282 \quad 0.000000$

$288 \quad 0.000000$

$294 \quad 0.000000$

$300 \quad 0.000000$

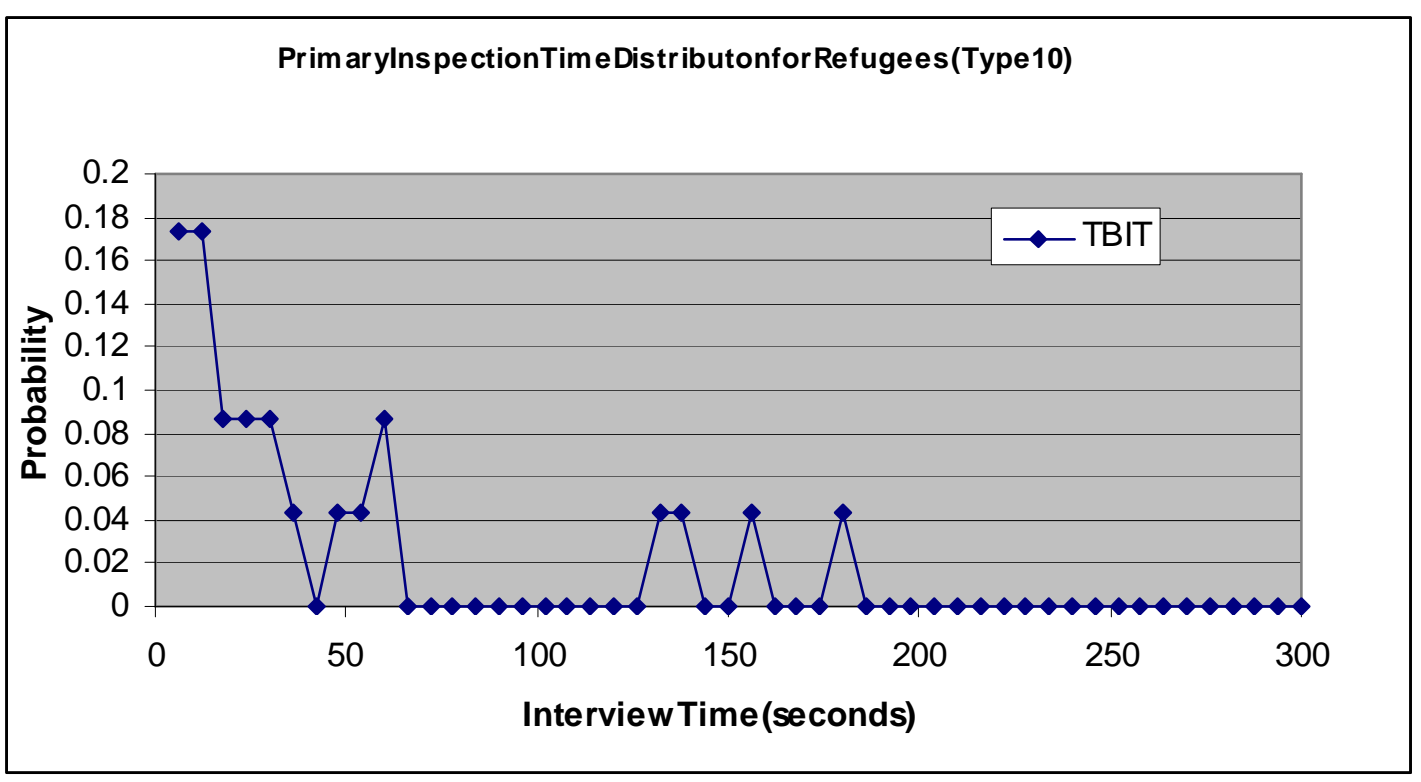




\section{B.11 On secondary or lookout list}

Passenger type 11 is not used in this analysis 


$\begin{array}{rrrrrrr}\text { Time (sec) } & \text { Probability } & \begin{array}{c}\text { Lognormal } \\ \text { Probability }\end{array} & \begin{array}{c}\text { Time } \\ \text { Psec) }\end{array} & \begin{array}{c}\text { TBIT } \\ \text { Probability }\end{array} & \begin{array}{c}\text { Lognormal } \\ \text { Probability }\end{array} \\ 12 & 0.014071 & 0.009810 & 324 & 0.010794 & 0.009183 \\ 24 & 0.048381 & 0.042273 & 336 & 0.010794 & 0.008509 \\ 36 & 0.064187 & 0.060960 & 348 & 0.009638 & 0.007895 \\ 48 & 0.062645 & 0.066679 & 360 & 0.008674 & 0.007335 \\ 60 & 0.059753 & 0.065903 & 372 & 0.007710 & 0.006823 \\ 72 & 0.058404 & 0.062227 & 384 & 0.005397 & 0.006355 \\ 84 & 0.060139 & 0.057432 & 396 & 0.007517 & 0.005926 \\ 96 & 0.057247 & 0.052381 & 408 & 0.006361 & 0.005532 \\ 108 & 0.053007 & 0.047484 & 420 & 0.004819 & 0.005171 \\ 120 & 0.043562 & 0.042922 & 432 & 0.006168 & 0.004838 \\ 132 & 0.041827 & 0.038761 & 444 & 0.005012 & 0.004531 \\ 144 & 0.044140 & 0.035010 & 456 & 0.005397 & 0.004248 \\ 156 & 0.035852 & 0.031649 & 468 & 0.004241 & 0.003986 \\ 168 & 0.028527 & 0.028649 & 480 & 0.004241 & 0.003744 \\ 180 & 0.027564 & 0.025974 & 492 & 0.004048 & 0.003520 \\ 192 & 0.024865 & 0.023589 & 504 & 0.004048 & 0.003312 \\ 204 & 0.021203 & 0.021462 & 516 & 0.004241 & 0.003119 \\ 216 & 0.018311 & 0.019563 & 528 & 0.003084 & 0.002940 \\ 228 & 0.018119 & 0.017864 & 540 & 0.003662 & 0.002773 \\ 240 & 0.013107 & 0.016342 & 552 & 0.003470 & 0.002618 \\ 252 & 0.013685 & 0.014976 & 564 & 0.002120 & 0.002473 \\ 264 & 0.013685 & 0.013749 & 576 & 0.003277 & 0.002338 \\ 276 & 0.010601 & 0.012643 & 588 & 0.005012 & 0.002212 \\ 288 & 0.011180 & 0.011645 & 600 & 0.002120 & 0.002094 \\ 300 & 0.010987 & 0.010742 & & & \\ 312 & 0.013107 & 0.009925 & & & \\ & & & & & \end{array}$

B.12 Other 


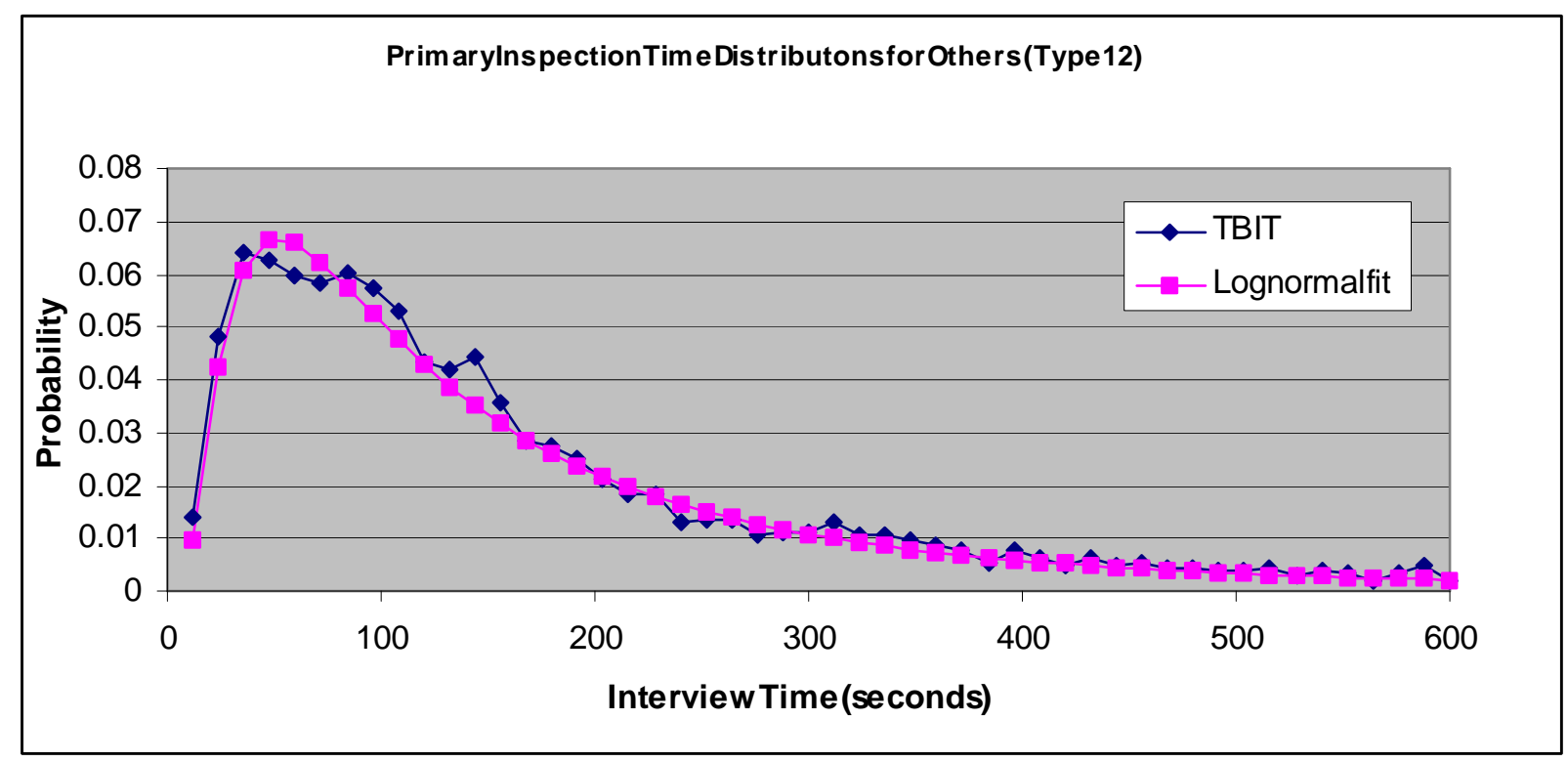




\section{Appendix C Views of Simulation Model}

\section{Figure C-1 - Traveler generation and characterization}

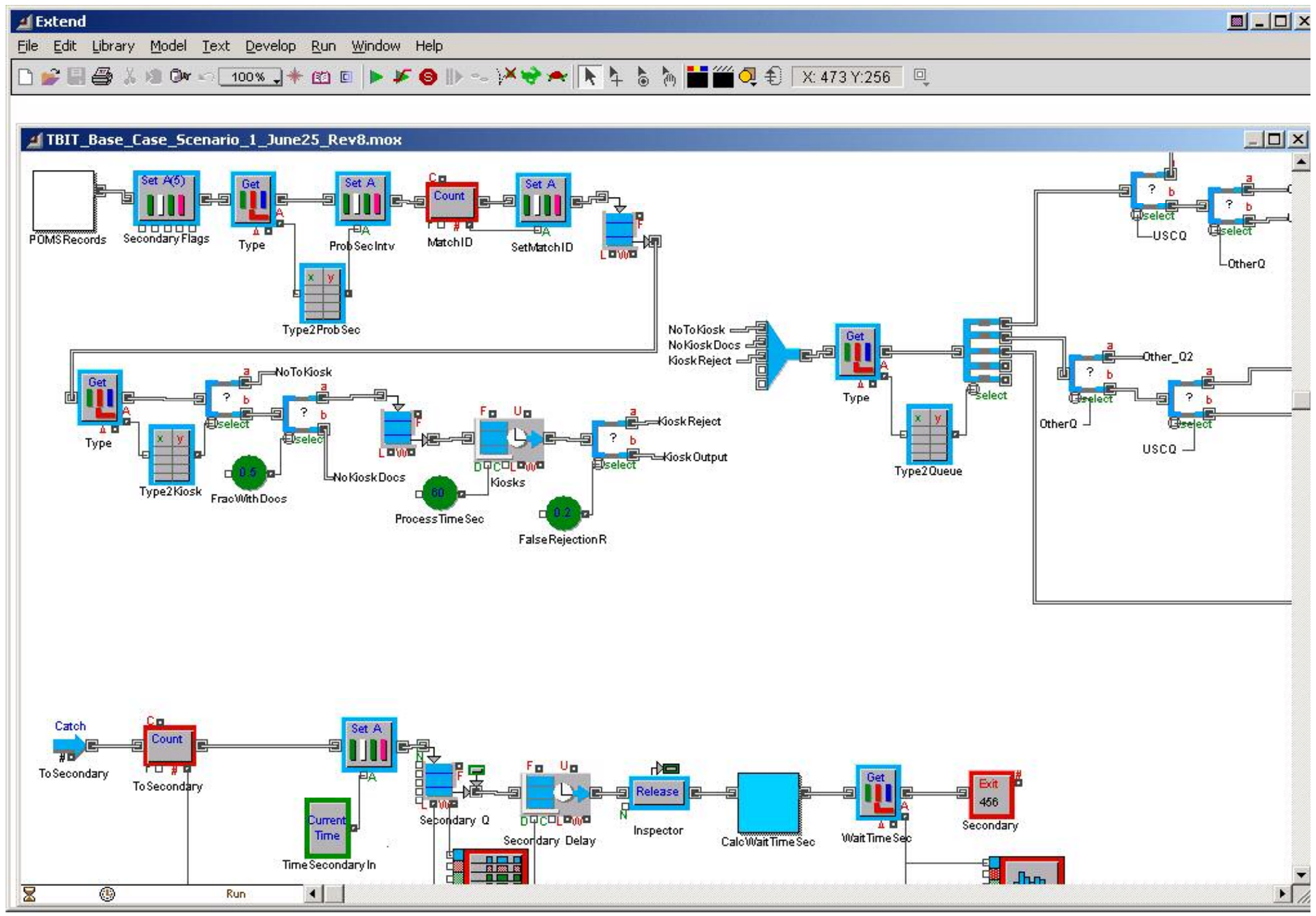


Figure C-2 - Details of traveler generation and inspection time sampling

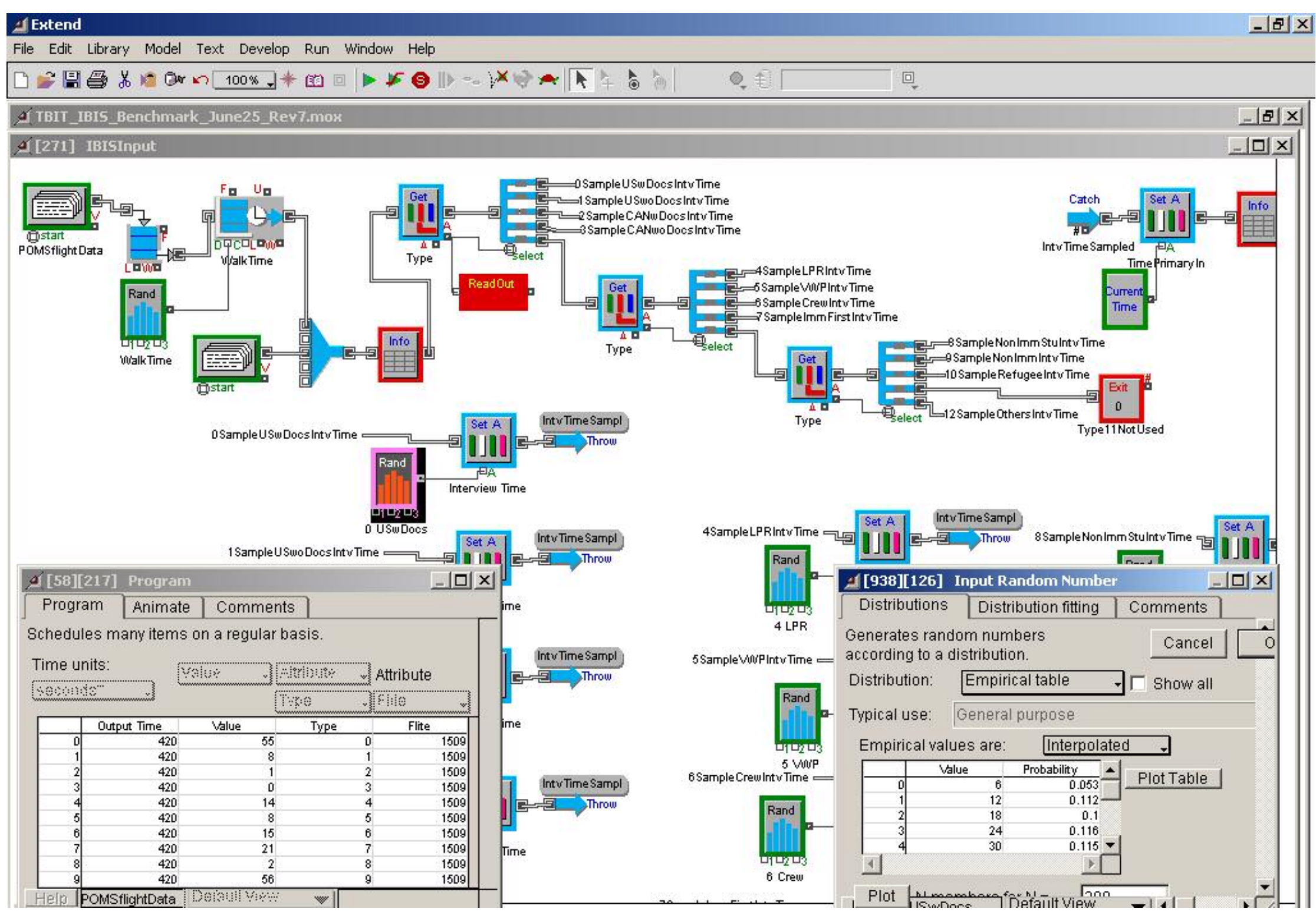


Figure C-3 - Traveler routing logic

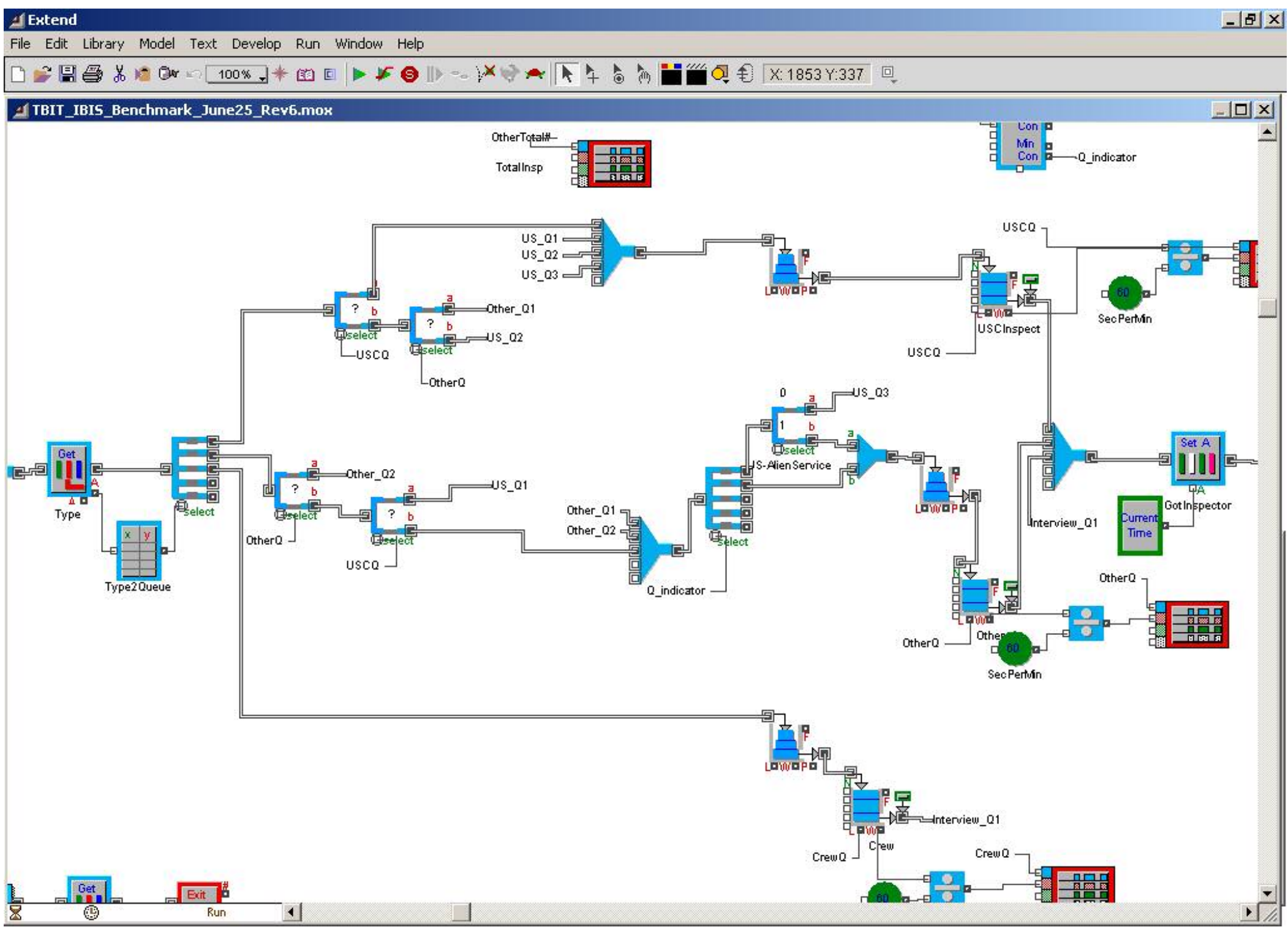




\section{Figure C-4 - Process routing by traveler type}

\section{Extend}

File Edit Library Model Text Develop Run Window Help

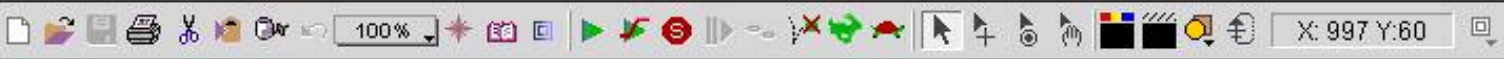

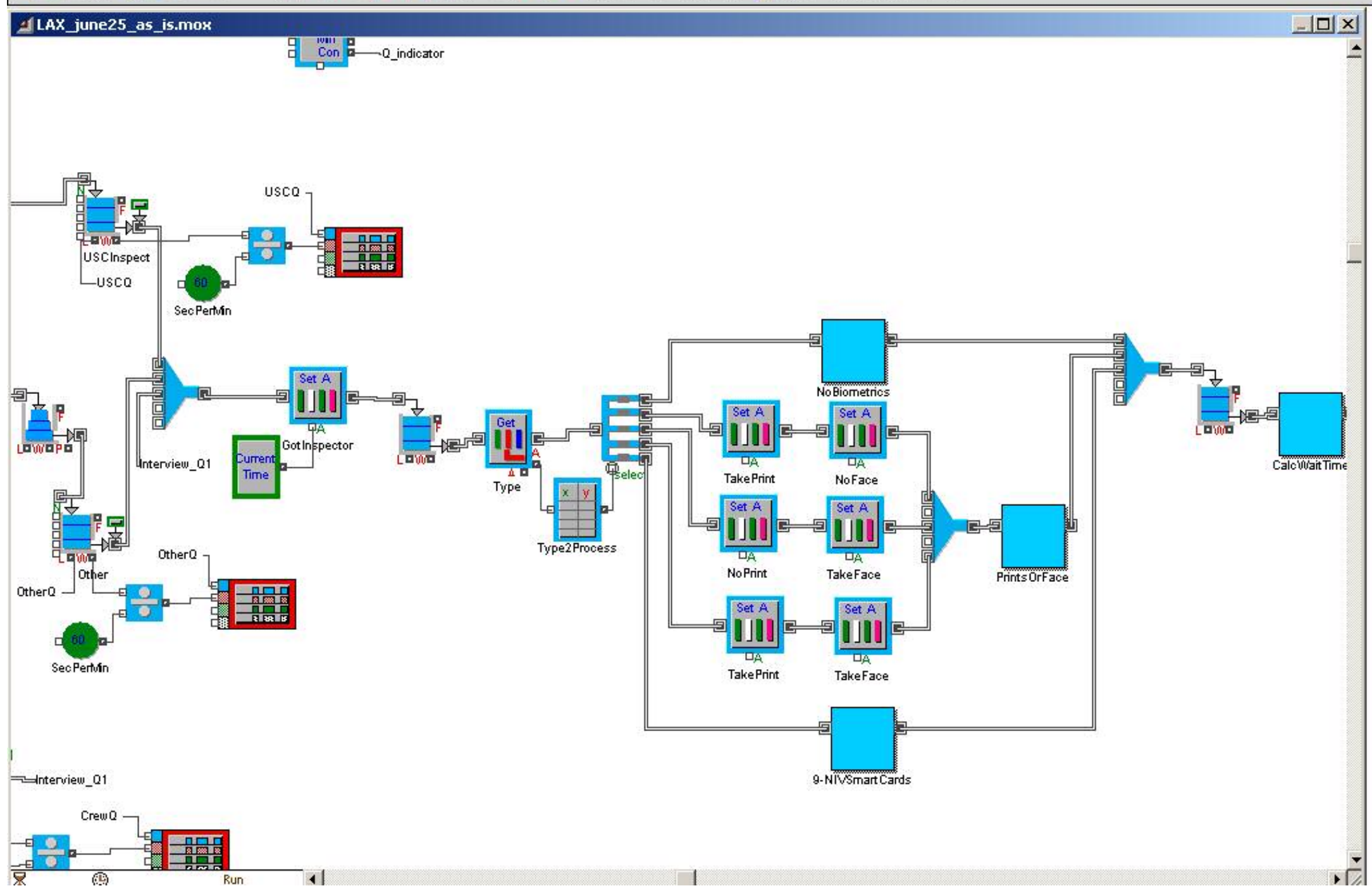


Figure C-5 - Details of prints and face processes - acquire biometrics in primary

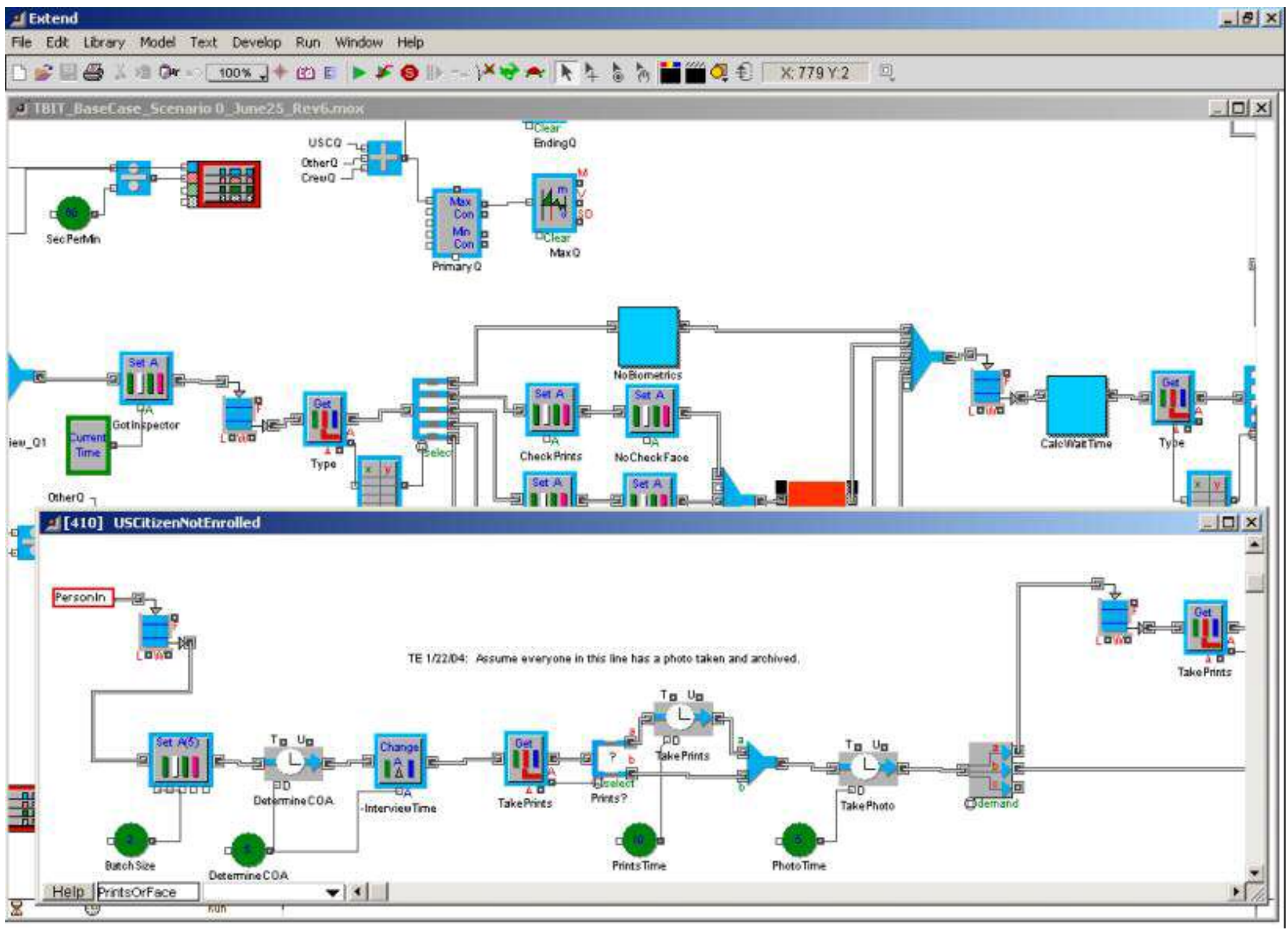


Figure C-6 - Details of prints and face processes - interview and check biometrics in parallel

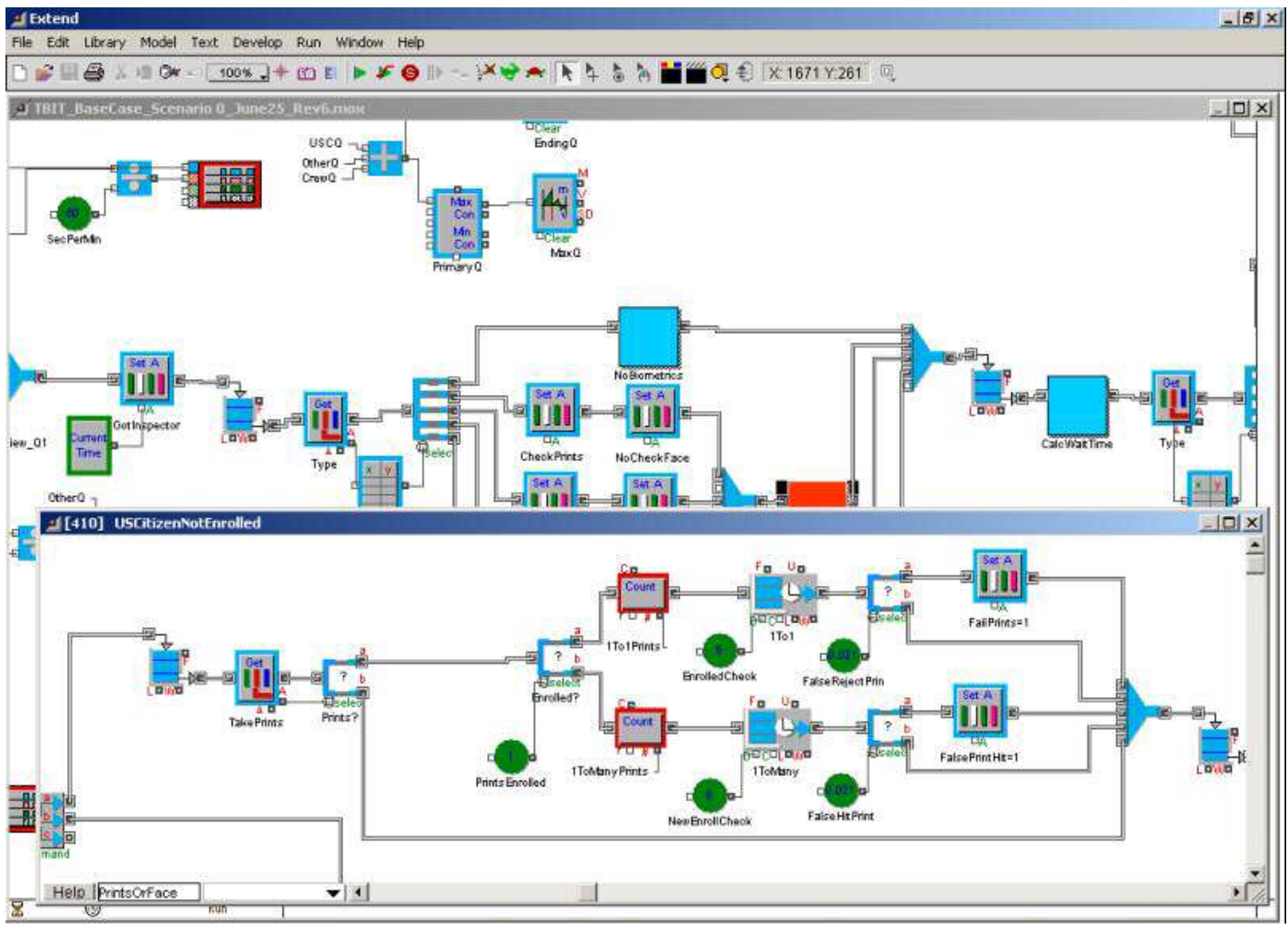




\section{Figure C-7 - Output of Simulation Model}

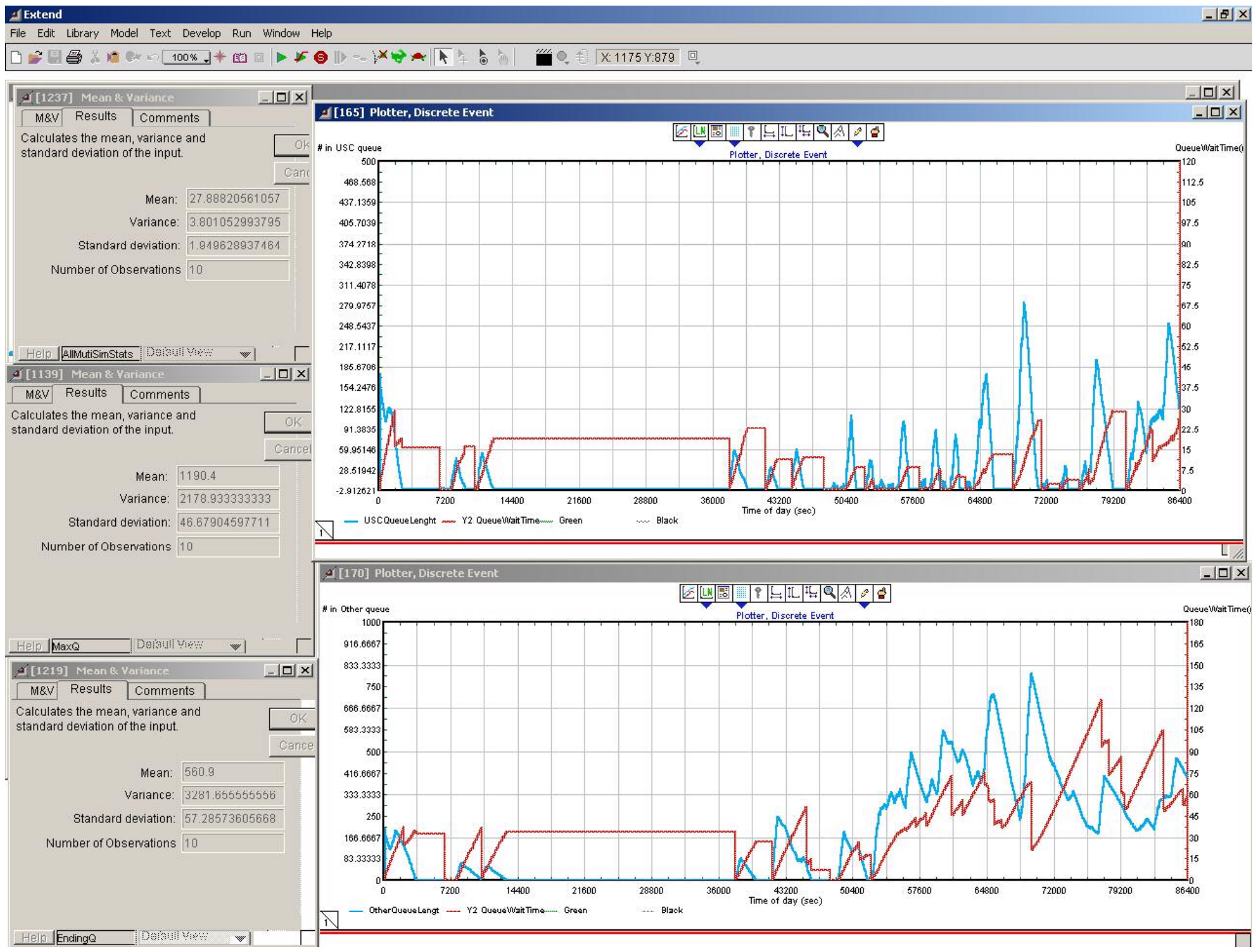




\section{Appendix D Traveler Arrival Data File}

\begin{tabular}{|c|c|c|c|}
\hline $\begin{array}{l}\text { Time } \\
(\mathrm{sec})\end{array}$ & $\begin{array}{l}\text { Number of } \\
\text { Travelers }\end{array}$ & $\begin{array}{l}\text { Traveler } \\
\text { Type }\end{array}$ & $\begin{array}{l}\text { Flight } \\
\text { index }\end{array}$ \\
\hline 420 & 55 & 0 & 1509 \\
\hline 420 & 8 & 1 & 1509 \\
\hline 420 & 1 & 2 & 1509 \\
\hline 420 & 0 & 3 & 1509 \\
\hline 420 & 14 & 4 & 1509 \\
\hline 420 & 8 & 5 & 1509 \\
\hline 420 & 15 & 6 & 1509 \\
\hline 420 & 21 & 7 & 1509 \\
\hline 420 & 2 & 8 & 1509 \\
\hline 420 & 56 & 9 & 1509 \\
\hline 420 & 0 & 10 & 1509 \\
\hline 420 & 4 & 12 & 1509 \\
\hline 720 & 18 & 0 & 1531 \\
\hline 720 & 3 & 1 & 1531 \\
\hline 720 & 0 & 2 & 1531 \\
\hline 720 & 0 & 3 & 1531 \\
\hline 720 & 4 & 4 & 1531 \\
\hline 720 & 2 & 5 & 1531 \\
\hline 720 & 6 & 6 & 1531 \\
\hline 720 & 8 & 7 & 1531 \\
\hline 720 & 0 & 8 & 1531 \\
\hline 720 & 13 & 9 & 1531 \\
\hline 720 & 0 & 10 & 1531 \\
\hline 720 & 1 & 12 & 1531 \\
\hline 6300 & 6 & 0 & 1499 \\
\hline 6300 & 1 & 1 & 1499 \\
\hline 6300 & 0 & 2 & 1499 \\
\hline 6300 & 0 & 3 & 1499 \\
\hline 6300 & 2 & 4 & 1499 \\
\hline 6300 & 0 & 5 & 1499 \\
\hline 6300 & 6 & 6 & 1499 \\
\hline 6300 & 16 & 7 & 1499 \\
\hline 6300 & 1 & 8 & 1499 \\
\hline 6300 & 17 & 9 & 1499 \\
\hline 6300 & 0 & 10 & 1499 \\
\hline 6300 & 1 & 12 & 1499 \\
\hline 6300 & 18 & 0 & 1537 \\
\hline 6300 & 3 & 1 & 1537 \\
\hline 6300 & 0 & 2 & 1537 \\
\hline 6300 & 0 & 3 & 1537 \\
\hline 6300 & 5 & 4 & 1537 \\
\hline 6300 & 1 & 5 & 1537 \\
\hline 6300 & 6 & 6 & 1537 \\
\hline 6300 & 14 & 7 & 1537 \\
\hline 6300 & 0 & 8 & 1537 \\
\hline 6300 & 6 & 9 & 1537 \\
\hline 6300 & 0 & 10 & 1537 \\
\hline 6300 & 1 & 12 & 1537 \\
\hline 7500 & 55 & 0 & 1546 \\
\hline 7500 & 8 & 1 & 1546 \\
\hline
\end{tabular}




\begin{tabular}{|l|l|l|l|}
\hline 7500 & 1 & 2 & 1546 \\
\hline 7500 & 0 & 3 & 1546 \\
\hline 7500 & 15 & 4 & 1546 \\
\hline 7500 & 0 & 5 & 1546 \\
\hline 7500 & 6 & 6 & 1546 \\
\hline 7500 & 15 & 7 & 1546 \\
\hline 7500 & 2 & 8 & 1546 \\
\hline 7500 & 47 & 9 & 1546 \\
\hline 7500 & 0 & 10 & 1546 \\
\hline 7500 & 3 & 12 & 1546 \\
\hline 10080 & 4 & 0 & 1513 \\
\hline 10080 & 1 & 1 & 1513 \\
\hline 10080 & 0 & 2 & 1513 \\
\hline 10080 & 0 & 3 & 1513 \\
\hline 10080 & 0 & 4 & 1513 \\
\hline 10080 & 3 & 5 & 1513 \\
\hline 10080 & 6 & 6 & 1513 \\
\hline 10080 & 8 & 7 & 1513 \\
\hline 10080 & 1 & 8 & 1513 \\
\hline 10080 & 30 & 9 & 1513 \\
\hline 10080 & 0 & 10 & 1513 \\
\hline 10080 & 2 & 12 & 1513 \\
\hline 10320 & 67 & 0 & 1527 \\
\hline 10320 & 10 & 1 & 1527 \\
\hline 10320 & 1 & 2 & 1527 \\
\hline 10320 & 0 & 3 & 1527 \\
\hline 10320 & 18 & 4 & 1527 \\
\hline 10320 & 0 & 5 & 1527 \\
\hline 10320 & 7 & 6 & 1527 \\
\hline 10320 & 7 & 7 & 1527 \\
\hline 10320 & 0 & 8 & 1527 \\
\hline 10320 & 3 & 9 & 1527 \\
\hline 10320 & 0 & 10 & 1527 \\
\hline 10320 & 0 & 12 & 1527 \\
\hline 37500 & 79 & 0 & 1523 \\
\hline 37500 & 11 & 1 & 1523 \\
\hline 37500 & 1 & 2 & 1523 \\
\hline 37500 & 0 & 3 & 1523 \\
\hline 37500 & 21 & 4 & 1523 \\
\hline 37500 & 24 & 5 & 1523 \\
\hline 37500 & 14 & 6 & 1523 \\
\hline 37500 & 0 & 7 & 1523 \\
\hline 37500 & 2 & 8 & 1523 \\
\hline 37500 & 69 & 9 & 1523 \\
\hline 37500 & 0 & 10 & 1523 \\
\hline 37500 & 5 & 12 & 1523 \\
\hline 41460 & 50 & 0 & 1520 \\
\hline 41460 & 7 & 1520 \\
\hline 41460 & 1 & 1520 \\
\hline 41460 & 0 & 14 & 1520 \\
\hline 41460 & 14 & 1520 \\
\hline 41460 & 211 & \\
\hline 41460 & 18 & 0 & 1520 \\
\hline 41460 & 0 & 2 & \\
\hline 41460 & 2 & 5 & \\
\hline & & 0 & 5 \\
\hline
\end{tabular}




\begin{tabular}{|c|c|c|c|}
\hline 41460 & 53 & 9 & 1520 \\
\hline 41460 & 0 & 10 & 1520 \\
\hline 41460 & 3 & 12 & 1520 \\
\hline 44220 & 85 & 0 & 1550 \\
\hline 44220 & 12 & 1 & 1550 \\
\hline 44220 & 1 & 2 & 1550 \\
\hline 44220 & 0 & 3 & 1550 \\
\hline 44220 & 23 & 4 & 1550 \\
\hline 44220 & 39 & 5 & 1550 \\
\hline 44220 & 0 & 6 & 1550 \\
\hline 44220 & 0 & 7 & 1550 \\
\hline 44220 & 0 & 8 & 1550 \\
\hline 44220 & 4 & 9 & 1550 \\
\hline 44220 & 0 & 10 & 1550 \\
\hline 44220 & 0 & 12 & 1550 \\
\hline 44700 & 1 & 0 & 1535 \\
\hline 44700 & 0 & 1 & 1535 \\
\hline 44700 & 0 & 2 & 1535 \\
\hline 44700 & 0 & 3 & 1535 \\
\hline 44700 & 1 & 4 & 1535 \\
\hline 44700 & 0 & 5 & 1535 \\
\hline 44700 & 6 & 6 & 1535 \\
\hline 44700 & 0 & 7 & 1535 \\
\hline 44700 & 0 & 8 & 1535 \\
\hline 44700 & 4 & 9 & 1535 \\
\hline 44700 & 0 & 10 & 1535 \\
\hline 44700 & 0 & 12 & 1535 \\
\hline 47700 & 42 & 0 & 1538 \\
\hline 47700 & 6 & 1 & 1538 \\
\hline 47700 & 0 & 2 & 1538 \\
\hline 47700 & 0 & 3 & 1538 \\
\hline 47700 & 12 & 4 & 1538 \\
\hline 47700 & 11 & 5 & 1538 \\
\hline 47700 & 6 & 6 & 1538 \\
\hline 47700 & 0 & 7 & 1538 \\
\hline 47700 & 1 & 8 & 1538 \\
\hline 47700 & 25 & 9 & 1538 \\
\hline 47700 & 0 & 10 & 1538 \\
\hline 47700 & 2 & 12 & 1538 \\
\hline 48300 & 21 & 0 & 1532 \\
\hline 48300 & 3 & 1 & 1532 \\
\hline 48300 & 0 & 2 & 1532 \\
\hline 48300 & 0 & 3 & 1532 \\
\hline 48300 & 6 & 4 & 1532 \\
\hline 48300 & 6 & 5 & 1532 \\
\hline 48300 & 6 & 6 & 1532 \\
\hline 48300 & 0 & 7 & 1532 \\
\hline 48300 & 2 & 8 & 1532 \\
\hline 48300 & 49 & 9 & 1532 \\
\hline 48300 & 0 & 10 & 1532 \\
\hline 48300 & 3 & 12 & 1532 \\
\hline 48600 & 61 & 0 & 1522 \\
\hline 48600 & 9 & 1 & 1522 \\
\hline 48600 & 1 & 2 & 1522 \\
\hline 48600 & 0 & 3 & 1522 \\
\hline
\end{tabular}




\begin{tabular}{|c|c|c|c|}
\hline 48600 & 16 & 4 & 1522 \\
\hline 48600 & 16 & 5 & 1522 \\
\hline 48600 & 26 & 6 & 1522 \\
\hline 48600 & 0 & 7 & 1522 \\
\hline 48600 & 6 & 8 & 1522 \\
\hline 48600 & 183 & 9 & 1522 \\
\hline 48600 & 0 & 10 & 1522 \\
\hline 48600 & 12 & 12 & 1522 \\
\hline 49500 & 43 & 0 & 1518 \\
\hline 49500 & 6 & 1 & 1518 \\
\hline 49500 & 0 & 2 & 1518 \\
\hline 49500 & 0 & 3 & 1518 \\
\hline 49500 & 13 & 4 & 1518 \\
\hline 49500 & 2 & 5 & 1518 \\
\hline 49500 & 5 & 6 & 1518 \\
\hline 49500 & 0 & 7 & 1518 \\
\hline 49500 & 1 & 8 & 1518 \\
\hline 49500 & 31 & 9 & 1518 \\
\hline 49500 & 0 & 10 & 1518 \\
\hline 49500 & 2 & 12 & 1518 \\
\hline 50040 & 17 & 0 & 1548 \\
\hline 50040 & 2 & 1 & 1548 \\
\hline 50040 & 0 & 2 & 1548 \\
\hline 50040 & 0 & 3 & 1548 \\
\hline 50040 & 5 & 4 & 1548 \\
\hline 50040 & 1 & 5 & 1548 \\
\hline 50040 & 6 & 6 & 1548 \\
\hline 50040 & 0 & 7 & 1548 \\
\hline 50040 & 1 & 8 & 1548 \\
\hline 50040 & 43 & 9 & 1548 \\
\hline 50040 & 0 & 10 & 1548 \\
\hline 50040 & 3 & 12 & 1548 \\
\hline 50100 & 187 & 0 & 1551 \\
\hline 50100 & 27 & 1 & 1551 \\
\hline 50100 & 2 & 2 & 1551 \\
\hline 50100 & 0 & 3 & 1551 \\
\hline 50100 & 50 & 4 & 1551 \\
\hline 50100 & 5 & 5 & 1551 \\
\hline 50100 & 12 & 6 & 1551 \\
\hline 50100 & 0 & 7 & 1551 \\
\hline 50100 & 0 & 8 & 1551 \\
\hline 50100 & 0 & 9 & 1551 \\
\hline 50100 & 0 & 10 & 1551 \\
\hline 50100 & 0 & 12 & 1551 \\
\hline 52080 & 99 & 0 & 1549 \\
\hline 52080 & 14 & 1 & 1549 \\
\hline 52080 & 1 & 2 & 1549 \\
\hline 52080 & 0 & 3 & 1549 \\
\hline 52080 & 27 & 4 & 1549 \\
\hline 52080 & 19 & 5 & 1549 \\
\hline 52080 & 21 & 6 & 1549 \\
\hline 52080 & 0 & 7 & 1549 \\
\hline 52080 & 4 & 8 & 1549 \\
\hline 52080 & 129 & 9 & 1549 \\
\hline 52080 & 0 & 10 & 1549 \\
\hline
\end{tabular}




\begin{tabular}{|l|l|l|l|}
\hline 52080 & 9 & 12 & 1549 \\
\hline 52380 & 75 & 0 & 1516 \\
\hline 52380 & 11 & 1 & 1516 \\
\hline 52380 & 1 & 2 & 1516 \\
\hline 52380 & 0 & 3 & 1516 \\
\hline 52380 & 20 & 4 & 1516 \\
\hline 52380 & 137 & 5 & 1516 \\
\hline 52380 & 21 & 6 & 1516 \\
\hline 52380 & 0 & 7 & 1516 \\
\hline 52380 & 1 & 8 & 1516 \\
\hline 52380 & 44 & 9 & 1516 \\
\hline 52380 & 0 & 10 & 1516 \\
\hline 52380 & 3 & 12 & 1516 \\
\hline 53040 & 34 & 0 & 1540 \\
\hline 53040 & 5 & 1 & 1540 \\
\hline 53040 & 0 & 2 & 1540 \\
\hline 53040 & 0 & 3 & 1540 \\
\hline 53040 & 9 & 4 & 1540 \\
\hline 53040 & 104 & 5 & 1540 \\
\hline 53040 & 14 & 6 & 1540 \\
\hline 53040 & 0 & 7 & 1540 \\
\hline 53040 & 1 & 8 & 1540 \\
\hline 53040 & 35 & 9 & 1540 \\
\hline 53040 & 0 & 10 & 1540 \\
\hline 53040 & 2 & 12 & 1540 \\
\hline 53700 & 88 & 0 & 1541 \\
\hline 53700 & 13 & 1 & 1541 \\
\hline 53700 & 1 & 2 & 1541 \\
\hline 53700 & 0 & 3 & 1541 \\
\hline 53700 & 24 & 4 & 1541 \\
\hline 53700 & 1 & 5 & 1541 \\
\hline 53700 & 14 & 6 & 1541 \\
\hline 53700 & 0 & 7 & 1541 \\
\hline 53700 & 4 & 8 & 1541 \\
\hline 53700 & 119 & 9 & 1541 \\
\hline 53700 & 0 & 10 & 1541 \\
\hline 53700 & 8 & 12 & 1541 \\
\hline 54600 & 79 & 0 & 1515 \\
\hline 54600 & 11 & 1 & 1515 \\
\hline 54600 & 1 & 2 & 1515 \\
\hline 54600 & 0 & 3 & 1515 \\
\hline 54600 & 21 & 4 & 1515 \\
\hline 54600 & 91 & 5 & 1515 \\
\hline 54600 & 0 & 6 & 1515 \\
\hline 54600 & 17 & 7 & 1515 \\
\hline 54600 & 1 & 8 & 1515 \\
\hline 54600 & 26 & 9 & 1515 \\
\hline 54600 & 0 & 10 & 1515 \\
\hline 54600 & 2 & 1515 \\
\hline 55440 & 37 & 5 & 1519 \\
\hline 55440 & 5 & 1519 \\
\hline 55440 & 0 & 1519 \\
\hline 55440 & 0 & 11 & 1519 \\
\hline 55440 & 2 & \\
\hline 55440 & 2 & 19 \\
\hline & & 0 & \\
\hline
\end{tabular}




\begin{tabular}{|l|l|l|l|}
\hline 55440 & 5 & 6 & 1519 \\
\hline 55440 & 0 & 7 & 1519 \\
\hline 55440 & 1 & 8 & 1519 \\
\hline 55440 & 31 & 9 & 1519 \\
\hline 55440 & 0 & 10 & 1519 \\
\hline 55440 & 2 & 12 & 1519 \\
\hline 55620 & 59 & 0 & 1530 \\
\hline 55620 & 9 & 1 & 1530 \\
\hline 55620 & 1 & 2 & 1530 \\
\hline 55620 & 0 & 3 & 1530 \\
\hline 55620 & 15 & 4 & 1530 \\
\hline 55620 & 1 & 5 & 1530 \\
\hline 55620 & 26 & 6 & 1530 \\
\hline 55620 & 0 & 7 & 1530 \\
\hline 55620 & 1 & 8 & 1530 \\
\hline 55620 & 34 & 9 & 1530 \\
\hline 55620 & 0 & 10 & 1530 \\
\hline 55620 & 2 & 12 & 1530 \\
\hline 55800 & 138 & 0 & 1526 \\
\hline 55800 & 20 & 1 & 1526 \\
\hline 55800 & 2 & 2 & 1526 \\
\hline 55800 & 0 & 3 & 1526 \\
\hline 55800 & 37 & 4 & 1526 \\
\hline 55800 & 113 & 5 & 1526 \\
\hline 55800 & 20 & 6 & 1526 \\
\hline 55800 & 0 & 7 & 1526 \\
\hline 55800 & 2 & 8 & 1526 \\
\hline 55800 & 69 & 9 & 1526 \\
\hline 55800 & 0 & 10 & 1526 \\
\hline 55800 & 5 & 12 & 1526 \\
\hline 58020 & 112 & 0 & 1529 \\
\hline 58020 & 16 & 1 & 1529 \\
\hline 58020 & 1 & 2 & 1529 \\
\hline 58020 & 0 & 3 & 1529 \\
\hline 58020 & 31 & 4 & 1529 \\
\hline 58020 & 3 & 5 & 1529 \\
\hline 58020 & 17 & 6 & 1529 \\
\hline 58020 & 0 & 7 & 1529 \\
\hline 58020 & 4 & 8 & 1529 \\
\hline 58020 & 120 & 9 & 1529 \\
\hline 58020 & 0 & 10 & 1529 \\
\hline 58020 & 8 & 12 & 1529 \\
\hline 59160 & 83 & 0 & 1528 \\
\hline 59160 & 12 & 1 & 1528 \\
\hline 59160 & 1 & 2 & 1528 \\
\hline 59160 & 0 & 3 & 1528 \\
\hline 59160 & 23 & 4 & 1528 \\
\hline 59160 & 62 & 5 & 1528 \\
\hline 59160 & 13 & 0 & 1528 \\
\hline 59160 & 0 & 1528 \\
\hline 59160 & 1 & 1528 \\
\hline 59160 & 19 & 0 & 1528 \\
\hline 59160 & 0 & 1528 \\
\hline 59160 & 1 & & \\
\hline 59220 & 108 & 0 & \\
\hline & & 0 & 644 \\
\hline
\end{tabular}




\begin{tabular}{|l|l|l|l|}
\hline 59220 & 16 & 1 & 1544 \\
\hline 59220 & 1 & 2 & 1544 \\
\hline 59220 & 0 & 3 & 1544 \\
\hline 59220 & 29 & 4 & 1544 \\
\hline 59220 & 135 & 5 & 1544 \\
\hline 59220 & 22 & 6 & 1544 \\
\hline 59220 & 0 & 7 & 1544 \\
\hline 59220 & 2 & 8 & 1544 \\
\hline 59220 & 53 & 9 & 1544 \\
\hline 59220 & 0 & 10 & 1544 \\
\hline 59220 & 3 & 12 & 1544 \\
\hline 60300 & 105 & 0 & 1543 \\
\hline 60300 & 15 & 1 & 1543 \\
\hline 60300 & 1 & 2 & 1543 \\
\hline 60300 & 0 & 3 & 1543 \\
\hline 60300 & 29 & 4 & 1543 \\
\hline 60300 & 26 & 5 & 1543 \\
\hline 60300 & 16 & 6 & 1543 \\
\hline 60300 & 0 & 7 & 1543 \\
\hline 60300 & 0 & 8 & 1543 \\
\hline 60300 & 14 & 9 & 1543 \\
\hline 60300 & 0 & 10 & 1543 \\
\hline 60300 & 1 & 12 & 1543 \\
\hline 61320 & 108 & 0 & 1511 \\
\hline 61320 & 16 & 1 & 1511 \\
\hline 61320 & 1 & 2 & 1511 \\
\hline 61320 & 0 & 3 & 1511 \\
\hline 61320 & 29 & 4 & 1511 \\
\hline 61320 & 4 & 5 & 1511 \\
\hline 61320 & 22 & 6 & 1511 \\
\hline 61320 & 0 & 7 & 1511 \\
\hline 61320 & 2 & 8 & 1511 \\
\hline 61320 & 71 & 9 & 1511 \\
\hline 61320 & 0 & 10 & 1511 \\
\hline 61320 & 5 & 12 & 1511 \\
\hline 61500 & 82 & 0 & 1501 \\
\hline 61500 & 12 & 1 & 1501 \\
\hline 61500 & 1 & 2 & 1501 \\
\hline 61500 & 0 & 3 & 1501 \\
\hline 61500 & 22 & 4 & 1501 \\
\hline 61500 & 0 & 5 & 1501 \\
\hline 61500 & 5 & 6 & 1501 \\
\hline 61500 & 0 & 7 & 1501 \\
\hline 61500 & 0 & 8 & 1501 \\
\hline 61500 & 0 & 9 & 1501 \\
\hline 61500 & 0 & 10 & 1501 \\
\hline 61500 & 0 & 12 & 1501 \\
\hline 63000 & 89 & 0 & 1497 \\
\hline 63000 & 13 & 1 & 1497 \\
\hline 63000 & 1 & 1497 \\
\hline 63000 & 0 & 1497 \\
\hline 63000 & 24 & 8 & 1497 \\
\hline 63000 & 80 & 16 & 1497 \\
\hline 63000 & 0 & \\
\hline 63000 & & 5 \\
\hline & & 0 & \\
\hline
\end{tabular}




\begin{tabular}{|l|l|l|l|}
\hline 63000 & 2 & 8 & 1497 \\
\hline 63000 & 49 & 9 & 1497 \\
\hline 63000 & 0 & 10 & 1497 \\
\hline 63000 & 3 & 12 & 1497 \\
\hline 63900 & 104 & 0 & 1525 \\
\hline 63900 & 15 & 1 & 1525 \\
\hline 63900 & 1 & 2 & 1525 \\
\hline 63900 & 0 & 3 & 1525 \\
\hline 63900 & 28 & 4 & 1525 \\
\hline 63900 & 53 & 5 & 1525 \\
\hline 63900 & 14 & 6 & 1525 \\
\hline 63900 & 0 & 7 & 1525 \\
\hline 63900 & 1 & 8 & 1525 \\
\hline 63900 & 40 & 9 & 1525 \\
\hline 63900 & 0 & 10 & 1525 \\
\hline 63900 & 3 & 12 & 1525 \\
\hline 63900 & 55 & 0 & 1536 \\
\hline 63900 & 8 & 1 & 1536 \\
\hline 63900 & 1 & 2 & 1536 \\
\hline 63900 & 0 & 3 & 1536 \\
\hline 63900 & 14 & 4 & 1536 \\
\hline 63900 & 3 & 5 & 1536 \\
\hline 63900 & 6 & 6 & 1536 \\
\hline 63900 & 0 & 7 & 1536 \\
\hline 63900 & 1 & 8 & 1536 \\
\hline 63900 & 22 & 9 & 1536 \\
\hline 63900 & 0 & 10 & 1536 \\
\hline 63900 & 1 & 12 & 1536 \\
\hline 64260 & 84 & 0 & 1508 \\
\hline 64260 & 12 & 1 & 1508 \\
\hline 64260 & 1 & 2 & 1508 \\
\hline 64260 & 0 & 3 & 1508 \\
\hline 64260 & 23 & 4 & 1508 \\
\hline 64260 & 178 & 5 & 1508 \\
\hline 64260 & 19 & 6 & 1508 \\
\hline 64260 & 0 & 7 & 1508 \\
\hline 64260 & 2 & 8 & 1508 \\
\hline 64260 & 47 & 9 & 1508 \\
\hline 64260 & 0 & 10 & 1508 \\
\hline 64260 & 3 & 12 & 1508 \\
\hline 64680 & 164 & 0 & 1514 \\
\hline 64680 & 24 & 1 & 1514 \\
\hline 64680 & 2 & 2 & 1514 \\
\hline 64680 & 0 & 3 & 1514 \\
\hline 64680 & 44 & 4 & 1514 \\
\hline 64680 & 19 & 5 & 1514 \\
\hline 64680 & 21 & 6 & 1514 \\
\hline 64680 & 0 & 7 & 1514 \\
\hline 64680 & 3 & 8 & 1514 \\
\hline 64680 & 88 & 1514 \\
\hline 64680 & 0 & 1514 \\
\hline 64680 & 6 & 1514 \\
\hline 68100 & 62 & 1498 \\
\hline 68100 & 9 & \\
\hline 68100 & 1 & & \\
\hline & & 0 & 1498 \\
\hline
\end{tabular}




\begin{tabular}{|l|l|l|l|}
\hline 68100 & 0 & 3 & 1498 \\
\hline 68100 & 16 & 4 & 1498 \\
\hline 68100 & 99 & 5 & 1498 \\
\hline 68100 & 17 & 6 & 1498 \\
\hline 68100 & 0 & 7 & 1498 \\
\hline 68100 & 2 & 8 & 1498 \\
\hline 68100 & 64 & 9 & 1498 \\
\hline 68100 & 0 & 10 & 1498 \\
\hline 68100 & 4 & 12 & 1498 \\
\hline 68100 & 92 & 0 & 1502 \\
\hline 68100 & 13 & 1 & 1502 \\
\hline 68100 & 1 & 2 & 1502 \\
\hline 68100 & 0 & 3 & 1502 \\
\hline 68100 & 25 & 4 & 1502 \\
\hline 68100 & 1 & 5 & 1502 \\
\hline 68100 & 5 & 6 & 1502 \\
\hline 68100 & 0 & 7 & 1502 \\
\hline 68100 & 0 & 8 & 1502 \\
\hline 68100 & 3 & 9 & 1502 \\
\hline 68100 & 0 & 10 & 1502 \\
\hline 68100 & 0 & 12 & 1502 \\
\hline 68340 & 75 & 0 & 1510 \\
\hline 68340 & 11 & 1 & 1510 \\
\hline 68340 & 1 & 2 & 1510 \\
\hline 68340 & 0 & 3 & 1510 \\
\hline 68340 & 20 & 4 & 1510 \\
\hline 68340 & 2 & 5 & 1510 \\
\hline 68340 & 20 & 6 & 1510 \\
\hline 68340 & 0 & 7 & 1510 \\
\hline 68340 & 4 & 8 & 1510 \\
\hline 68340 & 114 & 9 & 1510 \\
\hline 68340 & 0 & 10 & 1510 \\
\hline 68340 & 7 & 12 & 1510 \\
\hline 68700 & 88 & 0 & 1521 \\
\hline 68700 & 13 & 1 & 1521 \\
\hline 68700 & 1 & 2 & 1521 \\
\hline 68700 & 0 & 3 & 1521 \\
\hline 68700 & 24 & 4 & 1521 \\
\hline 68700 & 5 & 5 & 1521 \\
\hline 68700 & 25 & 6 & 1521 \\
\hline 68700 & 0 & 7 & 1521 \\
\hline 68700 & 5 & 8 & 1521 \\
\hline 68700 & 140 & 9 & 1521 \\
\hline 68700 & 0 & 10 & 1521 \\
\hline 68700 & 9 & 12 & 1521 \\
\hline 68700 & 126 & 0 & 1524 \\
\hline 68700 & 18 & 1 & 1524 \\
\hline 68700 & 1 & 2 & 1524 \\
\hline 68700 & 0 & 3 & 1524 \\
\hline 68700 & 34 & 146 \\
\hline 68700 & 146 & 1524 \\
\hline 68700 & 19 & 0 & 1524 \\
\hline 68700 & 0 & 2 & 1524 \\
\hline 68700 & 2 & 524 \\
\hline 68700 & 55 & & \\
\hline & & 5 & 9 \\
\hline
\end{tabular}




\begin{tabular}{|c|c|c|c|}
\hline 68700 & 0 & 10 & 1524 \\
\hline 68700 & 4 & 12 & 1524 \\
\hline 71160 & 63 & 0 & 1533 \\
\hline 71160 & 9 & 1 & 1533 \\
\hline 71160 & 1 & 2 & 1533 \\
\hline 71160 & 0 & 3 & 1533 \\
\hline 71160 & 17 & 4 & 1533 \\
\hline 71160 & 5 & 5 & 1533 \\
\hline 71160 & 12 & 6 & 1533 \\
\hline 71160 & 0 & 7 & 1533 \\
\hline 71160 & 1 & 8 & 1533 \\
\hline 71160 & 38 & 9 & 1533 \\
\hline 71160 & 0 & 10 & 1533 \\
\hline 71160 & 3 & 12 & 1533 \\
\hline 73200 & 79 & 0 & 1545 \\
\hline 73200 & 12 & 1 & 1545 \\
\hline 73200 & 1 & 2 & 1545 \\
\hline 73200 & 0 & 3 & 1545 \\
\hline 73200 & 21 & 4 & 1545 \\
\hline 73200 & 0 & 5 & 1545 \\
\hline 73200 & 13 & 6 & 1545 \\
\hline 73200 & 0 & 7 & 1545 \\
\hline 73200 & 2 & 8 & 1545 \\
\hline 73200 & 60 & 9 & 1545 \\
\hline 73200 & 0 & 10 & 1545 \\
\hline 73200 & 4 & 12 & 1545 \\
\hline 75300 & 86 & 0 & 1503 \\
\hline 75300 & 13 & 1 & 1503 \\
\hline 75300 & 1 & 2 & 1503 \\
\hline 75300 & 0 & 3 & 1503 \\
\hline 75300 & 23 & 4 & 1503 \\
\hline 75300 & 0 & 5 & 1503 \\
\hline 75300 & 5 & 6 & 1503 \\
\hline 75300 & 0 & 7 & 1503 \\
\hline 75300 & 0 & 8 & 1503 \\
\hline 75300 & 8 & 9 & 1503 \\
\hline 75300 & 0 & 10 & 1503 \\
\hline 75300 & 1 & 12 & 1503 \\
\hline 76200 & 85 & 0 & 1504 \\
\hline 76200 & 12 & 1 & 1504 \\
\hline 76200 & 1 & 2 & 1504 \\
\hline 76200 & 0 & 3 & 1504 \\
\hline 76200 & 23 & 4 & 1504 \\
\hline 76200 & 0 & 5 & 1504 \\
\hline 76200 & 5 & 6 & 1504 \\
\hline 76200 & 0 & 7 & 1504 \\
\hline 76200 & 0 & 8 & 1504 \\
\hline 76200 & 0 & 9 & 1504 \\
\hline 76200 & 0 & 10 & 1504 \\
\hline 76200 & 0 & 12 & 1504 \\
\hline 76500 & 86 & 0 & 1506 \\
\hline 76500 & 12 & 1 & 1506 \\
\hline 76500 & 1 & 2 & 1506 \\
\hline 76500 & 0 & 3 & 1506 \\
\hline 76500 & 23 & 4 & 1506 \\
\hline
\end{tabular}




\begin{tabular}{|c|c|c|c|}
\hline 76500 & 2 & 5 & 1506 \\
\hline 76500 & 5 & 6 & 1506 \\
\hline 76500 & 0 & 7 & 1506 \\
\hline 76500 & 0 & 8 & 1506 \\
\hline 76500 & 15 & 9 & 1506 \\
\hline 76500 & 0 & 10 & 1506 \\
\hline 76500 & 1 & 12 & 1506 \\
\hline 76560 & 79 & 0 & 1507 \\
\hline 76560 & 12 & 1 & 1507 \\
\hline 76560 & 1 & 2 & 1507 \\
\hline 76560 & 0 & 3 & 1507 \\
\hline 76560 & 21 & 4 & 1507 \\
\hline 76560 & 140 & 5 & 1507 \\
\hline 76560 & 19 & 6 & 1507 \\
\hline 76560 & 0 & 7 & 1507 \\
\hline 76560 & 1 & 8 & 1507 \\
\hline 76560 & 34 & 9 & 1507 \\
\hline 76560 & 0 & 10 & 1507 \\
\hline 76560 & 2 & 12 & 1507 \\
\hline 80280 & 91 & 0 & 1500 \\
\hline 80280 & 13 & 1 & 1500 \\
\hline 80280 & 1 & 2 & 1500 \\
\hline 80280 & 0 & 3 & 1500 \\
\hline 80280 & 25 & 4 & 1500 \\
\hline 80280 & 0 & 5 & 1500 \\
\hline 80280 & 5 & 6 & 1500 \\
\hline 80280 & 0 & 7 & 1500 \\
\hline 80280 & 0 & 8 & 1500 \\
\hline 80280 & 1 & 9 & 1500 \\
\hline 80280 & 0 & 10 & 1500 \\
\hline 80280 & 0 & 12 & 1500 \\
\hline 80700 & 20 & 0 & 1517 \\
\hline 80700 & 3 & 1 & 1517 \\
\hline 80700 & 0 & 2 & 1517 \\
\hline 80700 & 0 & 3 & 1517 \\
\hline 80700 & 5 & 4 & 1517 \\
\hline 80700 & 0 & 5 & 1517 \\
\hline 80700 & 5 & 6 & 1517 \\
\hline 80700 & 0 & 7 & 1517 \\
\hline 80700 & 1 & 8 & 1517 \\
\hline 80700 & 27 & 9 & 1517 \\
\hline 80700 & 0 & 10 & 1517 \\
\hline 80700 & 2 & 12 & 1517 \\
\hline 81000 & 83 & 0 & 1505 \\
\hline 81000 & 12 & 1 & 1505 \\
\hline 81000 & 1 & 2 & 1505 \\
\hline 81000 & 0 & 3 & 1505 \\
\hline 81000 & 23 & 4 & 1505 \\
\hline 81000 & 0 & 5 & 1505 \\
\hline 81000 & 5 & 6 & 1505 \\
\hline 81000 & 0 & 7 & 1505 \\
\hline 81000 & 0 & 8 & 1505 \\
\hline 81000 & 10 & 9 & 1505 \\
\hline 81000 & 0 & 10 & 1505 \\
\hline 81000 & 1 & 12 & 1505 \\
\hline
\end{tabular}




\begin{tabular}{|l|l|l|l|}
\hline 81240 & 46 & 0 & 1552 \\
\hline 81240 & 7 & 1 & 1552 \\
\hline 81240 & 1 & 2 & 1552 \\
\hline 81240 & 0 & 3 & 1552 \\
\hline 81240 & 12 & 4 & 1552 \\
\hline 81240 & 5 & 5 & 1552 \\
\hline 81240 & 5 & 6 & 1552 \\
\hline 81240 & 0 & 7 & 1552 \\
\hline 81240 & 1 & 8 & 1552 \\
\hline 81240 & 16 & 9 & 1552 \\
\hline 81240 & 0 & 10 & 1552 \\
\hline 81240 & 1 & 12 & 1552 \\
\hline 82500 & 88 & 0 & 1512 \\
\hline 82500 & 13 & 1 & 1512 \\
\hline 82500 & 1 & 2 & 1512 \\
\hline 82500 & 0 & 3 & 1512 \\
\hline 82500 & 24 & 4 & 1512 \\
\hline 82500 & 21 & 5 & 1512 \\
\hline 82500 & 22 & 6 & 1512 \\
\hline 82500 & 0 & 7 & 1512 \\
\hline 82500 & 3 & 8 & 1512 \\
\hline 82500 & 98 & 9 & 1512 \\
\hline 82500 & 0 & 10 & 1512 \\
\hline 82500 & 7 & 12 & 1512 \\
\hline 83100 & 65 & 0 & 1534 \\
\hline 83100 & 9 & 1 & 1534 \\
\hline 83100 & 1 & 2 & 1534 \\
\hline 83100 & 0 & 3 & 1534 \\
\hline 83100 & 17 & 4 & 1534 \\
\hline 83100 & 1 & 5 & 1534 \\
\hline 83100 & 9 & 6 & 1534 \\
\hline 83100 & 0 & 7 & 1534 \\
\hline 83100 & 1 & 8 & 1534 \\
\hline 83100 & 39 & 9 & 1534 \\
\hline 83100 & 0 & 10 & 1534 \\
\hline 83100 & 3 & 12 & 1534 \\
\hline 83700 & 57 & 0 & 1539 \\
\hline 83700 & 8 & 1 & 1539 \\
\hline 83700 & 1 & 2 & 1539 \\
\hline 83700 & 0 & 3 & 1539 \\
\hline 83700 & 15 & 4 & 1539 \\
\hline 83700 & 2 & 5 & 1539 \\
\hline 83700 & 6 & 6 & 1539 \\
\hline 83700 & 0 & 7 & 1539 \\
\hline 83700 & 1 & 8 & 1539 \\
\hline 83700 & 15 & 9 & 1539 \\
\hline 83700 & 0 & 10 & 1539 \\
\hline 83700 & 1 & 1539 \\
\hline 84300 & 179 & 2 & 1542 \\
\hline 84300 & 26 & 1542 \\
\hline 84300 & 2 & 1542 \\
\hline 84300 & 0 & 1542 \\
\hline 84300 & 48 & 2 & 1542 \\
\hline 84300 & 2 & 23 \\
\hline 84300 & 23 & 5 & \\
\hline & & 5 & 0 \\
\hline
\end{tabular}


Simulation Analysis of Inspections of International Travelers at Los Angeles Int'l Airport for US-VISIT

\begin{tabular}{|l|l|l|l|}
\hline 84300 & 0 & 7 & 1542 \\
\hline 84300 & 4 & 8 & 1542 \\
\hline 84300 & 116 & 9 & 1542 \\
\hline 84300 & 0 & 10 & 1542 \\
\hline 84300 & 7 & 12 & 1542 \\
\hline
\end{tabular}




\section{Appendix E Cross Index Between Visa Codes in IBIS and Traveler Type}

\begin{tabular}{|c|c|c|c|c|c|c|c|}
\hline $\begin{array}{l}\text { Visa } \\
\text { Code }\end{array}$ & $\begin{array}{c}\text { Traveler } \\
\text { Type }\end{array}$ & $\begin{array}{l}\text { Visa } \\
\text { Code }\end{array}$ & $\begin{array}{c}\text { Traveler } \\
\text { Type }\end{array}$ & $\begin{array}{l}\text { Visa } \\
\text { Code }\end{array}$ & $\begin{array}{c}\text { Traveler } \\
\text { Type }\end{array}$ & $\begin{array}{l}\text { Visa } \\
\text { Code }\end{array}$ & $\begin{array}{c}\text { Traveler } \\
\text { Type }\end{array}$ \\
\hline LPR & 4 & F32 & 7 & TD & 8 & N1 & 9 \\
\hline VWP & 5 & F33 & 7 & $\mathrm{TN}$ & 8 & $\mathrm{~N} 2$ & 9 \\
\hline WB & 5 & F41 & 7 & A1 & 9 & N3 & 9 \\
\hline WT & 5 & F42 & 7 & $\mathrm{~A} 2$ & 9 & $\mathrm{~N} 4$ & 9 \\
\hline D1 & 6 & F43 & 7 & $\mathrm{~A} 3$ & 9 & N5 & 9 \\
\hline D2 & 6 & FX1 & 7 & B1 & 9 & N6 & 9 \\
\hline CR1 & 7 & FX3 & 7 & B2 & 9 & N7 & 9 \\
\hline CR2 & 7 & IMM & 7 & $\mathrm{C} 1$ & 9 & N8 & 9 \\
\hline DV1 & 7 & IR1 & 7 & $\mathrm{C} 2$ & 9 & $\mathrm{O} 1$ & 9 \\
\hline DV2 & 7 & IR2 & 7 & $\mathrm{C} 3$ & 9 & $\mathrm{O} 2$ & 9 \\
\hline DV3 & 7 & IR3 & 7 & $\mathrm{C} 4$ & 9 & $\mathrm{O} 3$ & 9 \\
\hline E11 & 7 & IR4 & 7 & E1 & 9 & $\mathrm{P} 1$ & 9 \\
\hline E12 & 7 & IR5 & 7 & E2 & 9 & $\mathrm{P} 2$ & 9 \\
\hline E13 & 7 & IW1 & 7 & FSM & 9 & $\mathrm{P} 3$ & 9 \\
\hline E14 & 7 & IW2 & 7 & G1 & 9 & $\mathrm{P} 4$ & 9 \\
\hline E15 & 7 & NA3 & 7 & $\mathrm{G} 2$ & 9 & Q1 & 9 \\
\hline E21 & 7 & SB1 & 7 & G3 & 9 & Q2 & 9 \\
\hline E22 & 7 & SE1 & 7 & G4 & 9 & Q3 & 9 \\
\hline E23 & 7 & SE2 & 7 & G5 & 9 & $\mathrm{R} 1$ & 9 \\
\hline E31 & 7 & SE3 & 7 & $\mathrm{H} 1$ & 9 & $\mathrm{R} 2$ & 9 \\
\hline E32 & 7 & SR1 & 7 & $\mathrm{H} 1 \mathrm{~A}$ & 9 & $\mathrm{~T} 1$ & 9 \\
\hline E34 & 7 & SR2 & 7 & $\mathrm{H} 1 \mathrm{~B}$ & 9 & $\mathrm{~T} 2$ & 9 \\
\hline E35 & 7 & SR3 & 7 & $\mathrm{H} 1 \mathrm{C}$ & 9 & $\mathrm{~T} 3$ & 9 \\
\hline EW3 & 7 & T53 & 7 & $\mathrm{H} 2$ & 9 & $\mathrm{~T} 4$ & 9 \\
\hline EW4 & 7 & AS & 8 & $\mathrm{H} 2 \mathrm{~A}$ & 9 & $\mathrm{U} 2$ & 9 \\
\hline EW5 & 7 & $\mathrm{~F} 1$ & 8 & $\mathrm{H} 2 \mathrm{~B}$ & 9 & U3 & 9 \\
\hline F11 & 7 & $\mathrm{~F} 2$ & 8 & $\mathrm{H} 3$ & 9 & $\mathrm{U} 4$ & 9 \\
\hline F12 & 7 & IN & 8 & $\mathrm{H} 4$ & 9 & $\mathrm{~V} 2$ & 9 \\
\hline $\mathrm{F} 21$ & 7 & $\mathrm{~J} 1$ & 8 & I & 9 & V3 & 9 \\
\hline $\mathrm{F} 22$ & 7 & $\mathrm{~J} 2$ & 8 & IT & 9 & $\mathrm{RE}$ & 10 \\
\hline $\mathrm{F} 23$ & 7 & $\mathrm{~K} 1$ & 8 & K3 & 9 & SEC & 11 \\
\hline F24 & 7 & $\mathrm{~K} 2$ & 8 & K4 & 9 & & \\
\hline F25 & 7 & M1 & 8 & L1 & 9 & & \\
\hline F31 & 7 & M2 & 8 & L2 & 9 & & \\
\hline
\end{tabular}

Note: At the time this data was extracted from IBIS, visa codes could include hyphens. However, hyphens are ignored for cross referencing purposes. For example, visa code E-11 matches visa code E11. 


\section{Appendix F List of Acronyms and Terms}

Alien lane crossover rate - aliens are normally routed to dedicated alien lanes at primary inspection; if queues for U.S. citizen inspections are shorter, the alien crossover rate specifies the fraction of aliens that are allowed to move over to the shorter queues for U.S. citizen lanes

Base Case (As-Is) - configuration of processes and systems prior to implementation of US-VISIT Block time - time when aircraft 'officially' arrives at its gate - also known as flight arrival time Confirmation time and date (IBIS) - date and time at which data is entered into IBIS system; this is the approximate time at which primary inspection is completed

COA - Class-of-Admission - admission code assigned by the inspector in IBIS

Flight arrival time - time when aircraft 'officially' arrives at its gate - also known as block time IBIS - Interagency Border Inspection System

IDENT - the US VISIT automated fingerprint-based biometrics tool

Inspection time - time required to acquire biometrics, interview traveler, receive results of biographic and biometrics checks, and make an admissions decision

LAX - Los Angeles airport

TBIT - Tom Bradley International Terminal at Los Angeles International Airport

LPR - Legal permanent resident of the United States

NIV - non-immigrant visa

POE - port of entry

POMS - Port of Entry Office Management System

Primary inspection - the initial procedure whereby an officer makes a determination as to whether and under what conditions a traveler may enter the U.S.

Primary inspection cycle time - time to deplane and walk to primary queue + queue time + inspection time

Primary queue - location where travelers wait for primary inspection

Primary queue length - number of travelers waiting for primary inspection at a point in time

Queue time - time traveler spends waiting in queue for inspection

Scenario 1-4 - alternative implementation scenarios for US-VISIT and other traveler inspection programs

Secondary inspection - process for further evaluation of travelers who were not readily admissible at primary inspection

Traveler - passenger or crewmember

Traveler types - classification system used in this report for travelers; each of the 13 traveler types can be inspected with a different process, and statistics on each traveler type can be collected

US-VISIT - United States Visitor and Immigrant Status Indicator Technology Program 
VWP - Visa Waiver Program, citizens of countries participating in this program do not require visas to enter the United States as visitors for business or pleasure for no more than 90 days Wait time - the sum of queue time and inspection time

Walk time - time required to walk from the gate to the primary queue 


\section{Appendix G Business Rules to Populate Missing Class-of-Admission Fields}

The following business rules were used to assign visa-class-of-admission:

a) Identify "USC" records:

i) For "Doc Country Code" = "US" and "Doc Type" and "Visa Class of Entry" blank, assume US citizens

ii) For "Doc Type" = "F" (facilitation) but no "Visa Class of Entry," and the "Doc Country Code" = either "US" or blank, assume US citizens without passports

iii) For "Doc Type" = "M" (military ID or orders), assume US citizens

iv) For "Doc Type" = "P" and "Doc Country Code" = "US" but no "Visa Class of Entry," assume US citizens with passports

v) Set "Visa Class of Entry" to "USC"

b) Identify "LPR" records:

i) For "Doc Type" = "A" or "C" but "Visa Class of Entry" blank, assume LPRs to I551 (doc type "A") or PRC (doc type "C") cards

ii) Set "Visa Class of Entry" to "LPR"

c) Identify BCC holder records:

i) For "Doc Type" = "B" but "Visa Class of Entry" blank, assume Mexican BCC holders who may enter at air POEs in either B-1 or B-2 classifications; assume all entering as B-2.

ii) Set "Visa Class of Entry" to "B2"

d) Identify Visa Waiver Program records:

i) For "Doc Type" = "P" and "Doc Country Code" = one of 26 VWP country codes and "Visa Class of Entry" blank, assume Visa Waiver program entrant who may enter in either WT or WB . The VWP country codes include: AD, AU, AT, BE, BN, DK, FI, FR, DE, IS, IE, IT, JP, LI, LU, MC, NL, NZ, NO, PT, SM, SG, SI, ES, SE, $\mathrm{CH}$ GB.

ii) Set "Visa Class of Entry" to "WT"

e) Identify Canadian nonimmigrant records:

i) For "Doc Type" = "P" and "Doc Country Code" = "CA" but "Visa Class of Entry" blank, assume B-2

ii) Set "Visa Class of Entry" to "B2"

f) Identify Mexican nonimmigrant records:

i) For "Doc Type" = "P" or "V" and "Doc Country Code" = "MX" but "Visa Class of Entry" blank, assume B-2.

ii) Set "Visa Class of Entry" to "B2" 